Aus der Klinik für Kardiologie und Pneumologie

(Prof. Dr. med. G. Hasenfuß)

der Medizinischen Fakultät der Universität Göttingen

\title{
Etablierung von zirkulierenden DNA- Fragmenten als Biomarker für die klinische Progression einer Herzinsuffizienz mit erhaltener Ejektionsfraktion (HFpEF)
}

\author{
INAUGURAL-DISSERTATION \\ zur Erlangung des Doktorgrades \\ der Medizinischen Fakultät der \\ Georg-August-Universität zu Göttingen
}

vorgelegt von

Marleen Awe aus

Münster 
Dekan:

\section{Betreuungsausschuss}

Betreuer/in

Ko-Betreuer/in:

\section{Prüfungskommission}

Referent/in

Ko-Referent/in:

Drittreferent/in:

Datum der mündlichen Prüfung: $\quad$ 25.02.2020
Prof. Dr. rer. nat. H. K. Kroemer

Prof. Dr. med. E. Zeisberg

Prof. Dr. mult. T. Meyer

Prof. Dr. med. E. Zeisberg

Prof. Dr. mult. T. Meyer

Prof. Dr. M. Oppermann 
Hiermit erkläre ich, die Dissertation mit dem Titel "Etablierung von zirkulierenden DNA-Fragmenten als Biomarker für die klinische Progression einer Herzinsuffizienz mit erhaltener Ejektionsfraktion (HFpEF)" eigenständig angefertigt und keine anderen als die von mir angegebenen Quellen und Hilfsmittel verwendet zu haben.

Göttingen, den

(Unterschrift) 


\section{Inhaltsverzeichnis}

Abbildungsverzeichnis............................................................................................................ III

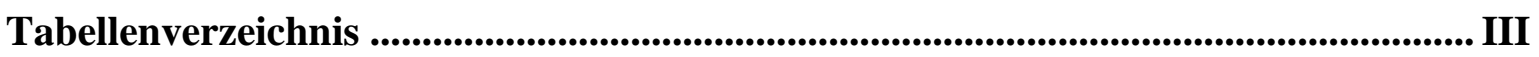

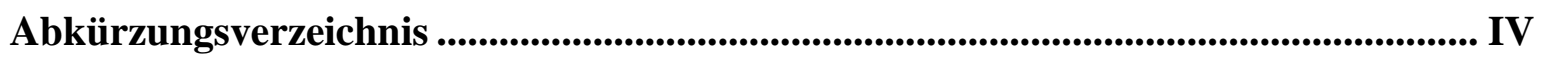

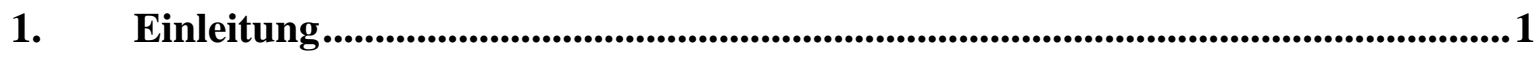

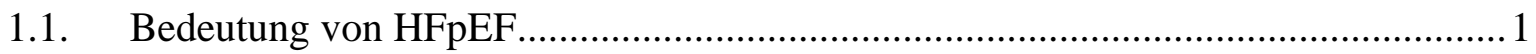

1.2. Zentrale Rolle von Fibrose im Pathomechanismus von HFpEF............................. 1

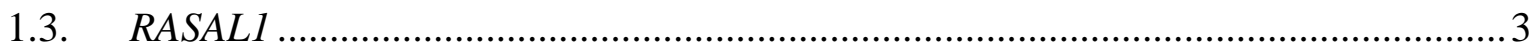

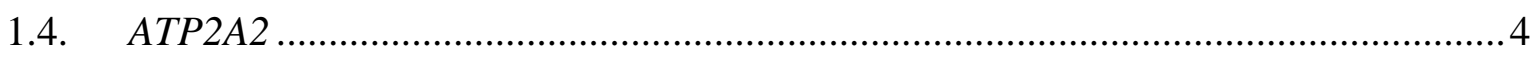

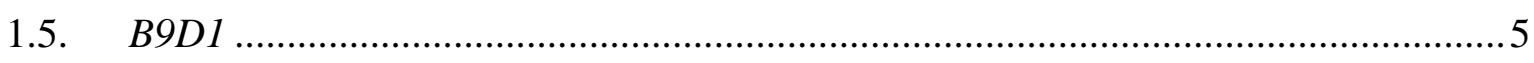

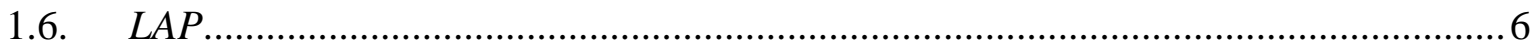

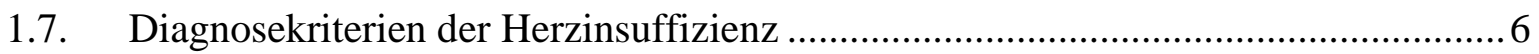

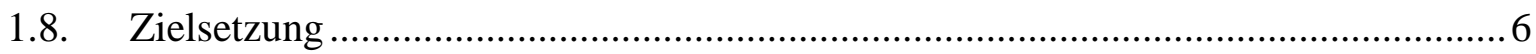

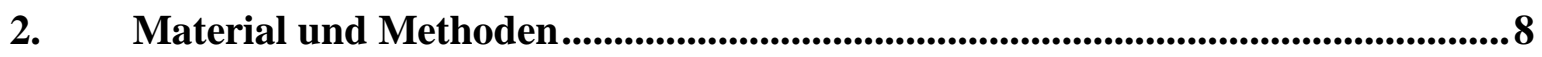

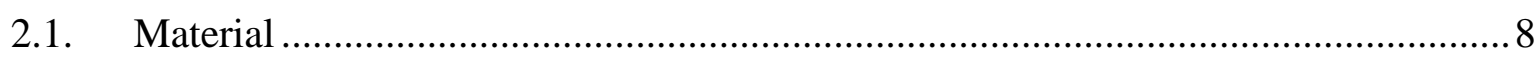

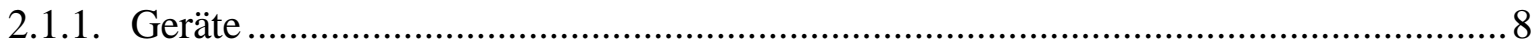

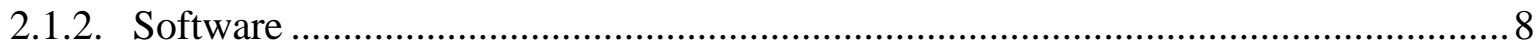

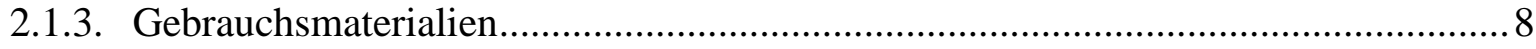

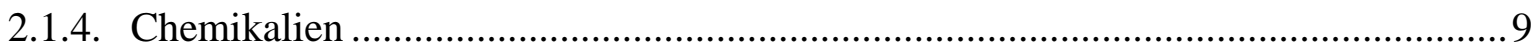

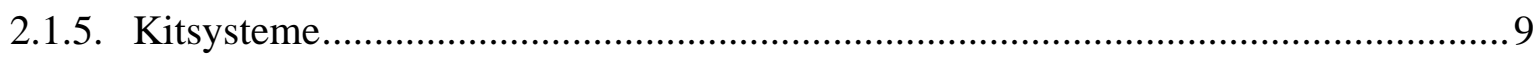

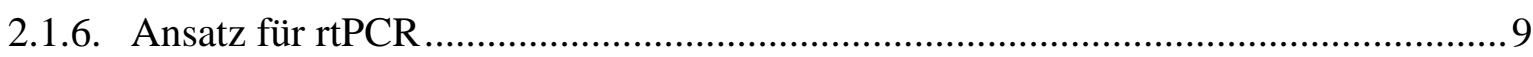

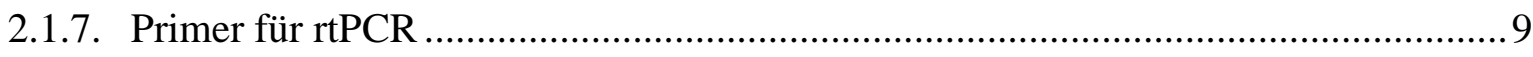

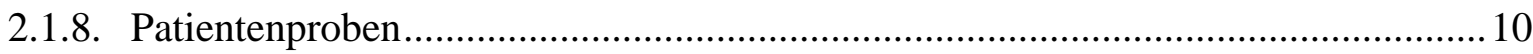

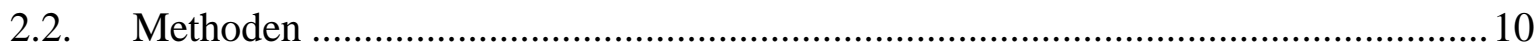

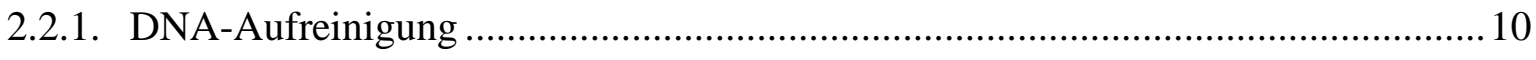

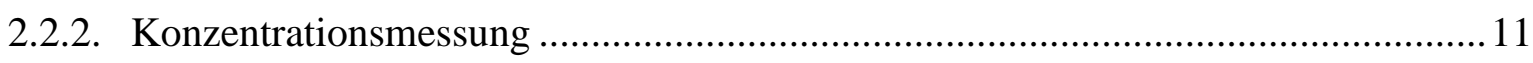

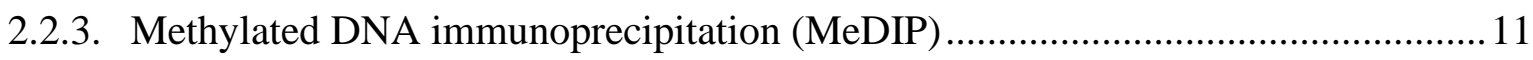

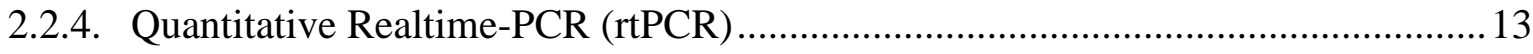

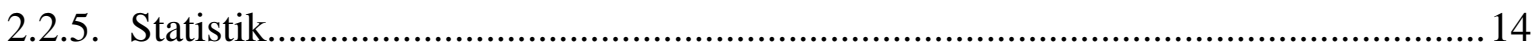




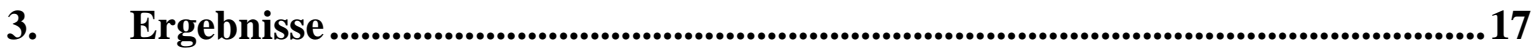

3.1. Detektion intervariabler Abhängigkeiten sowie Assoziation mit dem Überleben... 17

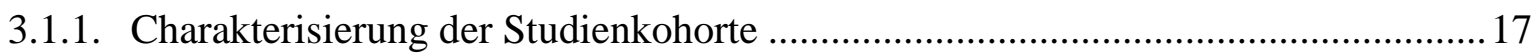

3.1.2. Korrelation der Promotormethylierung mit Patientenparametern ..........................2 23

3.1.3. Identifizierung von Überlebenszeit-beeinflussenden Parametern...........................25

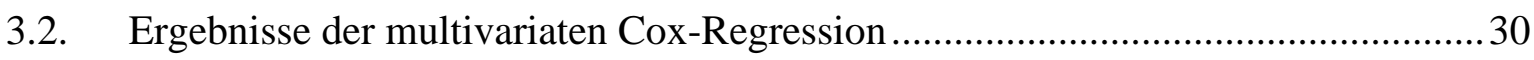

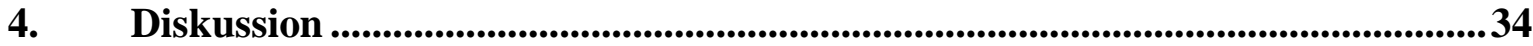

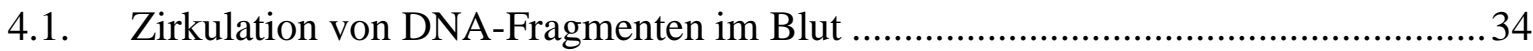

4.2. Assoziation der untersuchten Gene mit verschiedenen Patientenparametern.......... 34

4.2.1. Repräsentation unterschiedlicher Aspekte der Krankheit durch RASAL1, ATP2A2

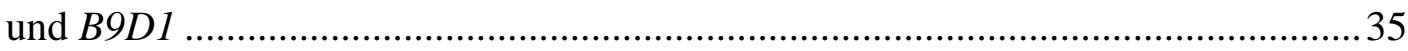

4.3. Identifikation von Risikopatienten mit Hilfe methylierter DNA-Fragmente im Blut

4.3.1. Der Parameter Überleben als stellvertretender Marker für Fibrose ........................... 36

4.3.2. Univariat signifikante Assoziation von drei Genen mit dem Tod ..........................37

4.3.3. RASAL1 und ATP2A2 als Progressionsmarker im multivariaten Modell ................39

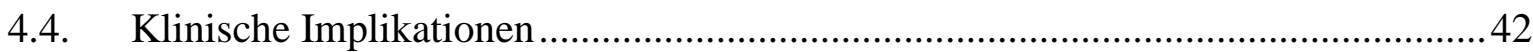

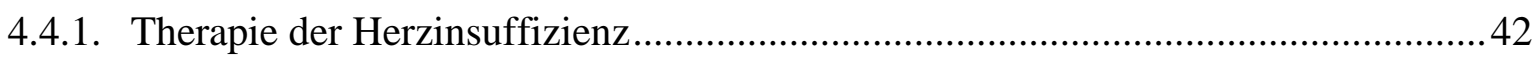

4.4.2. Neue Therapiemöglichkeiten durch Verständnis der Epigenetik ............................ 43

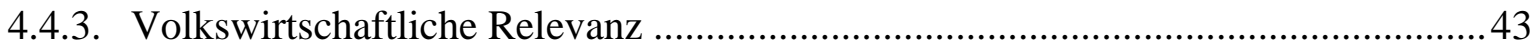

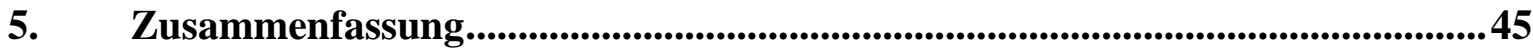

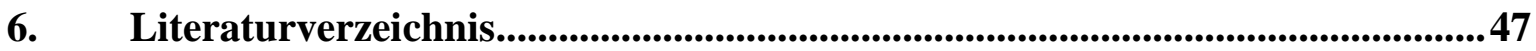




\section{Abbildungsverzeichnis}

Abbildung 1: Veranschaulichung der signifikanten Korrelationen mit Hilfe linearer

Regressionen. 24

Abbildung 2: Graphische Darstellung der ROC-Analysen.................................................26

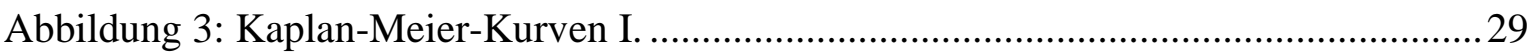

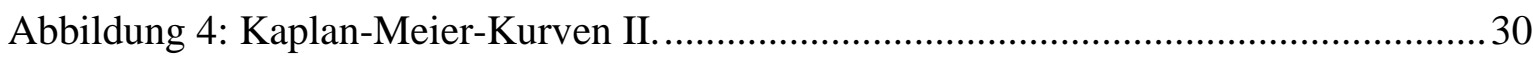

\section{Tabellenverzeichnis}

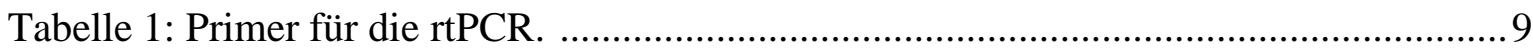

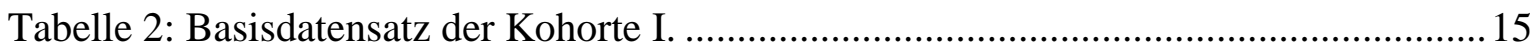

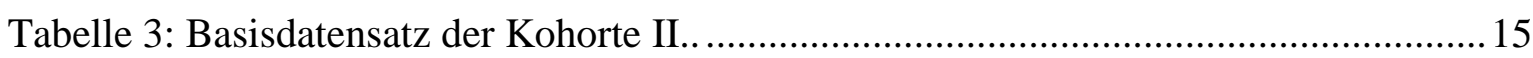

Tabelle 4: Charakterisierung der Studienkohorte anhand des RASAL1-Mediansplits I. ..... 18

Tabelle 5: Charakterisierung der Studienkohorte anhand des RASAL1-Mediansplits II..... 19

Tabelle 6: Charakterisierung der Studienkohorte anhand des ATP2A2-Mediansplits I.. .... 20

Tabelle 7: Charakterisierung der Studienkohorte anhand des ATP2A2-Mediansplits II..... 20

Tabelle 8: Charakterisierung der Studienkohorte anhand des B9D1-Mediansplits I...........21

Tabelle 9: Charakterisierung der Studienkohorte anhand des B9D1-Mediansplits II. ........ 22

Tabelle 10: Korrelationsanalyse der numerischen Parameter mit RASAL1, ATP2A2, B9D1

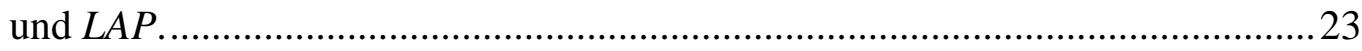

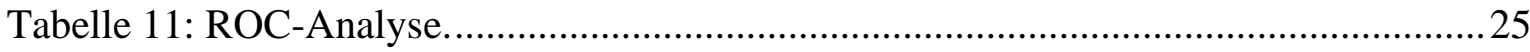

Tabelle 12: Mediansplit der Gene RASAL1, ATP2A2, B9D1 und LAP ............................26

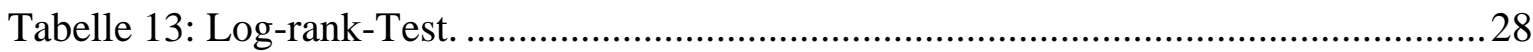

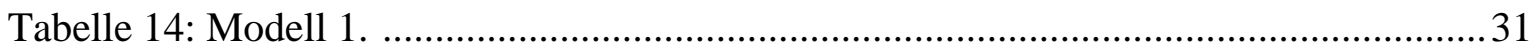

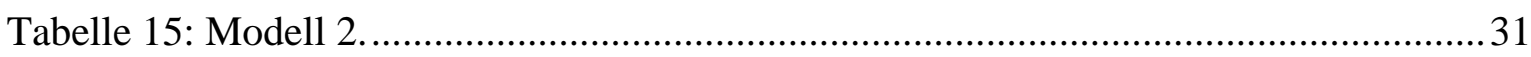

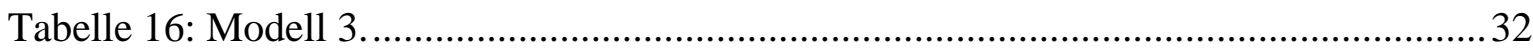

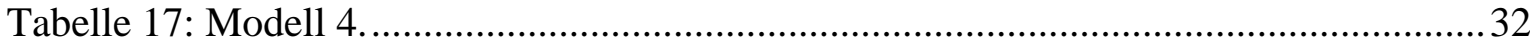

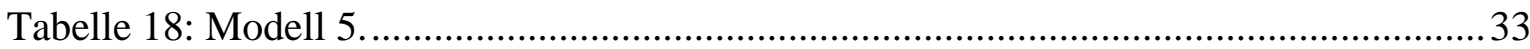




\section{Abkürzungsverzeichnis}

\begin{tabular}{|c|c|c|c|}
\hline $5 \mathrm{caC}$ & 5-Carboxylcytosin & EndMT & endothelial-to-mesenchymal \\
\hline $5 \mathrm{hmC}$ & 5-Hydroxymethylcytosin & & transition \\
\hline $5 \mathrm{mc}$ & 5-Methylcytosin & ESC & European Society of \\
\hline \multirow[t]{2}{*}{ ACE } & Angiontensin-converting & & Cardiology \\
\hline & enzyme & $\mathrm{EZM}$ & Extrazellularmatrix \\
\hline \multirow[t]{2}{*}{ ARNI } & Angiotensin-Rezeptor/ & GAP & GTPase activating protein \\
\hline & Neprilysin-Hemmer & GDP & Guanosindiphosphat \\
\hline ATPase & Adenosintriphosphatase & GTP & Guanosintriphosphat \\
\hline AV-Block & Atrioventrikular-Block & GTPase & Guanosintriphosphatase \\
\hline B9D1 & B9 protein domain 1 & HDL & high density lipoprotein \\
\hline BMI & body mass index & HFmrEF & heart failure with mid-range \\
\hline BNP & brain natriuretic peptide & & ejection fraction \\
\hline $\mathrm{Ca}^{2+}$ & Kalzium & HFpEF & heart failure with preserved \\
\hline \multirow[t]{2}{*}{ cfDNA } & zellfreie DNA & & ejection fraction \\
\hline & cell-free DNA & HFrEF & heart failure with reduced \\
\hline $\mathrm{CpG}$ & Cytosin-Guanin-Dinukleotid & & ejection fraction \\
\hline \multirow[t]{2}{*}{ CRT } & kardiale & HIF-1 $\alpha$ & hypoxia-inducible \\
\hline & Resychronisationstherapie & & factor 1-alpha \\
\hline \multirow[t]{2}{*}{$\mathrm{DCM}$} & dilatative Kardiomyopathie & ICD & implantierbarer \\
\hline & dilated cardiomyopathy & & Kardioverter-Defibrillator \\
\hline \multirow[t]{2}{*}{ DNA } & Desoxyribonukleinsäure & KHK & Koronare Herzkrankheit \\
\hline & deoxyribonucleic acid & Krea & Kreatinin \\
\hline DNMT & DNA-Methyltransferase & LAP & Leucin-Aminopeptidase \\
\hline \multirow[t]{2}{*}{ EDTA } & Ethylendiamintetraessigsäure & LDL & low density lipoprotein \\
\hline & ethylendiamintetraacetic acid & LSB & Linksschenkelblock \\
\hline $\mathrm{EF}$ & Ejektionsfraktion & LVEF & linksventrikuläre \\
\hline \multirow[t]{4}{*}{ eGFR } & geschätzte glomeruläre & & Ejektionsfraktion \\
\hline & Filtrationsrate & MeDIP & methylated DNA \\
\hline & estimated glomerular filtration & & immunoprecipitation \\
\hline & rate & MMP & Matrixmetalloproteinase \\
\hline
\end{tabular}


MRA Mineralkortikoid-

Rezeptorantagonisten

MTS Masson-Trichrom-Färbung

NO Stickstoffmonoxid

NT- $\quad$ N-terminales Propeptid

proBNP

NYHA New York Heart Association

PAS Perjodsäure-Schiff-Reaktion

periodic acid-Schiff reaction

PCR Polymerase-Kettenreaktion

polymerase chain reaction

RASAL1 RAS protein activator like 1

RNA Ribonukleinsäure

ribonucleic acid

ROS reaktive Sauerstoffspezies

RR Blutdruck (nach Riva-Rocci)

RSB Rechtsschenkelblock

rtPCR realtime-PCR

RV- rechtsventrikuläre Dilatation

Dilatation

SD Standardabweichung, standard

deviation

SERCA2 sarcoplasmic/

endoplasmic reticulum

$\mathrm{Ca}^{2+}$-ATPase 2

SR sarkoplasmatisches Retikulum

TAVI transcatheter aortic valve

implantation

TET ten-eleven translocation

TGF- $\beta \quad$ transforming growth factor $\beta$

Z. n. Zustand nach

a-SMA alpha smooth muscle actin 


\section{Einleitung}

\subsection{Bedeutung von HFpEF}

Weltweit leiden 38 Millionen Patienten an Herzinsuffizienz; jedes Jahr werden in den USA eine Million Menschen aus diesem Grund in Krankenhäuser eingewiesen. Bis 2030 soll die Zahl der Patienten mit Herzinsuffizienz um 50\% steigen, wenn in Diagnose und Therapie keine Verbesserungen eintreten. Diese Krankheit ist der häufigste Grund für eine Krankenhauseinweisung bei Erwachsenen über 65 Jahre (Braunwald 2015) und die dritthäufigste Todesursache in Deutschland (Statistisches Bundesamt 2017). Liegen Symptome und Zeichen von Herzinsuffizienz vor, können drei Untergruppen anhand der linksventrikulären Ejektionsfraktion (LVEF) unterschieden werden: Herzinsuffizienz mit reduzierter (LVEF < 40\%; heart failure with reduced ejection fraction, $\mathrm{HFrEF}$ ), mäßiggradig eingeschränkter (LVEF 40-49\%; HFmrEF) und erhaltener (LVEF $\geq 50 \%$; HFpEF) Ejektionsfraktion (European Society of Cardiology 2016). Mit einer Prävalenz von 1-3\% in der Gesamtbevölkerung leidet etwa die Hälfte aller Herzinsuffizienzpatienten an HFpEF (Nanayakkara et al. 2018; Dunlay et al. 2017), Tendenz steigend (Steinberg et al. 2012). Mit steigendem Alter nimmt die Prävalenz von HFpEF unter den herzinsuffizienten Patienten zu. Bei Patienten, bei denen die Krankheit mit $\geq 80$ Jahren diagnostiziert wird, liegt fast immer eine HFpEF vor (Upadhya et al. 2017).

\subsection{Zentrale Rolle von Fibrose im Pathomechanismus von HFpEF}

Verschiedene Komorbiditäten begünstigen die Entstehung von HFpEF. Lam et al. (2011a) betonen die Assoziation mit arterieller Hypertonie. Myokardiale Wanddehnung sowie Ventrikeldilatation und -hypertrophie wurden bereits vor Jahrzehnten von Linzbach (1960) und Grossman et al. (1975) aufgeführt. Ho et al. (2012), Lam et al. (2011b) und Shah (2010) weisen auf die Bedeutung von KHK, Vorhofflimmern und pulmonaler Dysfunktion für die Entstehung von HFpEF hin.

Auf zellulärer Ebene spielen die von van Heerebeek et al. (2006) beschriebene Kardiomyozytenhypertrophie und insbesondere die vermehrte Produktion von Extrazellularmatrix (EZM) eine entscheidende Rolle. Zile et al. (2004) und Westermann et al. (2008) erklären hierdurch die konsekutive Steifheit des Ventrikels, wodurch eine ausreichende Füllung nur unter erhöhtem Druck möglich ist. Myokardiale Fibrogenese ist ein Schlüsselfaktor in der Pathophysiologie von diastolischer Dysfunktion bei Patienten mit 
HFpEF (Su et al. 2014). Bei der physiologischen Wundheilung findet eine fibrotische Narbenbildung statt (Frangogiannis 2012; Gurtner et al. 2008), die von der pathologischen Fibrogenese bei HFpEF abgegrenzt werden muss. Zwar liegt beiden Arten eine Alteration von Parenchym mit konsekutiver Aktivierung von Fibroblasten und vermehrter Produktion von EZM zugrunde, jedoch unterscheiden sie sich durch die Dauer der Aktivierung. Der Wundheilungsprozess ist selbstterminierend, wohingegen die Fibrogenese nicht endet. Obwohl identische Signale in beiden Arten die Fibroblasten aktivieren, ist nicht geklärt, welche Mechanismen entscheiden, ob Wundheilung oder pathologische Fibrogenese angestoßen werden soll (Zeisberg und Zeisberg 2013; Swynghedauw 1999).

Vielfältige Ursachen wie Kardiomyopathien, Klappenvitien (Pagani et al. 1988; Weber et al. 1993), arterielle Hypertonie und damit assoziierte Faktoren (Ischämie, Diabetes sowie diverse Hormone und Peptide), Myokardinfarkt, Aortenstenose, renale Hypertonie (Chapman et al. 1990; Jalil et al. 1989; Nicoletti et al. 1995), Dehnung (Cheng et al. 1995) oder vasoaktive Substanzen wie NO und Angiotensin II (Pollman et al. 1996) führen zu einem fibrotischen Reiz. Obwohl, wie zuvor erwähnt, der genaue Mechanismus der pathologischen Fibrogenese noch nicht vollständig erfasst wurde, herrscht Einigkeit über die Bedeutung des transforming growth factor $\beta 1$ (TGF- $\beta 1$ ) in der Aktivierung von Fibroblasten zu Myofibroblasten (Dobaczewski et al. 2011). TGF- $\beta$ wird als inaktiver Komplex sezerniert und kann durch multiple Mediatoren aktiviert werden. $\mathrm{Zu}$ den Aktivatoren zählen unter anderem Plasmin, Matrix-Metalloproteinase (MMP) -2 und -9 und reaktive Sauerstoffspezies (ROS) (Annes et al. 2003; Rifkin et al. 1999). Durch Interaktion des aktivierten TGF- $\beta$ mit einem Rezeptor an der Zelloberfläche werden die Rezeptoren ALK5 und ALK1 rekrutiert (Massagué 2000; Goumans et al. 2002). Per Phosphorylierung aktivieren diese wiederum Smad-Proteine, welche im Zellkern die Gentranskription beeinflussen (Shi und Massagué 2003; Feng und Derynck 2005). Im Kontext der Herzfibrose werden durch aktiviertes TGF- $\beta$ in Myofibroblasten die Synthese von EZM induziert und Matrixmetalloproteasen (MMP) blockiert, wodurch eine Entstehung von Fibrose gefördert wird (Desmouliere et al. 1993; Mauviel 2005).

Die aktivierten Myofibroblasten exprimieren $\alpha$-Smooth-Muscle-Actin ( $\alpha$-SMA), Angiotensin-II-Rezeptoren und enthalten MMP (Weber et al. 1997). Eine gesteigerte Sezernierung von Kollagen I und III sorgt für Vermehrung der EZM, im Falle eines Myokardinfarkts für eine schnelle Narbenbildung sowie stets den Verlust an Elastizität (Cleutjens et al. 1995). Diese Umstrukturierung des Myokards (Remodeling) mit vermehrter Steifigkeit und Elastizitätsverlust hat direkten Einfluss auf die systolische und diastolische 
Herzleistung und stellt einen der pathophysiologischen Mechanismen bei Herzinsuffizienz und HFpEF dar (Janicki und Brower 2002; Swynghedauw 1999). Die differenziertere Betrachtung der zugrundeliegenden Pathomechanismen erfordert den Einbezug epigenetischer Erklärungsmodelle. Mit ihrer Hilfe konnten bereits in anderen Arbeiten neue Interaktionen verstanden werden.

Manches weist darauf hin, dass epigenetische Prozesse auf die persistierende Fibrogenese Einfluss haben (Xu et al. 2015). Im Rahmen epigenetischer Forschung wurde die DNAMethylierung an CpG-Inseln, welche häufig in Promotorregionen vorkommt, als ein wichtiger Faktor in der Regulierung von Zellaktivität untersucht (Bird 2002; Jones und Laird 1999). Im Gegensatz zur physiologischen Methylierung von CpG-Inseln, die der Zelldifferenzierung dient, werden bei der Hypermethylierung pathologische Prozesse in Gang gesetzt, die bei der Entstehung von Krebs entdeckt wurden (Tampe et al. 2015). Im Myokard dient eine Minderversorgung mit Sauerstoff als Induktor von HIF-1 $\alpha$. HIF-1 $\alpha$ stimuliert, ebenso wie TGF- $\beta 1$, eine Expression von DNA-Methyltransferasen (DNMTs), wodurch CpG-Inseln hypermethyliert werden (Watson et al. 2014). Durch Methylierung von Cytosin in der Promotorregion wird die Transkription des Gens supprimiert (Bird und Wolffe 1999). Eine konsekutive Minderexpression derart regulierter Proteine könnte also für eine persistierende Aktivität der Fibroblasten ursächlich sein, wodurch HFpEF entsteht (Grimaldi et al. 2017).

Die in dieser Arbeit untersuchten Gene, die für die Entstehung von Herzfibrose durch Promotorhypermethylierung mitverantwortlich sein könnten, sind RASAL1, ATP2A2 und B9D1. Das vierte hier betrachtete Gen, $L A P$, welches als Kontrollgen dient, wurde bereits in anderen Arbeiten als eben dieses etabliert (Weber et al. 2005), da es dort eine von anderen Einflussgrößen unabhängige Methylierung zeigte.

\subsection{RASALI}

RASAL1 ist ein Gen, das zur RAS-GAP-Familie gehört und die zelluläre Proliferation bzw. Differenzierung reguliert (Allen et al. 1998; Bechtel et al. 2010). Es kodiert für das RASGap-like Protein I, eine GTPase, die aktives RAS-GTP in inaktives RAS-GDP umwandelt (Walker et al. 2004). RASAL1 ist daher ein Inhibitor des RAS-Signalwegs (Xu et al. 2015). Dies bedeutet, dass bei einer hohen RASAL1-Expression wenig aktivierendes RAS-GTP vorhanden ist und somit der Signalweg für Proliferation und Differenzierung inhibiert ist. Wird RASAL1 durch DNMT1 hypermethyliert, ist die Expression verringert und eine hohe Konzentration von RAS-GTP liegt vor. Diese RAS-Hyperaktivität bewirkt eine erhöhte intrinsische Proliferation und verstärkte Kollagenexpression (Bechtel et al. 2010). In ihrer 
Arbeit konnten $\mathrm{Xu}$ et al. (2016) die enge Verbindung zwischen TGF- $\beta$ und RASAL1 darstellen. Unter Hypoxie führte die Aktivierung von TGF- $\beta 2$ über den Smad-Signalweg zu einer Aktivierung von DNMT3a, welcher zu einer Hypermethylierung von RASAL1 führte. Diese mündete in eine verstärkte RAS-GTP-Aktivität. Die verstärkte RAS-GTP-Aktivität mit konsekutiver Kollagenexpression führt dazu, dass Endothel in Mesenchym (endothelial to mesenchymal transition, EndMT) umgebaut wird (Xu et al. 2015). Kombiniert mit dem Wissen, dass EndMT mit Herzfibrose assoziiert ist (Zeisberg et al. 2007), stellten Xu et al. (2015) fest, dass die Hypermethylierung von RASAL1-Promotoren, welche zu einer niedrigen RASAL1-Expression und somit zu einer erhöhten RAS-GTP-Aktivität führt, zur Bildung von fibrotischem Herzgewebe beiträgt. Vorausgegangene Arbeiten haben den theoretischen Zusammenhang zwischen RASAL1, Methylierung und Fibrose im Herzen hergestellt. In der vorliegenden Arbeit soll untersucht werden, ob mit Hilfe der Quantifizierung von methylierten RASAL1-Promotoren im Blut die Progression von HFpEF beurteilt werden kann, die eng mit der Fibrogenese verknüpft zu sein scheint.

\subsection{ATP2A2}

ATP2A2 kodiert für die sarcoplasmic reticulum $\mathrm{Ca}^{2+}$-ATPase (SERCA2), eine $\mathrm{Ca}^{2+}$-Pumpe am Sarkoplasmatischen Retikulum (SR) im Herzen, die Kalzium aus dem Zytosol ins SR pumpt. Dies geschieht während der Diastole des Herzzyklus, damit für die folgende Kontraktion wieder ausreichend $\mathrm{Ca}^{2+}$ zur Verfügung steht (Wuytack et al. 2002). $\mathrm{Ca}^{2+}$ ist im Herzzyklus ein wichtiger Bestandteil für die Kontraktion der Herzkammern: In der Systole gelangt durch das Aktionspotenzial ein geringer $\mathrm{Ca}^{2+}$-Einstrom durch L-Typ-Ca ${ }^{2+-} \mathrm{Kanäle}$ ins Sarkoplasma. Dieser Einstrom triggert den Ryanodin-Rezeptor, sodass $\mathrm{Ca}^{2+}$ aus dem SR ins Sarkoplasma gelangt. $\mathrm{Ca}^{2+}$ bindet an das Protein Troponin $\mathrm{C}$ der Myofilamente und über weitere Mechanismen kontrahiert der Muskel. Am Ende des Kontraktionszyklus werden $30 \%$ des $\mathrm{Ca}^{2+}$ in den Extrazellularraum gepumpt, während die anderen $70 \%$ mit Hilfe der SERCA2 wieder ins SR aufgenommen werden (Bers et al. 1996). SERCA2 erfüllt also wichtige Funktionen: Sie ermöglicht einerseits die Relaxation, indem die diastolische Kalziumkonzentration im Zytoplasma gesenkt wird, andererseits stellt sie wieder $\mathrm{Ca}^{2+}$ für die darauffolgende Kontraktion zur Verfügung (Lipskaia et al. 2010; Frank et al. 2002). Nach der Transkription entstehen vier Isoformen: SERCA2a, 2b, 2c und 2d (Kimura et al. 2005). In Studien konnten Hinweise darauf gefunden werden, dass die Expression von ATP2A2 und die Konzentration von SERCA2a bei Herzinsuffizienz reduziert sind (Hasenfuß et al. 1994). Bei einer verminderten Konzentration von SERCA2 kann der Speicher des SR nicht ausreichend mit $\mathrm{Ca}^{2+}$ gefüllt werden, mehr $\mathrm{Ca}^{2+}$ verbleibt am Ende 
der Systole im Sarkoplasma. In der folgenden Diastole ist ein Kalziumüberangebot verantwortlich für eine reduzierte Relaxation und konsekutiv für eine geringere diastolische Füllung der Ventrikel (Lompré et al. 2010). In der Systole kann nicht mehr ausreichend $\mathrm{Ca}^{2+}$ aus dem leeren Speicher des SR zur Verfügung gestellt werden. Dadurch findet eine schwächere Kontraktion statt (Braunwald 2015). Sedej et al. (2014) veranschaulichen, dass die Fehlregulation des $\mathrm{Ca}^{2+}$-Gleichgewichts im Mausmodell durch eine geringe Serca2aKonzentration in Verbindung mit defekten Ryanodinrezeptoren steht. In ihrer Arbeit beschreiben sie, wie eine im Mausmodell induzierte Druckbelastung zu myokardialem Remodeling führt. Bezüglich der Entstehung von HFpEF im Menschen ist bisher wenig über die Rolle von ATP2A2 bekannt.

In dieser Arbeit wurde ATP2A2 betrachtet, weil Kao et al. (2010) im murinen Modell zeigen konnten, dass die Serca2-Konzentration durch epigenetische Veränderungen, nämlich durch aberrante Methylierung des Atp2a2-Promotors, reduziert wurde. Angrisano et al. (2014) konnten Hinweise darauf liefern, dass epigenetische Veränderungen von Atp2a2 im Mausmodell zur Progression von Herzinsuffizienz beitragen. Zusätzlich konnte in unveröffentlichten Studien der Arbeitsgruppe gezeigt werden, dass Fibrose im Mausmodell mit hypermethyliertem Atp2a2-Promotor assoziiert ist. Auf dieser Grundlage soll in der vorliegenden Arbeit, analog zu der Analyse von RASAL1, untersucht werden, ob eine Quantifizierung von methylierten ATP2A2-Promotoren mit Fibrose und konsekutiv mit einer Progression von HFpEF assoziiert werden kann.

\subsection{B9D1}

Das B9 Protein Domain 1 (B9D1) spielt eine wichtige Rolle in der Ziliogenese. GarciaGonzalo et al. (2011) beschreiben, dass B9D1 zusammen mit anderen Proteinen einen Komplex bildet, der an der Transitionszone der Zilien lokalisiert ist. Ein Verlust eines der Proteine aus dem Komplex bedeutet einen gewebespezifischen Defekt in der Ziliogenese (Dowdle et al. 2011). Dowdle et al (2011) haben festgestellt, dass Mäuse mit einem mutierten B9D1-Protein in der Embroynalphase in 44\% der Fälle Dextrokardie aufweisen. Zudem verursacht Ziliopathie häufiger Ventrikelseptumdefekte und eine dünnere Herzwand (Dowdle et al. 2011). Meder et al. (2017) haben in ihrer Arbeit gezeigt, dass methyliertes B9D1 als Biomarker für dilatative Kardiomyopathie genutzt werden kann. Die für die Analysen benötigte DNA wurde in ihren Versuchen aus Herzbiopsien und Blutproben gewonnen. Meder et al. (2017) vermuteten, dass fetal exprimierte Gene wie B9D1 als Reaktion auf Stress bei der Entstehung von Herzinsuffizienz reaktiviert werden, wobei noch unklar ist, wie genau diese Reaktivierung stattfinden kann. 
Im Rahmen dieser Arbeit wird untersucht, ob eine aberrante Promotormethylierung von B9D1 mit der klinischen Progression von HFpEF assoziiert ist.

\section{6. $L A P$}

Die Leucin-Aminopeptidase (LAP) wurde von Weber et al. (2005) als Kontrollgen bereits etabliert. In der vorliegenden Arbeit wird das Gen als Positivkontrolle eingesetzt, um Störfaktoren in der experimentellen Methodik auszuschließen, da dieses Gen in Studien eine hohe Methylierung aufwies (Bechtel et al. 2010). LAP ist ein etabliertes Gen in der Diagnostik von Leberkrebs (Abouzied et al. 2015) und spielt eine Rolle als Zielstruktur in der Therapie von Ovarialkrebs (Mizutani et al. 2007).

\subsection{Diagnosekriterien der Herzinsuffizienz}

Verschiedene Organisationen haben Algorithmen vorgeschlagen, um Herzinsuffizienz bei Patienten zu identifizieren. Neben den Kriterien aus der Framingham-Studie (Ho et al. 1993), den Boston-Kriterien (Carlson et al. 1985) und den Gothenburg-Kriterien (Eriksson et al. 1987) dienen die ESC-Leitlinien (European Society of Cardiology 2016) in Deutschland zur Diagnostik. Neben einer EF $\geq 50 \%$, werden diagnostische Kriterien wie Symptome und Zeichen von Herzinsuffizienz, die BNP- und NT-proBNP-Konzentration, der Ausschluss anderer Ursachen für die Symptomatik sowie bildgebende Verfahren herangezogen (Ponikowski et al. 2016; Yancy et al. 2013). Es ist bisher nicht möglich, jene Risikopatienten zu identifizieren, die durch eine rasche Progredienz der Krankheit früh versterben (Carson et al. 2015). Durch Ausnutzung der Vorteile einer liquid biopsy, die eine kostengünstige und wenig risikobehaftete Möglichkeit darstellt, DNA der Patienten zu gewinnen, die in ihren Eigenschaften mit der DNA im Herzgewebe übereinstimmt (Schwarzenbach et al. 2011; Tampe et al. 2015) sowie durch die Analyse der methylierten DNA-Fragmente im Blut mit anschließender statistischer Auswertung, sollen in dieser Arbeit Marker identifiziert werden, die diese Lücke schließen.

\subsection{Zielsetzung}

Bisher können Patienten mit HFpEF von jenen mit HFrEF durch die zuvor beschriebene Diagnostik unterschieden werden. Innerhalb der HFpEF-Patienten ist es jedoch bisher nicht möglich, diejenigen zu identifizieren, die durch eine rasche Progredienz zur hohen Mortalität von HFpEF beitragen. In der Literatur herrscht Einigkeit darüber, dass dies der zentrale Aspekt in der Erforschung des Krankheitsbilds HFpEF ist (Carson et al. 2015; Nanayakkara et al. 2018). Es konnte bereits gezeigt werden, dass aberrante Methylierung von CpG-Inseln 
des RASAL1-Gens zur Suppression von Transkription führt und mechanistisch für Fibrogenese im Myokard verantwortlich ist (Angrisano et al. 2014; Xu et al. 2015). Zudem konnte in unveröffentlichten Studien der Arbeitsgruppe der Zusammenhang zwischen hypermethylierten Atp2a2-Promotoren und Fibrose dargestellt werden. Ebenfalls ist bekannt, dass Fibrose mit der Progression chronischer Herzinsuffizienz assoziiert ist (Schelbert et al. 2014). Tampe et al. (2015) haben herausgefunden, dass methylierte Promoter-DNA aus verletzten Organen freigesetzt wird und im Blut detektiert werden kann. Bisher ist noch kein leicht messbarer Biomarker für Herzfibrose und die Progression von HFpEF gefunden. Studien haben gezeigt, dass der Grad an Fibrose eng mit der Mortalität assoziiert ist (Mascherbauer et al. 2013). In der vorliegenden Arbeit dient die Mortalität bei HFpEF-Patienten als Korrelat für Fibrose, durch einen Mangel an myokardialen Biopsien. Hieraus ergeben sich folgende Fragestellungen, die als Ziel dieser Arbeit beantwortet werden sollen:

a) Korrelieren die zu etablierenden Biomarker im Blut mit der Mortalität bei HFpEFPatienten?

b) Wenn eine Korrelation vorliegt, liefern die Biomarker Vorteile in der Erfassung des Mortalitätsrisikos gegenüber anderen klinischen Einflussgrößen?

c) Korreliert die Methylierung im Blut mit dem Grad der diastolischen Dysfunktion, gemessen mit Hilfe der Echokardiographie (E/e')? 


\section{Material und Methoden}

\subsection{Material}

\subsubsection{Geräte}

Eismaschine

Lichtmikroskop BX43

Multipette stream

Nanodrop 2000 Spectrophotometer

Pipette Reasearch Plus

Sonicator Misonix

StepOne Plus Real-Time PCR System

Thermomixer comfort

Vortex genie

Vortex VWR Lap Dancer

Wasserbad

Zentrifuge 5415R

Zentrifuge minispin

Zentrifuge perfect spin

\subsubsection{Software}

cellSensDimension 1.6

Microsoft Office

Nanodrop

GraphPad Software

SPSS

StepOne v.2.3

\subsubsection{Gebrauchsmaterialien}

Benchtop Cooler 96 Tube

Combitips advanced $1.0 \mathrm{ml}$

Kunststoffschaber

MicroAmp Fast Optical 96-Well

Reaction Plate $(0,1 \mathrm{ml})$
Scotsman Ice Systems, Vernon Hills, USA

Olympus, Tokio, Japan

Eppendorf, Hamburg, Deutschland

Peqlab, Erlangen, Deutschland

Eppendorf, Hamburg, Deutschland

Qsonica, Newtown, USA

Appliedbiosystems, Life Technologies, Carlsbad, USA

Eppendorf, Hamburg, Deutschland

Bender \& Hobein AG, Zürich, Schweiz

Bender \& Hobein AG, Zürich, Schweiz

Memmert GmbH, Schwabach, Deutschland

Eppendorf, Hamburg, Deutschland

Eppendorf, Hamburg, Deutschland

Peqlab, Erlangen, Deutschland

Olympus, Tokio, Japan

Microsoft Corporation, Redmond, USA

Thermo Fisher Scientific, Waltham, USA

GraphPad Software, La Jolla, USA

IBM Corporation, Armonk, USA

Applied Biosystems, Life Technologies, Carlsbad, USA

Agilent Technologies, Santa Clara, USA

Eppendorf, Hamburg, Deutschland

3M, Minnesota, USA

Applied Biosystems by Thermo Fisher Scientific, Life Technologies Corporation, Carlsbad, USA 
MicroAmp ${ }^{\mathrm{TM}}$ optical adhesive Film

Parafilm M

Pipettenspitzen Biosphere (10,

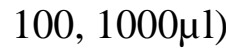

Pipettenspitzen TipOne (10, 100, $1000 \mu 1)$

Safe-Lock Tubes 1,5 ml; $2 \mathrm{ml}$

\subsubsection{Chemikalien}

Chloroform (Trichlormethan) EMSURE

Ethanol

Fast SYBR ${ }^{\mathrm{TM}}$ Green Master Mix

Nukleasefreies Wasser

\subsubsection{Kitsysteme}

DNeasy Blood \& Tissue Kit

Methylamp Methylated DNA

Capture Kit (MeDIP)

\subsubsection{Ansatz für rtPCR}

Nukleasefreies Wasser

Rückwärtsprimer $20 \mu \mathrm{M}$

SYBR Green Master Mix

Vorwärtsprimer $20 \mu \mathrm{M}$
Applied Biosystems by Thermo Fisher Scientific, Life Technologies Corporation, Carlsbad, USA

Bemis, Neenah, USA

Sarstedt, Nürmbrecht, Deutschland

Starlab, Hamburg, Deutschland

Eppendorf, Hamburg, Deutschland

Merck KGaA, Darmstadt, Deutschland

Merck KGaA, Darmstadt, Deutschland

Applied Biosystems, Life Tech., Carlsbad (CA), USA

QIAGEN, Hilden, Deutschland

QIAGEN, Hilden, Deutschland

Epigentek, Farmingdale, USA

\subsubsection{Primer für rtPCR}

$4,6 \mu 1$

$0,2 \mu 1$

$10 \mu 1$

$0,2 \mu 1$

Tabelle 1: Primer für die rtPCR. Hersteller Microsynth, Balgach, Schweiz

\begin{tabular}{|l|c|l|}
\hline \multicolumn{1}{|c|}{ Gen } & & \multicolumn{1}{c|}{ Primersequenz } \\
\hline RASAL1 & F & GCCAACTCACCAGGAGCCAGCGGC \\
\hline & R & CTACCGGCACCCCAGTCATGCGC \\
\hline$A T P 2 A 2$ & F & GGGCCCAGAACCCGCTGGGG \\
\hline & R & GGAGCTGGGAGCGCGGTCCAC \\
\hline$B 9 D 1$ & F & CCGCCCGAGAAAGCCACGCCTG \\
\hline & R & GAGAGCTTCATGGGGACGCGC \\
\hline$L A P$ & F & CACCGTTGCACCTGTGGAACAG \\
\hline & R & CGAGGTTTCACCATGTTGTCC \\
\hline
\end{tabular}




\subsubsection{Patientenproben}

Im Jahr 2004 wurde die Studie „Prävalenz und Verlauf der diastolischen Dysfunktion und der diastolischen Herzinsuffizienz“ (DIAST-CHF), eine prospektive Kohortenstudie mit zwei Patientenkollektiven und insgesamt 1660 Patienten, vom Kompetenznetz Herzinsuffizienz, gestartet. Den Patienten wurde zu verschiedenen Zeitpunkten Vollblut abgenommen und diverse Parameter zum Zeitpunkt Null (Baseline) sowie nach einem, zwei und nach fünf Jahren erhoben. Als Einschlusskriterien dienten entweder mindestens ein Risikofaktor für diastolische Dysfunktion, wie arterielle Hypertonie, Diabetes mellitus, Schlafapnoesyndrom und Zeichen einer Arteriosklerose, oder die durch einen Arzt dokumentierte Diagnose Herzinsuffizienz. Die Studienpopulation wurde demnach in zwei Gruppen, A und B, unterteilt. Während Gruppe A keine Zeichen der klinischen Herzinsuffizienz zeigte, hatten Patienten der Gruppe B entweder bereits eine solche Diagnose erhalten oder wiesen klinische Zeichen der Herzinsuffizienz auf. Ein Alter zwischen 50 und 85 Jahren und eine schriftliche Einverständniserklärung waren zudem Bedingung für den Studieneinschluss. Mangelnde Kooperationsbereitschaft, unzureichende Kommunikationsfähigkeit aufgrund von fehlenden Deutschkenntnissen oder Aphasien, Erkrankungen mit Beeinträchtigung der Einwilligungsfähigkeit sowie geographische Gründe galten als Ausschlusskriterien. Die Klinik für Kardiologie und Pneumologie des Universitätsklinikums Göttingen stellte Vollblutproben von 47 Patienten für diese Arbeit zur Verfügung. Diese wiesen eine $\mathrm{EF}$ von $\geq 45 \%, \mathrm{E} / \mathrm{e}^{\natural} \geq 12$ sowie entweder Ödeme und Belastungsdyspnoe oder eine ärztliche Diagnose für Herzinsuffizienz auf. Die Ethikkommission hat der Studie im Juli 2004 zugestimmt; der Antrag mit der Nummer 22/2/04 liegt vor.

\subsection{Methoden}

\subsubsection{DNA-Aufreinigung}

Um die methylierten Anteile der humanen Promoter $\mathrm{zu}$ bestimmen, musste die DNA zunächst isoliert werden. Sie wurde aus den 47 EDTA-Vollblutproben der DIAST- Kohorte aufgereinigt. Zur Aufreinigung der DNA aus Humanblut wurde das Kit DNeasy Blood \& Tissue Kit von QUIAGEN GmbH verwendet. Zunächst mussten in einem Safe-Lock Röhrchen je $200 \mu \mathrm{l}$ der Humanblutproben mit $20 \mu$ l Proteinkinase K und $200 \mu$ l AL Puffer aus dem Kit versetzt werden. Nach Mischung mit Hilfe des Vortex erfolgte eine Inkubation bei $56^{\circ} \mathrm{C}$ und $450 \mathrm{rpm}$ für 10-15 Minuten im Thermomixer comfort von Eppendorf. Danach 
wurden $200 \mu \mathrm{l}$ 100\%-iges Ethanol zu den aufgeschlossenen Zellen gegeben und der gesamte Inhalt der Röhrchen auf eine Säule pipettiert, die in einem Röhrchen steckte. Nachdem die DNA für eine Minute bei $8.000 \mathrm{rpm}$ zentrifugiert worden war, musste die Säule auf ein neues Röhrchen überführt und die alte verworfen werden. Es folgten zwei Waschungen mit $500 \mu 1$ AW1- bzw. AW2-Waschpuffer bei $8.000 \mathrm{rpm}$ für eine Minute bzw. $14.000 \mathrm{rpm}$ für drei Minuten. Zwischen den beiden Schritten musste der Durchfluss verworfen werden; nach der Waschung mit AW2 wurde die Säule auf ein beschriftetes Safe-Lock-Röhrchen gegeben. Im letzten Schritt wurde $200 \mu$ AE Elutionspuffer direkt auf den Filter der Säule gegeben und eine Minute bei Raumtemperatur inkubiert. Nach einminütiger Zentrifugation bei $8.000 \mathrm{rpm}$ konnte die Säule verworfen werden. Im Safe-Lock-Röhrchen befand sich am Ende die gereinigte DNA, die für Messungen benötigt wurde. Mit Hilfe der Software NanoDrop konnte die Nukleinsäurekonzentration jeder Probe bestimmt werden.

\subsubsection{Konzentrationsmessung}

Die Messung der DNA-Konzentration erfolgte mit Hilfe des NanoDrop Spektralphotometers, welches über eine gleichnamige Software mit einem Computer verbunden war. Zunächst musste eine Blindprobe erstellt werden. Hierfür wurde $1 \mu 1$ des zuvor verwendeten AE-Puffers auf den Sensor am unteren Arm des Geräts gegeben. Nachdem der Hebel geschlossen war, konnte die Messung mit der Auswahl „Blank“ im Computerprogramm gestartet werden. Nach Reinigung des Sensors durch ein faserfreies Tuch konnte $1 \mu \mathrm{l}$ der ersten DNA-Probe auf den Sensor gegeben werden und die Konzentrationsmessung nach Schließen des Hebels und Auswählen der Menüangabe „Measure“ erfolgen. Die Flüssigkeit überbrückte den Abstand zwischen zwei optischen Faserkabeln, die im oberen und unteren Arm des Gerätes installiert sind. Die während der Messung durch die Probe gesendeten Lichtblitze wurden in einem Spektralphotometer aufgefangen und in der Software verrechnet. Der Reinheitsgrad der DNA konnte ermittelt werden, indem die Absorptionskoeffizienten bei 260 und $280 \mathrm{~nm}$ ins Verhältnis gesetzt wurden. Bei reiner DNA erhält man ein Verhältnis von 1,8. Abweichungen konnten durch Verunreinigungen zustande kommen ( nach Anleitung von Thermo Fisher Scientific). Die Konzentration der Probe ließ sich aus der Software ablesen.

\subsubsection{Methylated DNA immunoprecipitation (MeDIP)}

Bei dieser Methode wurde die methylierte DNA mit Hilfe eines Antikörpers angereichert, der an 5-Methylcytosin (5mC) der zuvor gewonnenen DNA band (Weber et al. 2005). Zunächst verdünnte man die DNA mit dem Reaktionspuffer MC2 aus dem Methylamp 
Methylated DNA Capture Kit in einer Safe-Lock-Tube. Dieser Schritt stellte sicher, dass in jeder Probe dieselbe Konzentration DNA vorhanden war. Gemäß vorangegangenen Berechnungen wurden beide Flüssigkeiten gemischt, sodass eine Konzentration von 500 ng DNA in $108 \mu 1$ Volumen in jeder Probe vorhanden war. Im nächsten Schritt musste die DNA mit Hilfe des Sonicators Misonix in 20 Amplituden in kleinere Fragmente gespalten werden. Zwischen jedem Sonifikationsschritt wurde die DNA auf Eis gekühlt, das zu Beginn mit ins Gerät gegeben worden war. Die 200-1000 bp großen DNA-Fragmente wurden folgend bei $95{ }^{\circ} \mathrm{C}$ zwei Minuten lang denaturiert, sodass Einzelstränge entstanden. Ein anschließendes Abkühlen auf Eis verhinderte, dass sich die Stränge wieder zusammenlagerten. Während die DNA fragmentiert und denaturiert wurde, wurden jeweils $1 \mu 1$ Anti-5-Methylcytosin und $100 \mu \mathrm{l}$ des Antikörperpuffers MC1 aus dem Kit in eine Platte mit 8-Well-Assay-Strips pipettiert und verschlossen mit Parafilm für 60 Minuten bei Raumtemperatur und $50 \mathrm{rpm}$ inkubiert. Nach der Inkubation wurde der Überstand aus MC1 und Anti-5-Methylcytosin verworfen und die Probenplatte zweimal mit $150 \mu$ l Antikörperpuffer MC1 bzw. Waschpuffer MC3 gewaschen. In jede Plattenvertiefung wurden $100 \mu 1$ fragmentierte DNA gegeben und die Platte mit Parafilm abgedeckt. Anschließend erfolgte eine zweistündige Inkubation auf dem Belly Dancer auf Stufe 7 (50-100 rpm). Während dieser Zeit wurde die fragmentierte und denaturierte DNA an den Antikörper gebunden, der die DNA somit im Gefäß fixierte. Nach der Inkubation konnte der Überstand, der die nicht gebundene DNA enthielt, verworfen werden. Nach dreimaliger Waschung der Plattenvertiefungen mit jeweils $150 \mu 1$ Waschpuffer MC3, wurden $60 \mu 1$ eines Mix, der sich aus Proteinkinase K und DNALösungspuffer MC4 zusammensetzte, in jedes Well gegeben. Die Reaktionsansätze wurden dann mit einem Deckel aus dem Kit verschlossen und 60 Minuten in einem $65{ }^{\circ} \mathrm{C}$ warmen Wasserbad inkubiert.

Zusätzlich zu der an den Antikörper gebundenen, methylierten DNA, musste eine Ladekontrolle angefertigt werden, die zum Vergleich diente, sodass später quantitative Aussagen über den Grad der Methylierung gemacht werden konnten. Für diese Ladekontrollen wurden $5 \mu \mathrm{l}$ der DNA aus dem Sonicator in ein frisches Safe-Lock-Tube überführt und mit $60 \mu 1$ des Mastermix aus Proteinkinase K und DNA-Lösungspuffer MC4 versetzt. Der Input wurde ebenfalls 60 Minuten bei $65{ }^{\circ} \mathrm{C}$ im Wasserbad inkubiert. Im Gegensatz zur Antikörper-gebundenen DNA wurden diese Proben nicht an Antikörper gebunden, sodass hier am Ende die genomische DNA vorhanden war. Die folgenden Schritte wurden sowohl für den Input als auch für die ursprüngliche Antikörper-gebundene DNA ausgeführt. 
Entsprechend der Anzahl der Proben erfolgte die Vorbereitung der Zentrifugenröhrchen: Es wurde jeweils eine Säule in einen Tube gesteckt und $100 \mu$ 1 Bindungspuffer MC5 auf die Säule gegeben. Anschließend konnte der Inhalt der Probenansätze mit jeweils $180 \mu 1$ 100\%igem Ethanol gemixt und auf die Säule gegeben werden. Dann erfolgte eine Zentrifugation für 20 Sekunden bei 12.000 rpm. Der Inhalt, der dadurch in die Sammelröhrchen gelangte, wurde verworfen und die Säule wieder in die Sammelröhrchen gesteckt. Es schlossen sich zwei weitere Zentrifugationen bei $12.000 \mathrm{rpm}$ für 20 bzw. 35 Sekunden an, nachdem jeweils $200 \mu 190 \%$-iges Ethanol auf die Säule gegeben wurden. Nach dem letzten Durchlauf konnte das Sammelröhrchen verworfen und die Säule auf ein vorher beschriftetes Safe-Lock-Tube gesetzt werden. Der Elutionspuffer MC6 $(20 \mu \mathrm{l})$ wurde direkt auf den Filter der Säule pipettiert und wirkte eine Minute ein. Eine abschließende Zentrifugation für 20 Sekunden bei $12.000 \mathrm{rpm}$ ließ die gereinigte, methylierte DNA in das Safe-Lock-Tube gelangen. Die Säule wurde verworfen, die Proben mit $80 \mu$ l nukleasefreiem Wasser versetzt und anschließend bis zur Verwendung für die rtPCR bei $-20{ }^{\circ} \mathrm{C}$ eingefroren.

\subsubsection{Quantitative Realtime-PCR (rtPCR)}

Die Realtime-Polymerasekettenreaktion (rtPCR) basiert auf der von Mullis und Faloona 1987 beschriebenen Polymerasekettenreaktion (Mullis und Faloona 1987). Zusätzlich zur Denaturierungs-, Annealing- und Elongationsphase ermöglichte die rtPCR eine EchtzeitQuantifizierung der DNA. Dies wurde durch einen Farbstoff erreicht, der an die DNA bindet. Durch Messung der Fluoreszenz konnte die DNA-Menge bestimmt werden (Higuchi et al. 1992). Alternativ zu dem von Higuchi et al. verwendeten Ethidiumbromid wurde der Farbstoff SYBR-Green gebraucht. Dieser gestattete nicht nur eine Analyse der DNA-Menge am Ende der PCR, sondern eine Messung der Doppelstrang-DNA in jedem Zyklus (Wittwer et al. 2013).

Zunächst wurden die Wells mit insgesamt $20 \mu \mathrm{l}$ befüllt. Diese $20 \mu 1$ setzen sich zusammen aus $5 \mu \mathrm{l}$ DNA bzw. Input, $10 \mu \mathrm{l} \mathrm{SYBR-Green,} \mathrm{4,6} \mu$ l nukleasefreiem Wasser und 0,4 $\mu 1$ Primer (je 0,2 $\mu 120 \mu \mathrm{M}$ Vorwärts- bzw. Rückwärtsprimer). Für jede Probe wurden Tripletts angelegt. Nach kurzer Zentrifugation wurde die Platte mit den Proben in das StepOne Plus Real-Time PCR System gegeben und Einstellungen in der gleichnamigen Software vorgenommen. Unter „Experiment Properties“ wurde die Einstellung „Quantitation Comparative CT $(\Delta \Delta \mathrm{CT}) “$ gewählt und eingestellt, dass SYBR Green verwendet wurde. Nach einer initialen Denaturierung für 20 Sekunden bei $95{ }^{\circ} \mathrm{C}$ folgten drei Sekunden bei $95{ }^{\circ} \mathrm{C}$ und 30 Sekunden bei der Annealingtemperatur des Primers (RASAL1: $60{ }^{\circ} \mathrm{C}, A T P 2 A 2$ : $66^{\circ} \mathrm{C} ; B 9 D 1: 62^{\circ} \mathrm{C} ; \mathrm{LAP}: 60^{\circ} \mathrm{C}$ ). Dieser Zyklus wurde fünfzigmal wiederholt. 
Als Ergebnis erhielt man den Ct-Wert. Dieser gab die benötigte Zykluszahl an, bis genügend SYBR Green gebunden war, damit sich die Probe farblich abhob. Je mehr (methylierte) DNA in der Probe vorhanden war, desto früher war dieser Punkt erreicht und umso kleiner war folglich Ct. Verglich man den Ct-Wert des Inputs mit dem der methylierten DNA, so erhielt man Aufschluss darüber, wie hoch der Grad der Methylierung war. Hierfür wurde der Ct-Wert des Inputs von dem der DNA subtrahiert. Die Differenz, dCt, konnte anschließend in die Formel $\frac{2^{-d C T}}{20}$ eingesetzt werden, um die relative Genexpression zu erhalten.

\subsubsection{Statistik}

Die statistische Auswertung erfolgte mit den Programmen MS Office, SPSS und „GraphPad Prism 6“. Zusammen mit den Blutproben der 47 Patienten, wurden zu Beginn der DIASTStudie von jedem Patienten zahlreiche Daten erhoben. Im Rahmen dieser Arbeit wurde aus dem Grunddatensatz ein Basisdatensatz übernommen, der die Kohorte beschreibt. Die in Tabelle 2 und Tabelle 3 dargestellten Parameter charakterisierten die Patienten zum Zeitpunkt Baseline. 
Tabelle 2: Basisdatensatz der Kohorte I. Numerische Parameter, die für die Baselinecharakterisierung ausgewertet wurden.

\begin{tabular}{|c|c|}
\hline numerisch & Einheit \\
\hline LVEF & $\%$ \\
\hline Alter & Jahre \\
\hline Body-Mass-Index & $\mathrm{kg} / \mathrm{m}^{2}$ \\
\hline \begin{tabular}{|l|} 
RR systolisch \\
\end{tabular} & $\mathrm{mmHg}$ \\
\hline RR diastolisch & $\mathrm{mmHg}$ \\
\hline Herzfrequenz & $1 / \mathrm{min}$ \\
\hline Taillenumfang & $\mathrm{cm}$ \\
\hline Hüftumfang & $\mathrm{cm}$ \\
\hline \multicolumn{2}{|l|}{ NYHA-Klasse } \\
\hline Hinterwand & $\mathrm{mm}$ \\
\hline LDL-Cholesterin & $\mathrm{mmol} / \mathrm{l}$ \\
\hline HDL-Cholesterin & $\mathrm{mmol} / \mathrm{l}$ \\
\hline PQ-Zeit & $\mathrm{ms}$ \\
\hline QRS-Dauer & $\mathrm{ms}$ \\
\hline QT-Zeit & $\mathrm{ms}$ \\
\hline \multicolumn{2}{|l|}{ E/e' } \\
\hline NT-proBNP & $\mathrm{pg} / \mathrm{ml}$ \\
\hline BNP & $\mathrm{pg} / \mathrm{ml}$ \\
\hline Überleben & Tage \\
\hline Krea-Clearance & $\mathrm{ml} / \mathrm{min}$ \\
\hline
\end{tabular}

Tabelle 3: Basisdatensatz der Kohorte II. Kategoriale Parameter, die für die Baselinecharakterisierung ausgewertet wurden.

\begin{tabular}{|l|}
\hline \multicolumn{1}{|c|}{ kategorial } \\
\hline LSB \\
\hline RSB \\
\hline AV-Block \\
\hline RV-Dilatation \\
\hline Betablocker \\
\hline KHK \\
\hline Rauchen \\
\hline Hypertonie \\
\hline Herzinsuffizienz \\
\hline Geschlecht \\
\hline Z. n. Myokardinfarkt \\
\hline Diabetes \\
\hline Tod \\
\hline
\end{tabular}

Da die Messwerte der Promotormethylierung der in dieser Arbeit untersuchten Gene nicht normalverteilt waren, musste zunächst eine Logarithmierung der Werte durchgeführt werden. Die logarithmierten Werte erfüllten die Bedingungen für die anschließenden 
statistischen Tests. Im Rahmen der epidemiologischen Charakterisierung wurden für alle numerischen Parameter zunächst Mittelwert \pm Standardabweichung $(\mathrm{SD}=$ standard deviation) der gesamten Kohorte ermittelt. Zusätzlich wurde ein Mediansplit bezogen auf die methylierten Gene RASAL1, ATP2A2 und B9D1 durchgeführt und der Mittelwert \pm SD ober- und unterhalb des Splits ermittelt. Der Student-t-Test ermöglichte den Vergleich der Werte. Die Beschreibung der nicht numerischen Parameter erfolgte durch Häufigkeitstabellen. Mittelwert \pm SD ober- und unterhalb des Mediansplits wurden durch Kreuztabellen ermittelt. Der $\chi^{2}$-Test nach Pearson berechnete den p-Wert. Für die Analyse und Darstellung der Überlebenszeit wurden Kaplan-Meier-Kurven und Log-rank-Tests verwendet, nachdem der Grenzwert (Cutoff) mit optimaler Sensitivität und Spezifität mittels ROC-Analyse gefunden worden war. Für die vier untersuchten Gene diente der Mediansplit als Cutoff in der Kaplan-Meier-Analyse. Die Cox-Regression fand Anwendung in der multivariaten Analyse. Ein p-Wert kleiner als 0,05 wurde als statistisch signifikant definiert und mit mit dem Symbol * für p<0,05 gekennzeichnet. 


\section{Ergebnisse}

\subsection{Detektion intervariabler Abhängigkeiten sowie Assoziation mit dem Überleben}

\subsubsection{Charakterisierung der Studienkohorte}

Die Kohorte umfasste 47 Patienten, mit den Einschlusskriterien einer EF von $\geq 45 \%, E / e^{6} \geq$ 12 sowie entweder Ödeme und Belastungsdyspnoe oder die ärztliche Diagnose einer Herzinsuffizienz. Insgesamt waren 32 Studienteilnehmer $(68,1 \%)$ weiblich und $15(31,9 \%)$ männlich. Das mittlere Alter betrug zum Zeitpunkt der Erhebung 73,1 $( \pm 8,8)$ Jahre. Der durchschnittliche Body-Mass-Index (BMI) lag bei $32,4( \pm 7,2) \mathrm{kg} / \mathrm{m}^{2}$, was das Kollektiv im Mittel als Adipositas Grad I einstuft. Die linksventrikuläre Ejektionsfraktion lag im Mittel bei 59,7\% ( $\pm 6,9 \%)$, womit im Durchschnitt eine erhaltene Ejektionsfraktion vorlag. Die durchschnittliche Kreatinin-Clearance (Krea-Clearance) betrug $73( \pm 35) \mathrm{ml} / \mathrm{min}$. Unter den Patienten waren 13 (27,7\%) Diabetiker, 44 (93,6\%) hatten eine arterielle Hypertonie und 20 (43\%) waren Raucher.

Um eine Normalverteilung der Daten zu erhalten, wurden die Methylierungswerte der Gene logarithmiert. Wenn nicht anders vermerkt, wird im Folgenden auf die logarithmierten Werte Bezug genommen.

In der Studie betrug das durchschnittliche Überleben $3129( \pm 1225)$ Tage, was ungefähr 8,6 $( \pm 3,3)$ Jahren entspricht. Hier zeigte sich ein signifikanter Unterschied ober- und unterhalb des RASAL1-Mediansplits (Mediansplit RASAL1=-2,1487). Die Patienten mit einer RASAL1-Promotormethylierung oberhalb des Medians starben im Durchschnitt nach 2707 $( \pm 1304)$ Tagen [7,4 $( \pm 3,6)$ Jahre], während die Patienten unterhalb des Medians erst nach $3569( \pm 982)$ Tagen $[10( \pm 2,3)$ Jahre $]$ starben. Hier ist ein statistisch signifikantes $(\mathrm{p}=0,014)$ längeres Überleben von Patienten mit niedrigerer RASAL1-Promotormethylierung zu beobachten (Tabelle 4). Passend hierzu ließ sich ein signifikanter Unterschied $(\mathrm{p}=0,012) \mathrm{im}$ Tod ober- und unterhalb des Mediansplits beobachten. Es starben 62,5\% der Patienten mit einer RASAL1-Methylierung oberhalb des Mediansplits, während nur 26,1\% mit einer Methylierung unterhalb des Mediansplits starben. Von allen Patienten wurde bei 61,7\% vor Beginn der Studie die Diagnose Herzinsuffizienz vom Arzt gestellt bzw. Symptome der Herzinsuffizienz festgestellt, 18 Patienten $(38,3 \%)$ hatten keine Zeichen der klinischen Herzinsuffizienz. Hier unterschied sich die Diagnosehäufigkeit der Gruppe unterhalb des Mediansplits $(78,3 \%)$ signifikant $(\mathrm{p}=0,02)$ von der Gruppe oberhalb, in der lediglich $45,8 \%$ die Diagnose vorab erhalten hatten. Bei den Patienten, bei denen keine Herzinsuffizienz 
vorab diagnostiziert wurde bzw. bei denen keine Zeichen für eine Herzinsuffizienz vorlagen, konnte bei 54,2\% eine erhöhte Methylierung nachgewiesen werden. Somit hat die Mehrheit der Patienten mit einer Methylierung oberhalb des Mediansplits keine Zeichen einer Herzinsuffizienz (Tabelle 5).

Tabelle 4: Charakterisierung der Studienkohorte anhand des RASAL1-Mediansplits I. Für jeden numerischen Parameter wurden Mittelwert und SD insgesamt, sowie ober- und unterhalb des RASAL1Mediansplits berechnet. Die p-Werte wurden durch einen t-Test ermittelt.

\begin{tabular}{|c|c|c|c|c|c|}
\hline & \multirow[b]{2}{*}{ Einheit } & & \multicolumn{3}{|c|}{ RASAL1 } \\
\hline & & gesamt & $<$ Mediansplit & $>$ Mediansplit & $\mathrm{p}$-Wert \\
\hline & & \multicolumn{3}{|c|}{ [Mittelwert \pm Standardabweichung] } & \\
\hline LVEF & $\%$ & $59,7 \pm 6,9$ & $58,6 \pm 7,1$ & $50,7 \pm 6,7$ & 0,302 \\
\hline Alter & Jahre & $73,1 \pm 8,8$ & $71,4 \pm 8,2$ & $74,7 \pm 9,2$ & 0,195 \\
\hline Body-Mass-Index & $\mathrm{kg} / \mathrm{m}^{2}$ & $32,4 \pm 7,2$ & $33,5 \pm 8,3$ & $31,4 \pm 6,1$ & 0,335 \\
\hline RR systolisch & $\mathrm{mmHg}$ & $151,5 \pm 25,6$ & $144,9 \pm 22,7$ & $157,6 \pm 27,1$ & 0,093 \\
\hline RR diastolisch & $\mathrm{mmHg}$ & $79,0 \pm 13,2$ & $76,2 \pm 13,3$ & $81,7 \pm 12,8$ & 0,160 \\
\hline Herzfrequenz & $1 / \mathrm{min}$ & $71,6 \pm 12,5$ & $70,2 \pm 15,0$ & $73,0 \pm 9,7$ & 0,457 \\
\hline Taillenumfang & $\mathrm{cm}$ & $105,6 \pm 18,5$ & $110,0 \pm 21,2$ & $101,8 \pm 15,3$ & 0,138 \\
\hline Hüftumfang & $\mathrm{cm}$ & $114,2 \pm 14,9$ & $118,6 \pm 16,2$ & $110,4 \pm 12,9$ & 0,064 \\
\hline NYHA-Klasse & & $2,0 \pm 0,7$ & $1,94 \pm 0,8$ & $2,2 \pm 0,6$ & 0,394 \\
\hline Hinterwand & $\mathrm{mm}$ & $11,8 \pm 1,6$ & $11,8 \pm 1,9$ & $11,8 \pm 1,3$ & 0,945 \\
\hline LDL-Cholesterin & $\mathrm{mmol} / \mathrm{l}$ & $120,1 \pm 28,8$ & $116,8 \pm 19,4$ & $123,2 \pm 35,4$ & 0,455 \\
\hline HDL-Cholesterin & $\mathrm{mmol} / \mathrm{l}$ & $52,4 \pm 14,9$ & $50,2 \pm 13,9$ & $54,4 \pm 15,8$ & 0,345 \\
\hline PQ-Zeit & $\mathrm{ms}$ & $165,9 \pm 50,1$ & $162,6 \pm 45,7$ & $168,7 \pm 54,6$ & 0,710 \\
\hline QRS-Dauer & $\mathrm{ms}$ & $94,6 \pm 17,2$ & $97,2 \pm 17,12$ & $92,00 \pm 17,15$ & 0,302 \\
\hline QT-Zeit & $\mathrm{ms}$ & $404,3 \pm 44,4$ & $407,5 \pm 51,1$ & $401,17 \pm 37,61$ & 0,629 \\
\hline E/e' & & $16,1 \pm 5,9$ & $14,5 \pm 2,1$ & $17,6 \pm 7,9$ & 0,080 \\
\hline NT-proBNP & $\mathrm{pg} / \mathrm{ml}$ & $671,0 \pm 1112,3$ & $585,8 \pm 670,1$ & $752,8 \pm 1425,0$ & 0,612 \\
\hline BNP & $\mathrm{pg} / \mathrm{ml}$ & $182,4 \pm 192,6$ & $147,9 \pm 138,2$ & $215,5 \pm 231,4$ & 0,233 \\
\hline Überleben & Tage & $3129 \pm 1225$ & $3569 \pm 982$ & $2707 \pm 1304$ & $0,014 *$ \\
\hline Krea-Clearance & $\mathrm{ml} / \mathrm{min}$ & $73,0 \pm 35,0$ & $77,72 \pm 34,7$ & $68,5 \pm 33,3$ & 0,384 \\
\hline
\end{tabular}


Tabelle 5: Charakterisierung der Studienkohorte anhand des RASAL1-Mediansplits II. Für die kategorialen Parameter wurden absolute und relative Häufigkeiten der Gesamtkohorte sowie ober- und unterhalb des RASAL1-Mediansplits berechnet. Der p-Wert wurde mit Hilfe des Chi-Quadrat-Tests ermittelt.

\begin{tabular}{|l|r|r|r|c|}
\hline & & \multicolumn{3}{|c|}{ RASAL1 } \\
\hline & \multicolumn{1}{|c|}{ gesamt } & \multicolumn{3}{|c|}{$\mathrm{n}[\%]$} \\
\hline & \multicolumn{3}{|c|}{ < } & pediansplit \\
\hline & $3(6,4 \%)$ & $1(4,3 \%)$ & $2(8,3 \%)$ & 0,580 \\
\hline RSB & $4(8,5 \%)$ & $3(13 \%)$ & $1(4,2 \%)$ & 0,276 \\
\hline AV-Block & $5(10,6 \%)$ & $3(13 \%)$ & $2(8,3 \%)$ & 0,600 \\
\hline RV-Dilatation & $7(14,9 \%)$ & $5(21,7 \%)$ & $2(8,3 \%)$ & 0,197 \\
\hline Betablocker & $26(55,3 \%)$ & $13(56,5 \%)$ & $13(54,2 \%)$ & 0,870 \\
\hline KHK & $14(29,8 \%)$ & $5(21,7 \%)$ & $9(37,5 \%)$ & 0,238 \\
\hline Rauchen & $20(43 \%)$ & $10(45,5 \%)$ & $10(41,7 \%)$ & 0,796 \\
\hline Hypertonie & $44(93,6 \%)$ & $21(91,3 \%)$ & $23(95,8 \%)$ & 0,525 \\
\hline Herzinsuffizienz & $29(61,7 \%)$ & $18(78,3 \%)$ & $11(45,8 \%)$ & $0,022 *$ \\
\hline Geschlecht & w: $32(68,1 \%)$ & $15(65,2 \%)$ & $17(70,8 \%)$ & 0,680 \\
\hline Z. n. Myokardinfarkt & $4(8,5 \%)$ & $1(4,3 \%)$ & $3(12,5 \%)$ & 0,317 \\
\hline Diabetes & $13(27,7 \%)$ & $6(26,1 \%)$ & $7(29,2 \%)$ & 0,810 \\
\hline Tod & $21(44,7 \%)$ & $6(26,1 \%)$ & $15(62,5 \%)$ & $0,012 *$ \\
\hline
\end{tabular}

Bezogen auf das Überleben zeigten auch die anderen betrachteten Gene einen signifikanten Unterschied ober- und unterhalb des Mediansplits. Die Patienten mit einer ATP2A2Promotormethylierung oberhalb des Mediansplits (Mediansplit ATP2A2=-2,3665) überlebten durchschnittlich $2553( \pm 1308)$ Tage [7 $( \pm 3,6)$ Jahre] und unterschieden sich damit signifikant $(\mathrm{p}=0,001)$ von der Kohorte unterhalb des Mediansplits, die im Durchschnitt nach $3681( \pm 846)$ Tagen $[10,1( \pm 2,3)$ Jahre] starben. Zusätzlich unterschied sich das Alter der Patienten signifikant $(\mathrm{p}=0,018)$ ober- und unterhalb des ATP2A2Mediansplits. Patienten oberhalb waren mit durchschnittlich 76,1 $( \pm 7,8)$ Jahren älter als die Patienten unterhalb des Mediansplits mit durchschnittlich 70,1 ( $\pm 8,9)$ Jahren (Tabelle 6). Bezogen auf den Tod zeigte sich eine signifikant $(p=0,001)$ höhere Sterbequote oberhalb des Mediansplits mit 69,6\%, als unterhalb mit 20,8\% (Tabelle 7). 
Tabelle 6: Charakterisierung der Studienkohorte anhand des ATP2A2-Mediansplits I. Für jeden numerischen Parameter wurden Mittelwert und SD ober- und unterhalb des ATP2A2-Mediansplits berechnet. Die p-Werte wurden durch einen t-Test ermittelt.

\begin{tabular}{|l|l|r|r|r|}
\hline & & \multicolumn{3}{|c|}{ ATP2A2 } \\
\cline { 2 - 5 } & Einheit & $<$ Mediansplit & $>$ Mediansplit & p-Wert \\
\hline & & [Mittelwert \pm Standardabweichung] & \\
\hline LVEF & $\%$ & $60,0 \pm 7,0$ & $59,3 \pm 6,9$ & 0,719 \\
\hline Alter & Jahre & $70,1 \pm 8,9$ & $76,1 \pm 7,8$ & $0,018^{*}$ \\
\hline Body-Mass-Index & $\mathrm{kg} / \mathrm{m}^{2}$ & $34,2 \pm 8,3$ & $30,6 \pm 5,6$ & 0,091 \\
\hline RR diastolisch & $\mathrm{mmHg}$ & $76,7 \pm 14,1$ & $81,4 \pm 12,0$ & 0,237 \\
\hline Herzfrequenz & $1 / \mathrm{min}$ & $72,5 \pm 14,8$ & $70,8 \pm 9,9$ & 0,222 \\
\hline Taillenumfang & $\mathrm{cm}$ & $110,6 \pm 21,4$ & $100,8 \pm 14,1$ & 0,650 \\
\hline Hüftumfang & $\mathrm{cm}$ & $118,1 \pm 16,6$ & $110,5 \pm 12,3$ & 0,081 \\
\hline NYHA-Klasse & & $2,1 \pm 0,8$ & $1,9 \pm 0,7$ & 0,085 \\
\hline Hinterwand & $\mathrm{mm}$ & $11,7 \pm 2,0$ & $11,9 \pm 1,0$ & 0,674 \\
\hline LDL-Cholesterin & $\mathrm{mmol} / 1$ & $115,2 \pm 22,4$ & $125,0 \pm 33,8$ & 0,251 \\
\hline HDL-Cholesterin & $\mathrm{mmol} / 1$ & $52,6 \pm 16,1$ & $52,2 \pm 13,9$ & 0,930 \\
\hline PQ-Zeit & $\mathrm{ms}$ & $163,9 \pm 42,7$ & $167,9 \pm 58,0$ & 0,807 \\
\hline QRS-Dauer & $\mathrm{ms}$ & $95,2 \pm 17,4$ & $93,9 \pm 17,2$ & 0,805 \\
\hline QT-Zeit & $\mathrm{ms}$ & $399,9 \pm 48,3$ & $408,9 \pm 40,5$ & 0,493 \\
\hline E/e' & & $15,2 \pm 4,2$ & $16,9 \pm 7,4$ & 0,321 \\
\hline NT-proBNP & $\mathrm{pg} / \mathrm{ml}$ & $509,5 \pm 578,7$ & $839,6 \pm 1476,0$ & 0,314 \\
\hline BNP & $\mathrm{pg} / \mathrm{ml}$ & $133,0 \pm 121,3$ & $234,1 \pm 238,2$ & 0,078 \\
\hline Überleben & Tage & $3681 \pm 846$ & $2553 \pm 1308$ & $0,001 *$ \\
\hline Krea-Clearance & $\mathrm{ml} / \mathrm{min}$ & $81,4 \pm 40,0$ & $64,5 \pm 27,5$ & 0,102 \\
\hline
\end{tabular}

Tabelle 7: Charakterisierung der Studienkohorte anhand des ATP2A2-Mediansplits II. Für die kategorialen Parameter wurden absolute und relative Häufigkeiten ober- und unterhalb des ATP2A2Mediansplits berechnet. Der p-Wert wurde mit Hilfe des Chi-Quadrat-Tests ermittelt.

\begin{tabular}{|l|r|r|r|}
\hline & \multicolumn{3}{|c|}{ ATP2A2 } \\
\hline & \multicolumn{2}{|c|}{$\mathrm{n}[\%]$} & $\mathrm{p}$-Wert \\
\hline & $1(4,2 \%)$ & $2(8,7 \%)$ & 0,525 \\
\hline LSB & $3(12,5 \%)$ & $1(4,3 \%)$ & 0,317 \\
\hline RSB & $2(8,3 \%)$ & $3(13,0 \%)$ & 0,601 \\
\hline AV-Block & $5(20,8 \%)$ & $2(8,7 \%)$ & 0,243 \\
\hline RV-Dilatation & $11(45,8 \%)$ & $15(65,2 \%)$ & 0,181 \\
\hline Betablocker & $6(25,0 \%)$ & $8(34,8 \%)$ & 0,464 \\
\hline KHK & $11(47,8 \%)$ & $9(39,1 \%)$ & 0,552 \\
\hline Rauchen & $22(91,7 \%)$ & $22(95,7 \%)$ & 0,576 \\
\hline Hypertonie & $17(70,8 \%)$ & $12(52,2 \%)$ & 0,188 \\
\hline Herzinsuffizienz & $16(66,7 \%)$ & $16(69,6 \%)$ & 0,831 \\
\hline Geschlecht & $1(4,2 \%)$ & $3(13 \%)$ & 0,276 \\
\hline Z. n. Myokardinfarkt & $7(29,2 \%)$ & $6(26,1 \%)$ & 0,813 \\
\hline Diabetes & $5(20,8 \%)$ & $16(69,6 \%)$ & $0,001 *$ \\
\hline Tod & & & \\
\hline
\end{tabular}


Ebenso unterschied sich das Überleben der Patienten mit einer B9D1-Promotormethylierung oberhalb des Mediansplits (Mediansplit B9D1=-1,6077) mit durchschnittlich $2667( \pm 1260)$ Tagen [7,3 $( \pm 3,5)$ Jahren] signifikant $(\mathrm{p}=0,007)$ vom Überleben unterhalb des Mediansplits, welches durchschnittlich bei $3610( \pm 1002)$ Tagen $[9,9( \pm 2,7)$ Jahre] lag. Bezogen auf die Methylierung des B9D1-Promotors ließ sich bei niedrigerem Methylierungsgrad ein längeres Überleben beobachten (Tabelle 8). Ebenfalls signifikant ( $\mathrm{p}=0,002)$ verhielt sich die Anzahl der Todesfälle ober- und unterhalb des Mediansplits. So starben nur 21,7\% der Patienten mit einer Methylierung unterhalb des Splits, während 66,7\% mit einer Methylierung oberhalb starben (Tabelle 9). Ergänzend konnte ein signifikanter Unterschied $(\mathrm{p}=0,031)$ des Taillenumfanges ober- und unterhalb des Mediansplits festgestellt werden (Tabelle 8). Insgesamt wurde bei vier Patienten ein Rechtschenkelblock festgestellt. Alle diese Patienten wiesen eine B9D1-Methylierung unterhalb des Mediansplits auf ( $\mathrm{p}=0,033)$ und machten einen Anteil von 17,4\% der Patienten unterhalb aus (Tabelle 9).

Tabelle 8: Charakterisierung der Studienkohorte anhand des B9D1-Mediansplits I. Für jeden numerischen Parameter wurden Mittelwert und SD ober- und unterhalb des B9D1-Mediansplits berechnet. Die p-Werte wurden durch einen t-Test ermittelt.

\begin{tabular}{|l|l|r|r|r|}
\hline & & \multicolumn{3}{|c|}{ B9D1 } \\
\cline { 2 - 5 } & Einheit & $<$ Mediansplit & $>$ Mediansplit & p-Wert \\
\hline & & [Mittelwert \pm Standardabweichung] & \\
\hline Llter & $\%$ & $59,8 \pm 6,9$ & $59,5 \pm 7,1$ & 0,890 \\
\hline Body-Mass-Index & $\mathrm{kg} / \mathrm{m}^{2}$ & $33,7 \pm 8,5$ & $31,1 \pm 5,7$ & 0,103 \\
\hline RR systolisch & $\mathrm{mmHg}$ & $148,7 \pm 29,0$ & $154,1 \pm 22,4$ & 0,226 \\
\hline RR diastolisch & $\mathrm{mmHg}$ & $78,5 \pm 13,1$ & $79,5 \pm 13,5$ & 0,481 \\
\hline Herzfrequenz & $1 / \mathrm{min}$ & $72,3 \pm 15,3$ & $71,0 \pm 9,4$ & 0,792 \\
\hline Taillenumfang & $\mathrm{cm}$ & $111,9 \pm 20,3$ & $100,1 \pm 15,2$ & $0,031 *$ \\
\hline Hüftumfang & $\mathrm{cm}$ & $118,5 \pm 16,5$ & $110,5 \pm 12,6$ & 0,070 \\
\hline NYHA-Klasse & & $2,17 \pm 0,7$ & $1,9 \pm 0,8$ & 0,431 \\
\hline Hinterwand & $\mathrm{mm}$ & $11,7 \pm 1,9$ & $12,0 \pm 1,3$ & 0,651 \\
\hline LDL-Cholesterin & $\mathrm{mmol} / \mathrm{l}$ & $121,2 \pm 28,9$ & $119,1 \pm 29,3$ & 0,808 \\
\hline HDL-Cholesterin & $\mathrm{mmol} / \mathrm{l}$ & $51,6 \pm 14,9$ & $53,1 \pm 15,2$ & 0,739 \\
\hline PQ-Zeit & $\mathrm{ms}$ & $160,3 \pm 44,1$ & $171,1 \pm 55,9$ & 0,509 \\
\hline QRS-Dauer & $\mathrm{ms}$ & $95,7 \pm 19,3$ & $93,4 \pm 15,2$ & 0,648 \\
\hline QT-Zeit & $\mathrm{ms}$ & $400,5 \pm 47,5$ & $407,9 \pm 41,9$ & 0,571 \\
\hline E/e' & & $14,6 \pm 2,9$ & $17,4 \pm 7,6$ & 0,109 \\
\hline NT-proBNP & $\mathrm{pg} / \mathrm{ml}$ & $525,8 \pm 706,5$ & $810,2 \pm 1398,4$ & 0,387 \\
\hline BNP & $\mathrm{pg} / \mathrm{ml}$ & $156,9 \pm 160,7$ & $206,9 \pm 219,6$ & 0,379 \\
\hline Überleben & Tage & $3610 \pm 1002$ & $2667 \pm 1260$ & $0,007 *$ \\
\hline Krea-Clearance & $\mathrm{ml} / \mathrm{min}$ & $76,9 \pm 35,6$ & $69,4 \pm 35,0$ & 0,474 \\
\hline
\end{tabular}


Tabelle 9: Charakterisierung der Studienkohorte anhand des B9D1-Mediansplits II. Für die kategorialen Parameter wurden absolute und relative Häufigkeiten ober- und unterhalb des B9D1Mediansplits berechnet. Der p-Wert wurde mit Hilfe des Chi-Quadrat-Tests ermittelt.

\begin{tabular}{|c|c|c|c|}
\hline & \multicolumn{3}{|c|}{ B9D1 } \\
\hline & $<$ Mediansplit & Mediansplit & p-Wert \\
\hline & \multicolumn{2}{|c|}{$\mathrm{n}[\%]$} & \\
\hline LSB & $1(4,3 \%)$ & $2(8,3 \%)$ & 0,576 \\
\hline RSB & $4(17,4 \%)$ & $0(0 \%)$ & $0,033^{*}$ \\
\hline AV-Block & $2(8,7 \%)$ & $3(12,5 \%)$ & 0,672 \\
\hline RV-Dilatation & $4(17,4 \%)$ & $3(12,5 \%)$ & 0,638 \\
\hline Betablocker & $13(56,5 \%)$ & $13(54,2 \%)$ & 0,871 \\
\hline KHK & $5(21,7 \%)$ & $9(37,5 \%)$ & 0,238 \\
\hline Rauchen & $10(45,5 \%)$ & $10(41,7 \%)$ & 0,796 \\
\hline Hypertonie & $21(91,3 \%)$ & $23(95,8 \%)$ & 0,525 \\
\hline Herzinsuffizienz & $12(52,2 \%)$ & $17(70,8 \%)$ & 0,188 \\
\hline Geschlecht & $16(69,6 \%)$ & $16(66,7 \%)$ & 0,831 \\
\hline Z. n. Myokardinfarkt & $3(13 \%)$ & $1(4,2 \%)$ & 0,276 \\
\hline Diabetes & $7(30,4 \%)$ & $6(25,0 \%)$ & 0,677 \\
\hline Tod & $5(21,7 \%)$ & $16(66,7 \%)$ & $0,002 *$ \\
\hline
\end{tabular}

Für alle weiteren Patientenparameter ließ sich kein signifikanter Unterschied zwischen den Gruppen ober- und unterhalb des Mediansplits feststellen. Die detaillierten Angaben zur Charakterisierung der Stichprobe zeigen Tabelle 4 - Tabelle 9. 


\subsubsection{Korrelation der Promotormethylierung mit Patientenparametern}

Im nächsten Schritt wurde jeder Parameter mit der Promotormethylierung jedes Gens korreliert. Für das Überleben in Tagen ergab sich eine statistisch signifikante Korrelation mit der Promotormethylierung der drei Gene RASAL1, ATP2A2 und B9D1 (Abbildung 1 AC). Zudem korreliert BNP signifikant $(\mathrm{p}=0,025)$ mit der Methylierung der ATP2A2Promotoren (Abbildung 1 D), während E/e` und Taillenumfang signifikant ( $\mathrm{p}=0,016$ bzw. $\mathrm{p}=0,042$ ) mit der B9D1-Methylierung korrelieren (Abbildung 1 E-F; Tabelle 10). Das Kontrollgen LAP korreliert zwar signifikant mit der NYHA-Klasse und BNP, nicht jedoch mit dem Überleben der Patienten. Für alle weiteren Parameter ließ sich keine signifikante Korrelation mit LAP feststellen.

Tabelle 10: Korrelationsanalyse der numerischen Parameter mit RASAL1, ATP2A2, B9D1 und LAP. Der Pearson-Korrelationskoeffizient sowie der im t-Test ermittelte p-Wert stellen Zusammenhänge zwischen Parametern und Genen dar.

\begin{tabular}{|c|c|c|c|c|c|c|c|c|}
\hline & \multicolumn{2}{|c|}{ RASAL1 } & \multicolumn{2}{|c|}{$A T P 2 A 2$} & \multicolumn{2}{|c|}{ B9D1 } & \multicolumn{2}{|c|}{$L A P$} \\
\hline & $\mathrm{r}$ & p-Wert & $\mathrm{r}$ & p-Wert & $\mathrm{r}$ & p-Wert & $\mathrm{r}$ & p-Wert \\
\hline LVEF & 0,140 & 0,350 & 0,091 & 0,544 & 0,112 & 0,455 & 0,163 & 0,274 \\
\hline Alter & 0,233 & 0,114 & 0,240 & 0,104 & 0,236 & 0,110 & 0,174 & 0,244 \\
\hline Body-Mass-Index & $-\quad 0,209$ & 0,163 & $-0,276$ & 0,063 & $-0,183$ & 0,223 & $-\quad 0,115$ & 0,448 \\
\hline RR systolisch & 0,142 & 0,348 & $\begin{array}{l}-0,009 \\
\end{array}$ & 0,952 & 0,020 & 0,895 & $-\quad 0,209$ & 0,163 \\
\hline RR diastolisch & 0,131 & 0,387 & 0,123 & 0,414 & $\begin{array}{l}-0,006 \\
\end{array}$ & 0,969 & $-\quad 0,030$ & 0,844 \\
\hline Herzfrequenz & 0,139 & 0,358 & 0,058 & 0,702 & 0,000 & 1,000 & 0,207 & 0,167 \\
\hline Taillenumfang & $-\quad 0,230$ & 0,129 & $-\quad 0,244$ & 0,106 & $-\quad 0,305$ & $0,042 *$ & $-\quad 0,122$ & 0,425 \\
\hline Hüftumfang & $-\quad 0,241$ & 0,111 & $-0,208$ & 0,171 & - $\quad 0,217$ & 0,152 & $-\quad 0,084$ & 0,583 \\
\hline NYHA-Klasse & 0,163 & 0,407 & 0,186 & 0,342 & 0,006 & 0,976 & 0,393 & $0,039 *$ \\
\hline Hinterwand & 0,017 & 0,911 & 0,009 & 0,953 & 0,015 & 0,920 & 0,053 & 0,725 \\
\hline LDL-Cholesterin & $-\quad 0,045$ & 0,765 & 0,094 & 0,534 & 0,124 & 0,411 & $-\quad 0,074$ & 0,625 \\
\hline HDL-Cholesterin & - $\quad 0,059$ & 0,699 & $-0,075$ & 0,619 & 0,021 & 0,891 & $-\quad 0,193$ & 0,198 \\
\hline PQ-Zeit & $-0,088$ & 0,593 & - 0,088 & 0,594 & $-0,133$ & 0,418 & 0,070 & 0,674 \\
\hline QRS-Dauer & $-\quad 0,164$ & 0,270 & - 0,067 & 0,656 & - $\quad 0,112$ & 0,452 & 0,050 & 0,741 \\
\hline QT-Zeit & - $\quad 0,042$ & 0,780 & 0,034 & 0,818 & 0,103 & 0,491 & $-\quad 0,005$ & 0,972 \\
\hline E/e' & 0,200 & 0,177 & 0,129 & 0,387 & 0,351 & $0,016^{*}$ & 0,078 & 0,601 \\
\hline NT-proBNP & 0,149 & 0,316 & 0,251 & 0,089 & 0,102 & 0,497 & 0,236 & 0,110 \\
\hline BNP & 0,207 & 0,162 & 0,326 & $0,025^{*}$ & 0,202 & 0,173 & 0,355 & $0,014 *$ \\
\hline Überleben & $-\quad 0,425$ & $0,003 *$ & - 0,467 & $0,001 *$ & - $\quad 0,292$ & $0,046^{*}$ & $-\quad 0,131$ & 0,379 \\
\hline Krea-Clearance & $-\quad 0,087$ & 0,567 & $-0,107$ & 0,478 & $-\quad 0,099$ & 0,514 & $-\quad 0,003$ & 0,984 \\
\hline
\end{tabular}


A

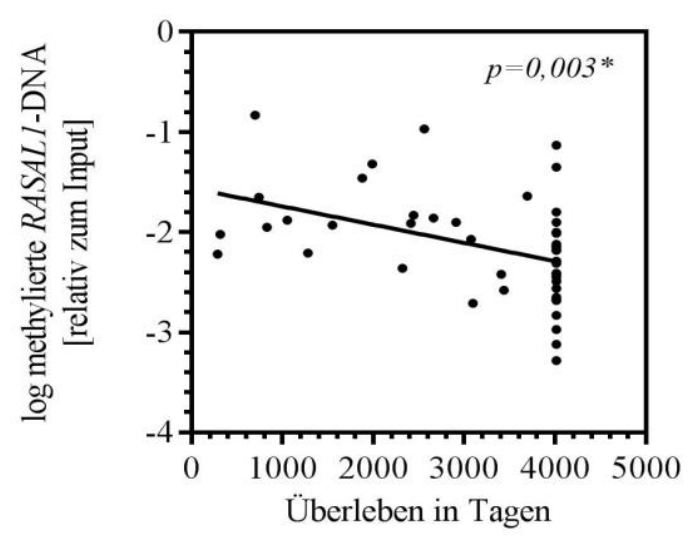

C

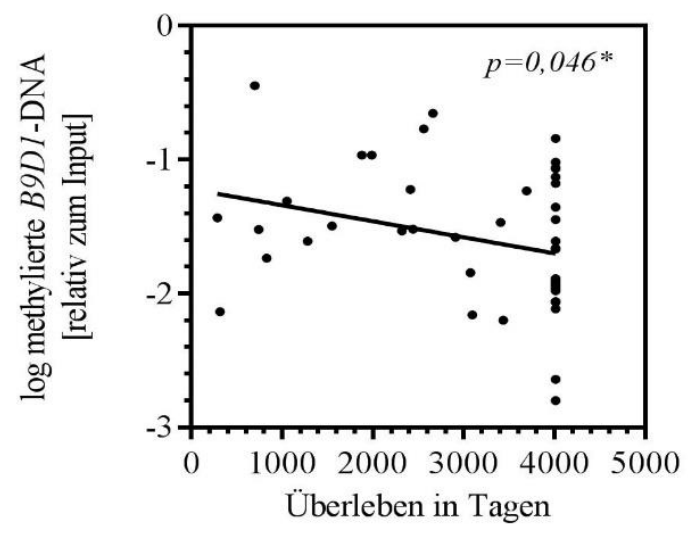

$\mathbf{E}$

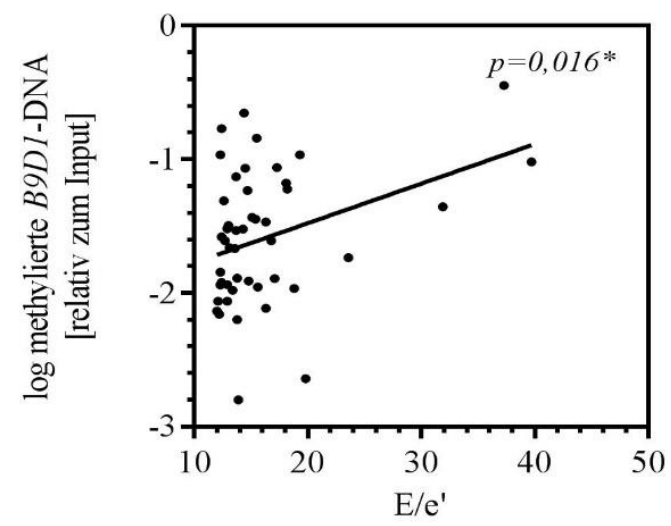

B

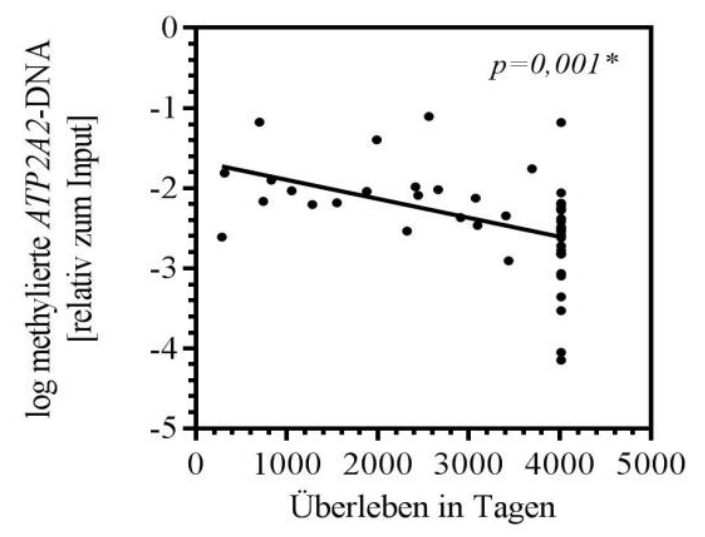

D

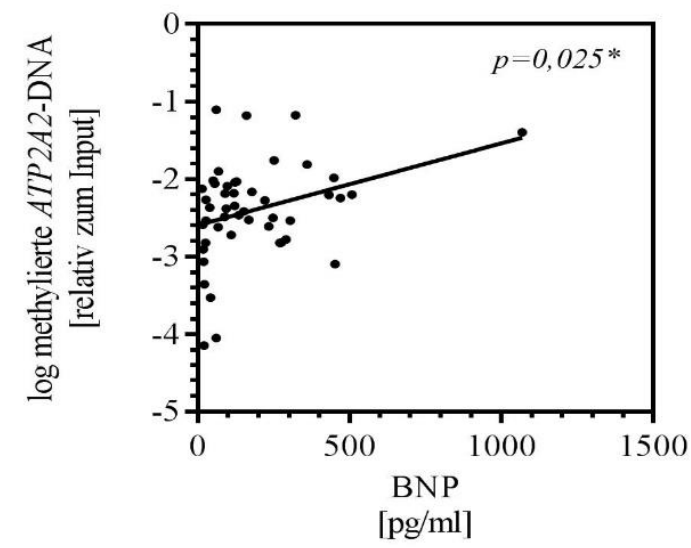

$\mathbf{F}$

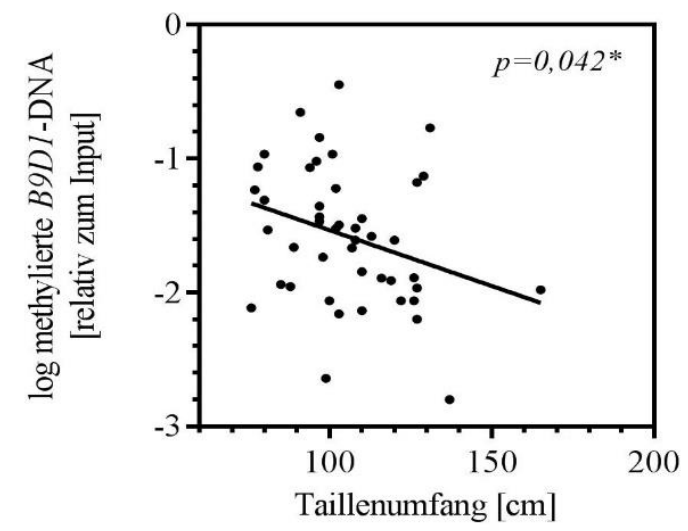

Abbildung 1: Veranschaulichung der signifikanten Korrelationen mit Hilfe linearer Regression. Die Gene (A) RASAL1, (B) ATP2A2 und (C) B9D1 zeigen einen signifikanten Zusammenhang mit dem Überleben. (D) ATP2A2 und BNP zeigen eine signifikante Korrelation. (E, F) B9Dl korreliert signifikant mit E/e' und dem Taillenumfang. 


\subsubsection{Identifizierung von Überlebenszeit-beeinflussenden Parametern}

In der Überlebenszeitanalyse nach Kaplan-Meier sollte ermittelt werden, ob ein Unterschied im Überleben von der Ausprägung der analysierten Merkmale abhängt. Um zwei Gruppen vergleichen zu können, wurden zunächst alle Patientencharakteristika in jeweils zwei Gruppen unterteilt. Zunächst wurde mit Hilfe einer Receiver Operating CharacteristicKurve (ROC-Kurve) der Wert je Parameter bestimmt, der über die höchste Sensitivität und Spezifität verfügt. Dieser Wert wurde als Grenze definiert, der die Werte in zwei Bereiche unterteilt: kleiner als $(<)$ der Grenzwert (Cutoff) und größer als (>) Cutoff. Nachdem die Kohorte geteilt worden war, erfolgte die Analyse der Überlebenszeit für alle drei Gruppen $(</>$ und gesamt) mit Hilfe von Kaplan-Meier-Kurven. Die detaillierten Ergebnisse der ROC-Kurven-Analyse werden in Tabelle 11 dargestellt. Abbildung 2 zeigt ausgewählte ROC-Kurven, um die Auswahl des Cutoffs zu veranschaulichen. Bei den nicht numerischen Parametern musste vorab keine ROC-Kurven-Analyse erfolgen, da die Werte natürlich in zwei Gruppen geteilt waren (Merkmal vorhanden, Merkmal nicht vorhanden).

Tabelle 11: ROC-Analyse. Unter Maximierung der Sensitivität und Spezifität wurde der Cutoff ermittelt.

\begin{tabular}{|c|c|c|c|c|c|}
\hline & Sensitivität[\%] & Spezifität[\%] & Cutoff & $\mathrm{n}<$ Cutoff & $n>$ Cutoff \\
\hline LVEF & 57,1 & 61,5 & 58,5 & 22 & 25 \\
\hline Alter & 61,9 & 80,8 & 76,5 & 29 & 18 \\
\hline Body-Mass-Index & 81,0 & 60,0 & 31,5 & 27 & 19 \\
\hline RR systolisch & 42,9 & 80,0 & 164,0 & 32 & 14 \\
\hline RR diastolisch & 47,6 & 76,0 & 84,5 & 30 & 16 \\
\hline Herzfrequenz & 57,1 & 56,0 & 70,5 & 23 & 23 \\
\hline Taillenumfang & 52,4 & 54,2 & 102,5 & 22 & 23 \\
\hline Hüftumfang & 66,7 & 62,5 & 114,0 & 23 & 22 \\
\hline NYHA-Klasse & 80,0 & 30,8 & 1,5 & 7 & 22 \\
\hline Hinterwand & 71,4 & 60,0 & 11,5 & 21 & 25 \\
\hline LDL-Cholesterin & 47,6 & 68,0 & 113,5 & 18 & 28 \\
\hline HDL-Cholesterin & 38,1 & 76,0 & 59,0 & 32 & 14 \\
\hline PQ-Zeit & 50,0 & 56,5 & 169,0 & 20 & 18 \\
\hline QRS-Dauer & 66,7 & 42,3 & 91,0 & 29 & 18 \\
\hline QT-Zeit & 71,4 & 50,0 & 415,0 & 28 & 19 \\
\hline E/e' & 47,6 & 76,9 & 13,1 & 16 & 31 \\
\hline NT-proBNP & 61,9 & 46,2 & 194,6 & 20 & 27 \\
\hline BNP & 61,9 & 53,9 & 115,2 & 22 & 25 \\
\hline Überleben & 61,9 & 68,0 & 64,4 & 21 & 25 \\
\hline Krea-Clearance & 71,4 & 76,9 & 2,1 & 26 & 21 \\
\hline$A T P 2 A 2$ & 81,0 & 73,0 & 2,3 & 23 & 24 \\
\hline B9D1 & 76,2 & 69,2 & 1,6 & 23 & 24 \\
\hline$L A P$ & 52,4 & 61,5 & 2,0 & 25 & 22 \\
\hline
\end{tabular}



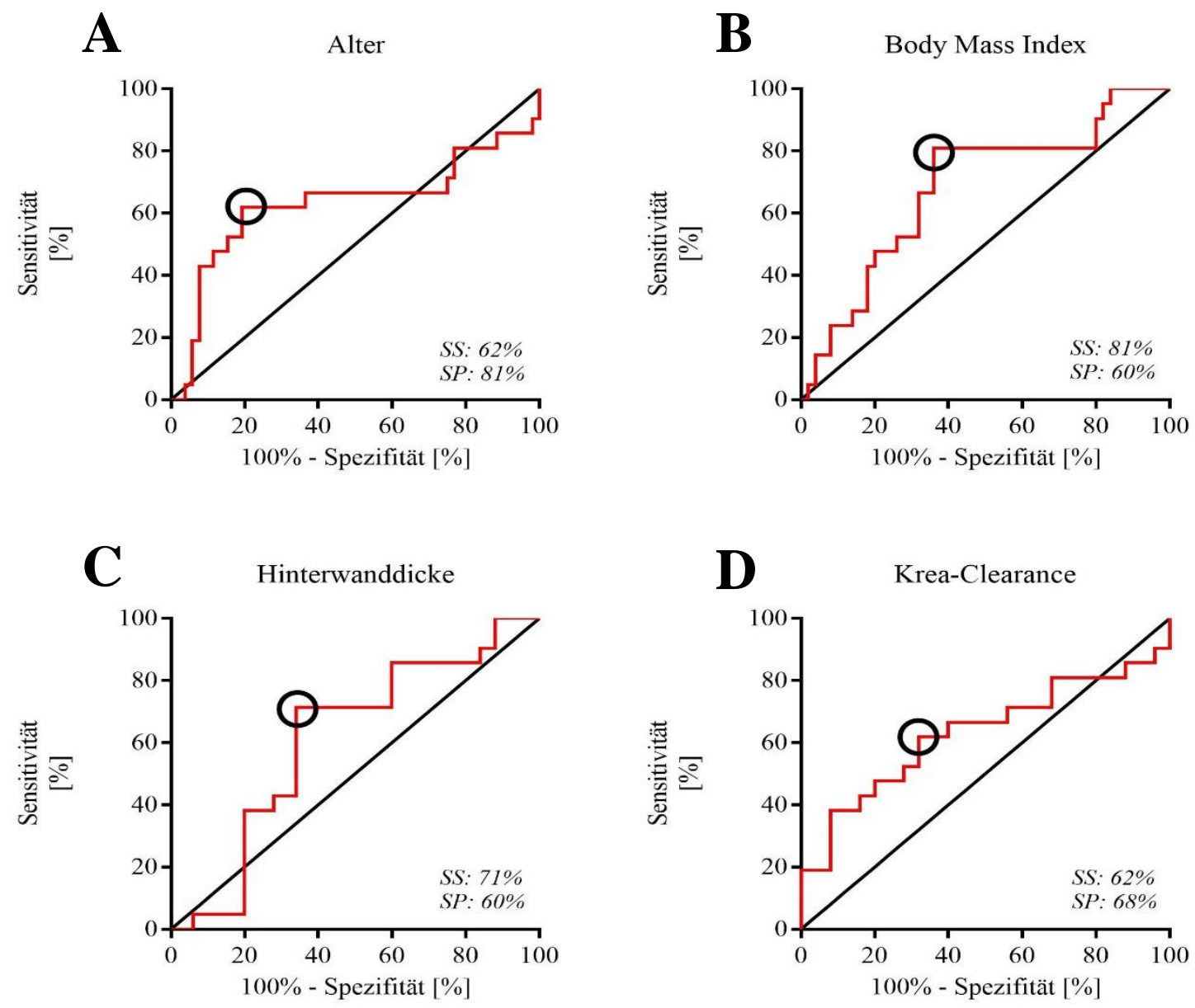

Abbildung 2: Graphische Darstellung der ROC-Analysen. Mit Hilfe der ROC-Analyse wurde der Cutoff für die Überlebenszeitanalyse nach Kaplan Meier ermittelt (A) Alter; (B) BMI; (C) Hinterwanddicke; (D) Krea-Clearance.

Für die methylierten Gene wurde wie zuvor der Median herangezogen, um die Kohorte in je zwei Gruppen gleicher Größe zu unterteilen (Tabelle 12).

Tabelle 12: Mediansplit der Gene RASAL1, ATP2A2, B9D1 und LAP.

\begin{tabular}{|l|r|r|r|}
\hline & Median & $\mathrm{n}<$ Median & $\mathrm{n}>$ Median \\
\hline RASAL1 & $-2,1487$ & 23 & 24 \\
\hline ATP2A2 & $-2,3665$ & 24 & 23 \\
\hline B9D1 & $-1,6077$ & 23 & 24 \\
\hline LAP & $-2,0564$ & 24 & 23 \\
\hline
\end{tabular}

Anschließend wurde untersucht, ob sich ein Unterschied im Überleben in Abhängigkeit von der Ausprägung der oben dargestellten Merkmale abzeichnete. Die Signifikanz im Unterschied wurde mit Hilfe des im Log-rank-Test ermittelten p-Werts dargestellt. 
Es zeigten insgesamt sieben Parameter im Log-rank-Test signifikante Ergebnisse: Bezogen auf Alter, BMI, Kreatinin-Clearance, Hinterwanddicke, KHK und systolischen Blutdruck (RR systolisch) ließen sich statistisch signifikante Unterschiede im Überleben zwischen den Gruppen unter- und oberhalb des Grenzwertes feststellen (Abbildung 3 A-F). Demgegenüber zeigte NT-proBNP keinen statistisch signifikanten Unterschied $(p=0,31)$ im Überleben der Gruppen unter- und oberhalb des Cutoffs (Abbildung 3 G).

Darüber hinaus zeigte die RASAL1-Promotormethylierung signifikante Unterschiede zwischen beiden Gruppen ( $\mathrm{p}=0,032$ ) (Abbildung 4 A). Auch die ATP2A2- und B9D1Promotormethylierung wiesen eine statistisch signifikante Assoziation mit dem Überleben ( $\mathrm{p}=0,002$ bzw. $\mathrm{p}=0,006$ ) auf (Abbildung 4 B, C). Das Kontrollgen LAP (Abbildung 4 D) sowie alle weiteren analysierten Parameter zeigten keine signifikanten Werte im Log-rankTest (Tabelle 13). 
Tabelle 13: Log-rank-Test. Der Test stellt Unterschiede im Überleben zwischen den Gruppen in Bezug auf den jeweiligen Cutoff mit Hilfe des p-Werts dar.

\begin{tabular}{|l|c|}
\hline \multirow{2}{*}{ RASAL1 } & Log-rank-Test \\
\cline { 2 - 2 } & p-Wert \\
\hline ATP2A2 & $0,032^{*}$ \\
\hline B9D1 & $0,002^{*}$ \\
\hline LAP & $0,006^{*}$ \\
\hline Alter & 0,909 \\
\hline Body-Mass-Index & 0,115 \\
\hline RR systolisch & $<0,001^{*}$ \\
\hline RR diastolisch & $0,004^{*}$ \\
\hline Herzfrequenz & $0,0495^{*}$ \\
\hline Taillenumfang & 0,186 \\
\hline Hüftumfang & 0,695 \\
\hline NYHA-Klasse & 0,868 \\
\hline Hinterwand & 0,097 \\
\hline LDL-Cholesterin & 0,876 \\
\hline HDL-Cholesterin & $0,028^{*}$ \\
\hline PQ-Zeit & 0,250 \\
\hline QRS-Dauer & 0,483 \\
\hline QT-Zeit & 0,980 \\
\hline E/e' & 0,726 \\
\hline NT-proBNP & 0,131 \\
\hline BNP & 0,073 \\
\hline Krea-Clearance & 0,310 \\
\hline LSB & 0,190 \\
\hline RSB & $0,013^{*}$ \\
\hline AV-Block & 0,236 \\
\hline RV-Dilatation & 0,105 \\
\hline Betablocker & 0,366 \\
\hline KHK & 0,371 \\
\hline Rauchen & 0,552 \\
\hline Hypertonie & $0,012^{*}$ \\
\hline Herzinsuffizienz & 0,208 \\
\hline Geschlecht & 0,739 \\
\hline Z. n. Myokardinfarkt & 0,187 \\
\hline Diabetes & \\
\hline & 0,104 \\
\hline & \\
\hline
\end{tabular}


A

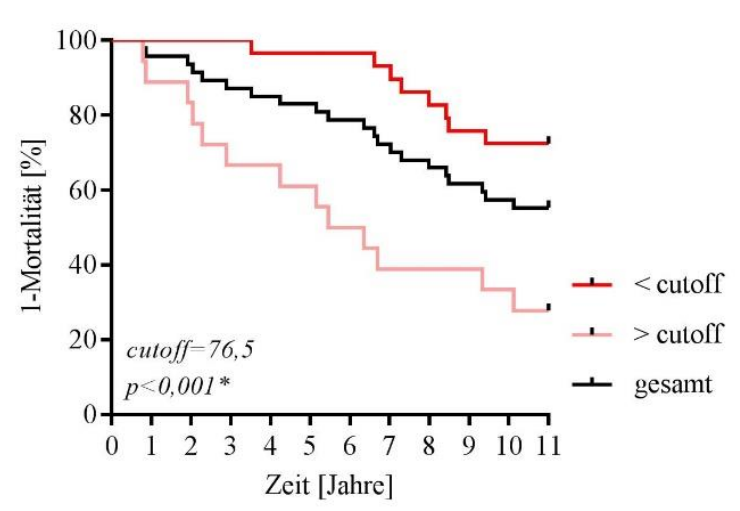

C

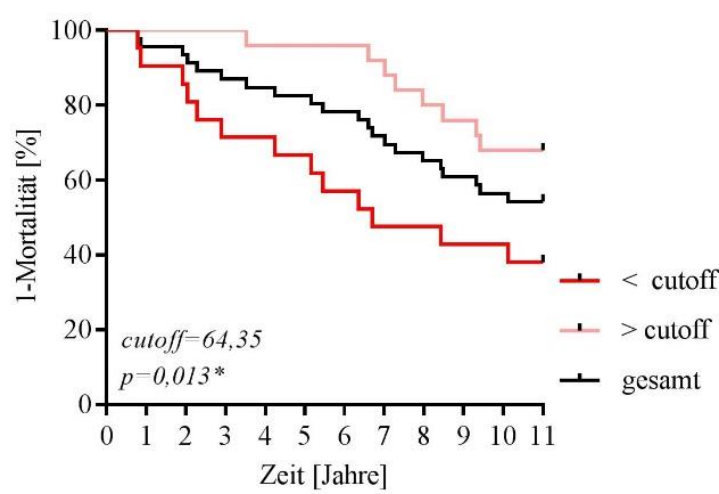

$\mathbf{E}$

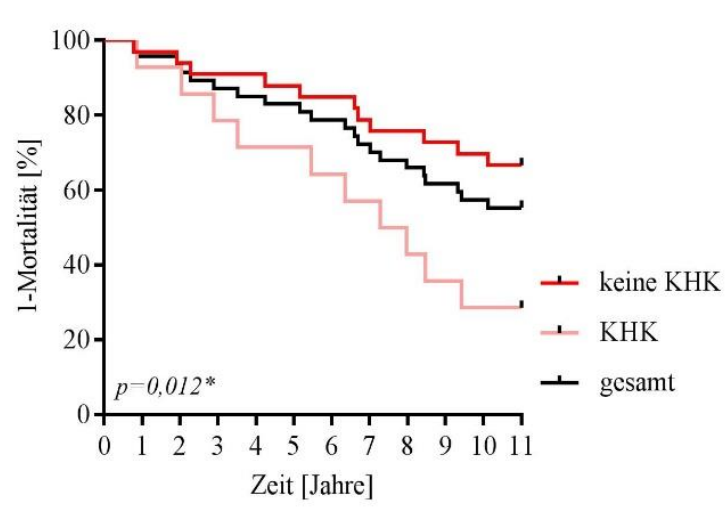

G

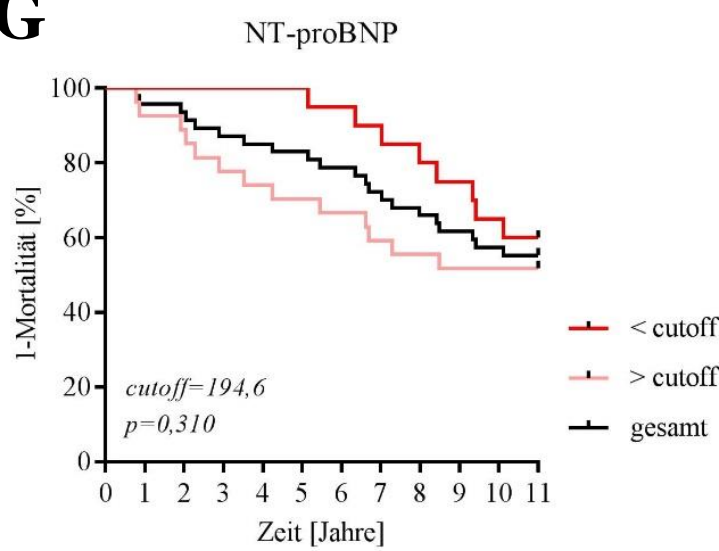

B Body Mass Index

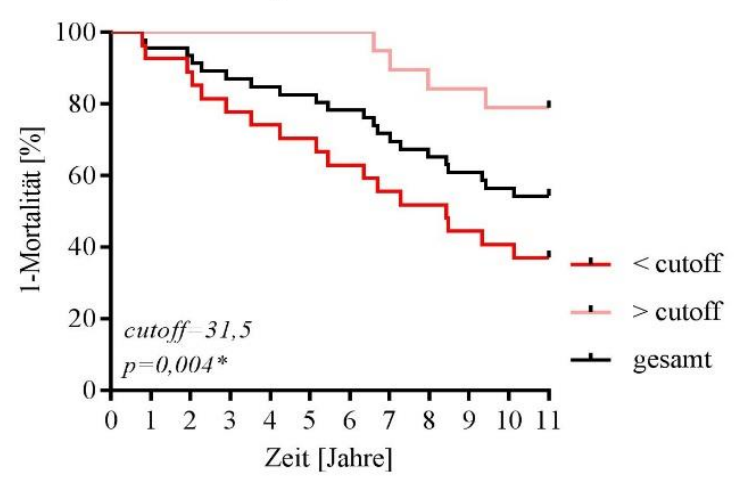

D

Hinterwanddicke

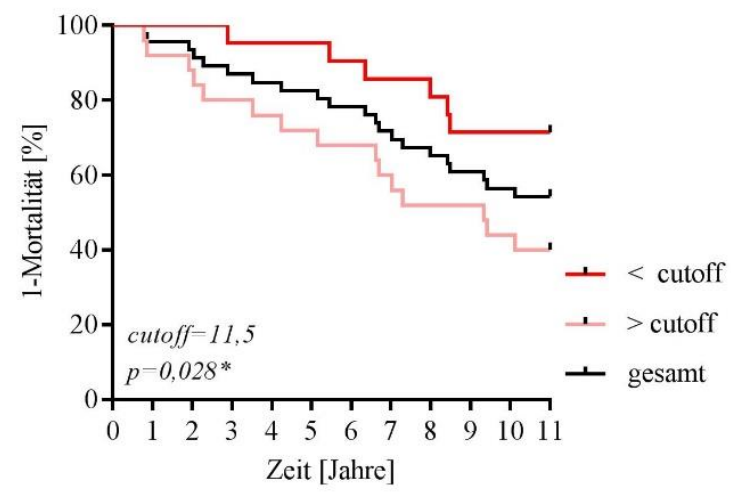

$\mathbf{F}$

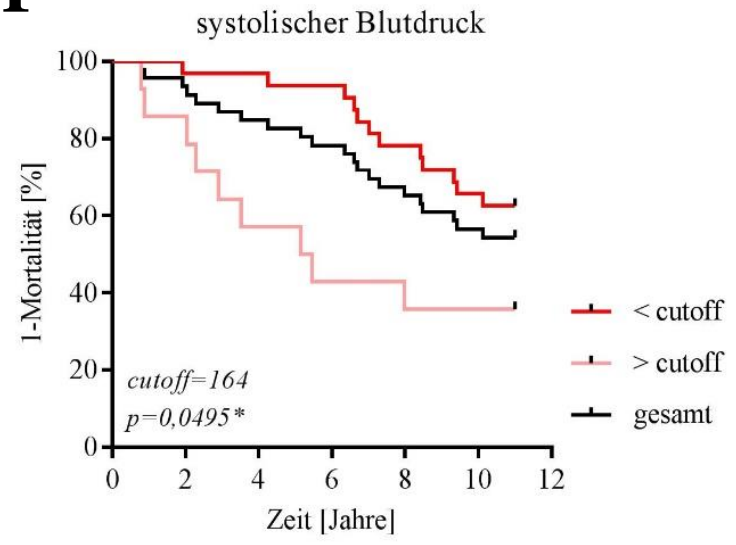

Abbildung 3: Kaplan-Meier-Kurven I. Eine signifikante Assoziation mit dem Überleben zeigten die Parameter (A) Alter, (B) BMI, (C) Kreatinin-Clearance, (D) Hinterwanddicke, (E) KHK und (F) systolischer Blutdruck, während (G) NT-proBNP keine Signifikanz aufwies. 
A

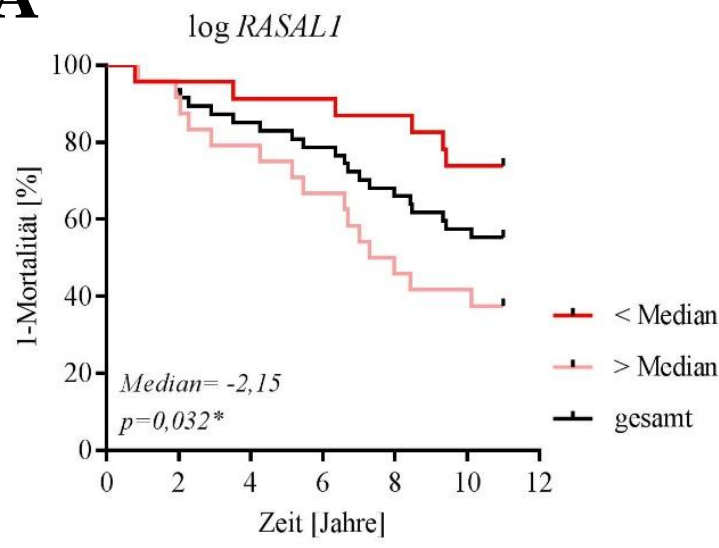

C

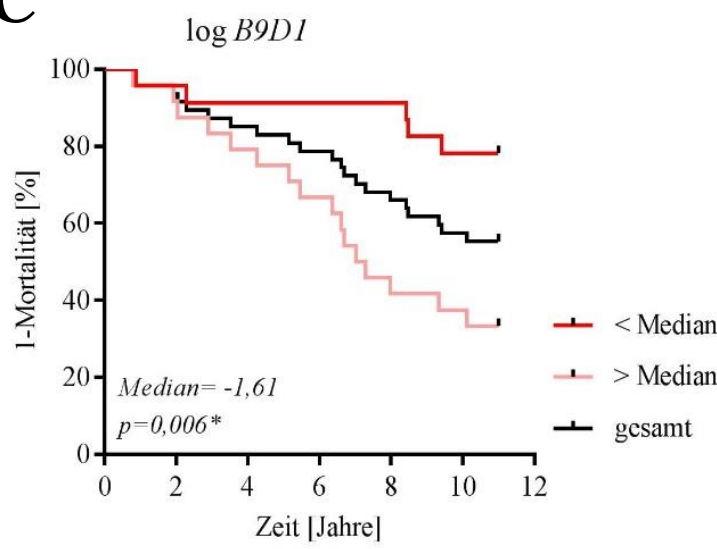

B

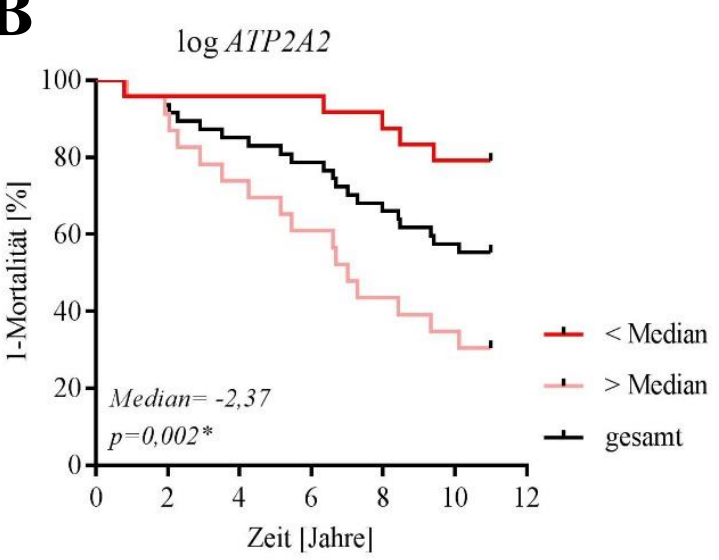

D

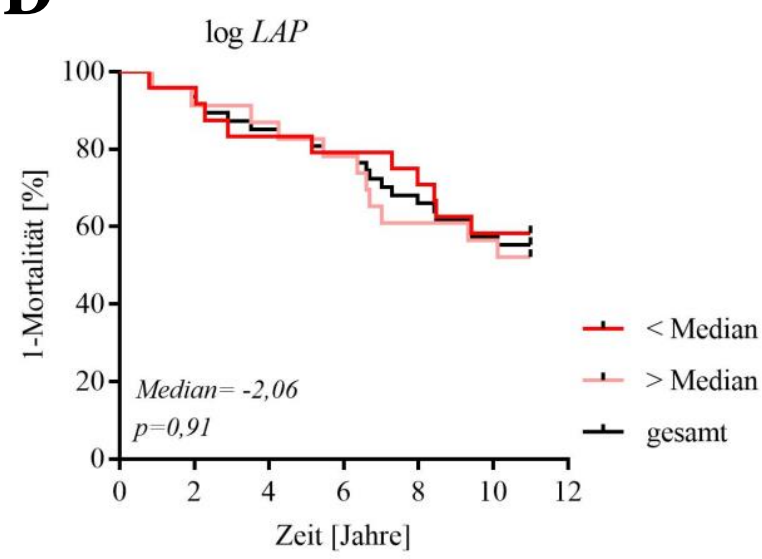

Abbildung 4: Kaplan-Meier-Kurven II. (A-C) RASAL1, ATP2A2, B9D1 sind signifikant mit dem Überleben assoziiert (D) $L A P$ ist nicht signifikant mit dem Überleben assoziiert.

\subsection{Ergebnisse der multivariaten Cox-Regression}

Nachdem mit Hilfe der Kaplan-Meier-Kurven und des Log-rank-Tests Unterschiede im Überleben jedes einzelnen Parameters ermittelt worden waren, sollte in einer multivarianten Cox-Regression festgestellt werden, wie groß der Einfluss von Confoundern auf die Überlebenszeitprognose der zu etablierenden Biomarker RASAL1, ATP2A2 und B9D1 war. Parameter, die univariat in der Kaplan-Meier-Analyse signifikant mit dem Überleben assoziiert waren, wurden in die Cox-Regression eingeschlossen, zusätzlich wurde das Geschlecht einbezogen. Die Güte des Gesamtmodells wurde mit Hilfe eines Omnibustests ermittelt. Der Wald-Test prüft, genau wie ein t-Test, ob die einzelnen Prädiktoren einen signifikanten Einfluss auf das Überleben haben.

Im ersten Modell wurden die Parameter Alter, Geschlecht, BMI, KHK, RR systolisch, KreaClearance und Hinterwanddicke betrachtet. Die Gesamtgüte des Modells wurde mit $p=0,003$ angegeben. In diesem Modell sind die Parameter BMI, KHK und Hinterwanddicke 
unabhängige und statistisch signifikante Einflussgrößen auf das Überleben innerhalb von 10 Jahren (Tabelle 14).

Tabelle 14: Modell 1. Im ersten Modell wurden die Parameter ohne Einfluss der Gene untersucht.

\begin{tabular}{|l|c|c|c|l|}
\hline $\begin{array}{l}\text { Modell 1 } \\
\text { Chi-Quadrat=21,90 } \\
\mathrm{p}=0,003^{*}\end{array}$ & $\operatorname{Exp(B)}$ & Wald & $\begin{array}{c}95,0 \% \text { Konfidenzintervall für } \\
\operatorname{Exp}(\mathrm{B})\end{array}$ & $\mathrm{p}$-Wert \\
\hline Alter & 1,00 & 0,001 & $0,88-1,15$ & 0,973 \\
\hline Geschlecht & 2,04 & 1,21 & $0,57-7,23$ & 0,272 \\
\hline BMI & 0,81 & 7,08 & $0,70-0,95$ & $0,008^{*}$ \\
\hline KHK & 2,91 & 4,41 & $1,07-7,87$ & $0,036^{*}$ \\
\hline RR systolisch & 1,01 & 0,29 & $0,99-1,02$ & 0,590 \\
\hline Krea-Clearance & 1,00 & 0,02 & $0,96-1,04$ & 0,883 \\
\hline Hinterwand & 1,68 & 4,33 & $1,03-2,75$ & $0,037^{*}$ \\
\hline
\end{tabular}

Bei der Betrachtung der Parameter Alter, Geschlecht, BMI, KHK, RR systolisch, KreatininClearance, Hinterwanddicke und RASAL1-Methylierung im Modell 2 zeigten die Parameter BMI, KHK, Hinterwanddicke und RASAL1-Methylierung einen signifikanten Einfluss auf die Überlebenszeit. Anhand der Hazard-Ratio $(\operatorname{Exp}(B))$ ließ sich das Ausmaß des Einflusses darstellen. Während mit Zunahme des BMI das Risiko zu sterben um 100\% - $(100 \% \times 0.80)$ $=20 \%$ abnahm, stieg das Risiko mit Zunahme der Hinterwanddicke um den Faktor 1,63; bei Vorhandensein einer KHK um den Faktor 3,65. Ein Anstieg in der RASAL1-Methylierung erhöhte das Risiko zu sterben um den Faktor 4,8. Die Güte des Gesamtmodells verbesserte sich durch Hinzunahme von RASAL1 im Vergleich zum Modell 1 auf $\mathrm{p}=0,002$ (Tabelle 15).

Tabelle 15: Modell 2. Im zweiten Modell wurden die Parameter unter Einbezug von RASAL1 untersucht.

\begin{tabular}{|l|c|c|c|c|}
\hline $\begin{array}{l}\text { Modell 2 } \\
\text { Chi-Quadrat=25,03 } \\
\mathrm{p}=0,002 *\end{array}$ & $\operatorname{Exp(B)}$ & Wald & $\begin{array}{c}95,0 \% \text { Konfidenzintervall für } \\
\operatorname{Exp}(\mathrm{B})\end{array}$ & $\mathrm{p}$-Wert \\
\hline Alter & 0,95 & 0,41 & $0,83-1,10$ & 0,521 \\
\hline Geschlecht & 2,37 & 1,54 & $0,61-9,27$ & 0,214 \\
\hline BMI & 0,80 & 6,84 & $0,68-0,95$ & $0,009 *$ \\
\hline KHK & 3,65 & 5,24 & $1,21-11,07$ & $0,022^{*}$ \\
\hline RR systolisch & 1,00 & 0,06 & $0,97-1,02$ & 0,802 \\
\hline Krea-Clearance & 0,99 & 0,20 & $0,95-1,03$ & 0,658 \\
\hline Hinterwand & 1,63 & 3,96 & $1,01-2,64$ & $0,047^{*}$ \\
\hline RASAL1 (log) & 4,80 & 4,31 & $1,09-21,07$ & $0,038^{*}$ \\
\hline
\end{tabular}

Die Güte des Gesamtmodells verbesserte sich im Gegensatz zu Modell 1 und 2 weiter, wenn $A T P 2 A 2$ statt RASAL1 einbezogen wurde. Sie wurde im dritten Modell mit $\mathrm{p}<0,001$ 
angegeben. Ebenfalls stellten BMI, KHK, Hinterwanddicke und das methylierte Gen unabhängige und signifikante Prognosefaktoren für das Überleben dar (Tabelle 16).

Tabelle 16: Modell 3. Im dritten Modell wurden die Parameter unter Einbezug von ATP2A2 untersucht.

\begin{tabular}{|l|c|c|c|l|}
\hline $\begin{array}{l}\text { Modell 3 } \\
\text { Chi-Quadrat=26,96 } \\
\mathrm{p}=<0,001^{*}\end{array}$ & $\operatorname{Exp(B)}$ & Wald & $\begin{array}{c}95,0 \% \text { Konfidenzintervall für } \\
\operatorname{Exp}(\mathrm{B})\end{array}$ & $\mathrm{p}$-Wert \\
\hline Alter & 0,91 & 1,52 & $0,78-1,06$ & 0,217 \\
\hline Geschlecht & 1,97 & 1,01 & $0,53-7,43$ & 0,314 \\
\hline BMI & 0,81 & 6,82 & $0,69-0,95$ & $0,009^{*}$ \\
\hline KHK & 3,66 & 5,64 & $1,25-10,70$ & $0,018^{*}$ \\
\hline RR systolisch & 1,00 & 0,11 & $0,98-1,03$ & 0,745 \\
\hline Krea-Clearance & 0,98 & 0,71 & $0,94-1,03$ & 0,401 \\
\hline Hinterwand & 2,05 & 6,38 & $1,18-3,59$ & $0,012^{*}$ \\
\hline ATP2A2 (log) & 9,73 & 9,63 & $2,31-40,92$ & $0,002^{*}$ \\
\hline
\end{tabular}

Im vierten Modell wurde geprüft, wie sich die Bedeutung von B9D1 in der multivariaten Analyse verhält. Die Gesamtgüte dieses Modells wurde mit $\mathrm{p}=0,004$ angegeben. Der BMI ist hier der einzige unabhängige und statistisch signifikante Prognosemarker für das Überleben. B9D1 konnte im multivariaten Modell mit $\mathrm{p}=0,11$ keine Unabhängigkeit und statistische Signifikanz erreichen (Tabelle 17).

Tabelle 17: Modell 4. Im vierten Modell wurden die Parameter unter Einbezug von B9D1 untersucht.

\begin{tabular}{|l|c|c|c|l|}
\hline $\begin{array}{l}\text { Modell 4 } \\
\text { Chi-Quadrat=22,78 } \\
\mathrm{p}=0,004^{*}\end{array}$ & $\operatorname{Exp(B)}$ & Wald & $\begin{array}{c}95,0 \% \text { Konfidenzintervall für } \\
\operatorname{Exp}(\mathrm{B})\end{array}$ & $\mathrm{p}$-Wert \\
\hline Alter & 0,97 & 0,16 & $0,84-1,12$ & 0,688 \\
\hline Geschlecht & 3,45 & 2,65 & $0,78-15,36$ & 0,104 \\
\hline BMI & 0,79 & 7,60 & $0,67-0,94$ & $0,006^{*}$ \\
\hline KHK & 2,55 & 3,35 & $0,94-6,94$ & 0,067 \\
\hline RR systolisch & 1,01 & 0,29 & $0,99-1,03$ & 0,589 \\
\hline Krea-Clearance & 0,99 & 0,09 & $0,95-1,04$ & 0,759 \\
\hline Hinterwand & 1,52 & 2,91 & $0,94-2,47$ & 0,088 \\
\hline B9D1 (log) & 2,91 & 2,51 & $0,78-10,93$ & 0,113 \\
\hline
\end{tabular}

Werden die drei Gene in einem multivariaten Modell kombiniert, erlangt neben den Parametern BMI, KHK und Hinterwanddicke lediglich ATP2A2 mit p=0,025 Unabhängigkeit und statistische Signifikanz als Prognosemarker für das Überleben. Mit einer Hazard-Ratio von $\operatorname{Exp}(B)=14,48$ stellt die $A T P 2 A 2$-Methylierung gegenüber dem Methylierungsgrad der anderen Gene in diesem Modell den größten Einflussfaktor auf das Überleben dar (Tabelle 18). 
Tabelle 18: Modell 5. Im fünften Modell wurden die Parameter unter Einbezug aller drei Gene untersucht.

\begin{tabular}{|l|c|c|c|l|}
\hline $\begin{array}{l}\text { Modell 5 } \\
\text { Chi-Quadrat=28,67 } \\
\mathrm{p}=0,001^{*}\end{array}$ & $\operatorname{Exp(B)}$ & Wald & $\begin{array}{c}95,0 \% \text { Konfidenzintervall für } \\
\operatorname{Exp}(\mathrm{B})\end{array}$ & $\mathrm{p}$-Wert \\
\hline Alter & 0,91 & 1,29 & $0,78-1,07$ & 0,256 \\
\hline Geschlecht & 1,80 & 0,47 & $0,34-9,56$ & 0,493 \\
\hline BMI & 0,82 & 5,67 & $0,70-0,97$ & $0,017^{*}$ \\
\hline KHK & 3,63 & 4,41 & $1,09-12,08$ & $0,036^{*}$ \\
\hline RR systolisch & 1,01 & 0,16 & $0,98-1,03$ & 0,689 \\
\hline Krea-Clearance & 0,98 & 0,64 & $0,94-1,03$ & 0,423 \\
\hline Hinterwand & 2,12 & 6,24 & $1,18-3,83$ & $0,013^{*}$ \\
\hline ATP2A2 (log) & 14,48 & 5,05 & $1,41-148,81$ & $0,025^{*}$ \\
\hline B9D1 (log) & 0,94 & 0,004 & $0,11-7,76$ & 0,950 \\
\hline RASAL1 (log) & 0,63 & 0,10 & $0,04-10,60$ & 0,748 \\
\hline
\end{tabular}

Insgesamt fällt auf, dass die Parameter Alter, RR systolisch und Krea-Clearance, welche univariat signifikant mit dem Überleben assoziiert sind, in der multivariaten Analyse ihre Signifikanz verlieren. Die Parameter BMI, KHK und Hinterwanddicke stellen sich hingegen neben den Genen RASAL1 und ATP2A2 nicht nur univariat in der Kaplan-Meier-Analyse, sondern auch multivariat in den ersten drei Modellen als unabhängige und signifikante Prognosemarker für das Überleben innerhalb von 10 Jahren dar. 


\section{Diskussion}

In dieser Arbeit wurden die Methylierungsgrade der drei betrachteten Gene RASAL1, $A T P 2 A 2$ und $B 9 D 1$ von 47 Patienten ermittelt. Diese wurden als potenzielle Biomarker jeweils mit weiteren Patientenparametern korreliert, um Aussagen über die vom Biomarker gemessenen Prozesse treffen zu können. Anschließend wurden Einflussfaktoren auf das Überleben der Patienten bestimmt und in einem multivariaten Modell überprüft, ob intervariate Abhängigkeiten bestanden. Ziel war die Identifizierung von Biomarker im Blut, welche die klinische Progression von HFpEF vorhersagen.

\subsection{Zirkulation von DNA-Fragmenten im Blut}

In der Krebsforschung konnte gezeigt werden, dass im Blut zirkulierende DNA-Fragmente des Tumors in allen Mutationen mit dem Primärtumor übereinstimmen (Schwarzenbach et al. 2011). Ebenso konnte für die Nierenfibrose gezeigt werden, dass der Methylierungsgrad von zirkulierenden DNA-Fragmenten mit dem Befund aus intrarenalen Biopsien korreliert (Tampe et al. 2015). Die Gewinnung von DNA aus Vollblut durch Blutabnahme (liquid biopsy) ist gegenüber der herkömmlichen, invasiven Gewinnung von Organgewebe kostengünstiger und mit weniger Risiken für den Patienten verbunden (Schwarzenbach et al. 2011).

\subsection{Assoziation der untersuchten Gene mit verschiedenen Patientenparametern}

Bereits aus der klinisch-epidemiologischen Charakterisierung der Studienpatienten konnten interessante Erkenntnisse zu den methylierten Genen gewonnen werden. Erste Hinweise für eine Bedeutung als Progressionsmarker lieferten die signifikanten Werte ober- und unterhalb des Mediansplits der Gene in Bezug auf den Tod. Es fiel auf, dass von den Patienten oberhalb des Mediansplits ein größerer Teil verstarb und diese Patienten im Durchschnitt statistisch signifikant kürzer lebten, als jene mit einer niedrigeren Promotormethylierung.

Zudem fiel auf, dass signifikante Unterschiede oberhalb und unterhalb des Mediansplits der RASAL1-Methylierung bezüglich der Diagnosehäufigkeit bei Herzinsuffizienz vorlagen. Insgesamt wurde bei Patienten ohne klinische Symptome einer Herzinsuffizienz eine signifikant höhere RASAL1-Promotormethylierung im Blut nachgewiesen als bei Patienten, die bereits die Diagnose erhalten haben bzw. klinische Symptome vorweisen konnten. Verbunden mit der Tatsache, dass eine Methylierung oberhalb des Mediansplits mit einem kürzeren Überleben einhergeht, könnte dies bedeuten, dass die Messung der RASAL1Promotormethylierung in dieser Kohorte ein genauerer Parameter für die Prognose ist, als 
eine klinisch gestellte Diagnose. Es könnte anhand der Daten dieser Kohorte die Vermutung abgeleitet werden, dass die Patienten mit einer erhöhten RASAL1-Methylierung nicht nur eine ungünstigere Prognose haben, sondern auch durch die bisherigen etablierten Diagnosekriterien nicht ausreichend detektiert werden.

Abgesehen von einer signifikanten Assoziation mit dem Überleben waren bezüglich RASAL1 in der Korrelationsanalyse keine weiteren Werte signifikant. Kein statistischer Zusammenhang konnte für die bereits etablierten Biomarker der Herzinsuffizienz, NTproBNP und BNP ermittelt werden. Ebenso wenig korrelierte RASAL1 mit der LVEF, E/e“ oder der Hinterwanddicke. Bezogen auf die Prognosekraft der klinisch gestellten Diagnose der Herzinsuffizienz stützt dieses Ergebnis die zuvor erläuterte Theorie, dass Risikopatienten mit bisher etablierten Verfahren nicht suffizient detektiert werden können. Im Falle von ATP2A2 konnte neben dem signifikanten Zusammenhang mit dem Überleben eine positive statistisch signifikante Korrelation mit BNP ermittelt werden. Darüber hinaus besteht hier kein Zusammenhang zwischen ATP2A2 und weiteren Parametern, die die Herzleistung charakterisieren. Bei der Analyse von B9D1 wurde neben einer signifikanten Verbindung mit dem Überleben ein statistischer Zusammenhang mit dem Taillenumfang und E/e gefunden. Als einziges der analysierten Gene korreliert das immer methylierte Kontrollgen $L A P$ nicht mit dem Überleben. Dies unterstreicht die Bedeutung der anderen drei untersuchten Gene hinsichtlich prognostischer Angaben. Da jedoch eine Korrelation von LAP mit der NYHA-Klassifikation und mit der BNP-Konzentration vorlag, deren Bedeutung unklar ist, sollte für zukünftige Studien evtl. ein gänzlich unabhängiges Kontrollgen verwendet werden.

\subsubsection{Repräsentation unterschiedlicher Aspekte der Krankheit durch RASAL1, $A T P 2 A 2$ und $B 9 D 1$}

Aufgrund der in der Korrelationsanalyse unterschiedlichen Ergebnisse kann überlegt werden, ob RASAL1, ATP2A2 und B9D1 Marker für unterschiedliche Pathomechanismen sind. Wie bereits dargestellt, ist eine aberrante Methylierung von RASAL1 eng mit der Entstehung von Fibrose verknüpft. Die Tatsache, dass RASAL1 lediglich mit dem Überleben und keinem weiteren der hier untersuchten Parameter korreliert, deutet darauf hin, dass mit Hilfe von RASAL1 der Grad der Fibrose bzw. die Progression der Fibrose bestimmt werden kann, welcher in dieser Arbeit durch das Überleben repräsentiert wird. Für ATP2A2 ist nicht eindeutig geklärt, wie es zur Entstehung von Herzinsuffizienz, die auf Fibrose basiert, beiträgt. Dennoch besteht eine signifikante Korrelation mit dem Überleben in der Kohorte, welche einen Zusammenhang mit Fibrose bzw. der Progression der Erkrankung vermuten 
lässt. Die Korrelation mit BNP deutet darauf hin, dass zusätzlich andere Mechanismen, die zur Entstehung von Herzinsuffizienz beitragen mit Hilfe von ATP2A2 gemessen werden können. Während für RASAL1 in Vorarbeiten gezeigt werden konnte, dass wenigstens theoretisch eine starke Assoziation mit HFpEF besteht, muss für ATP2A2 noch untersucht werden, ob in HFpEF- oder HFrEF-Patienten eine stärkere Prognosekraft besteht.

Analog hierzu sind die Ergebnisse der Korrelationsanalyse von B9D1 zu interpretieren. Die Korrelation mit dem Überleben sowie zusätzlich mit E/e‘ und Taillenumfang kann darauf hinweisen, dass B9D1 über Fibrose hinaus weitere Pathomechanismen misst. Der Mangel an Informationen zu B9D1 erschwert die Interpretation.

Bei der Interpretation der Ergebnisse sollte zudem berücksichtigt werden, dass bei 20 untersuchten Parametern eine statistisch zufällig signifikante Korrelation einer Variablen mit dem Überleben möglich ist. Durch den Mangel an Informationen über ATP2A2 und BNP sowie B9D1 lassen die Ergebnisse Raum für Interpretationen.

\subsection{Identifikation von Risikopatienten mit Hilfe methylierter DNA-Fragmente im Blut}

\subsubsection{Der Parameter Überleben als stellvertretender Marker für Fibrose}

Ziel dieser Arbeit war die Etablierung eines Biomarkers, der die Progression von HFpEF beschreibt. Schelbert et al. (2014) betonen die Bedeutung von vermehrter EZM und Fibrose für die Progression von chronischer Herzinsuffizienz. Die Literatur besagt, dass der Fibrosegrad im Herzen mit dem Auftreten letaler Ereignisse assoziiert ist: In der Arbeit von Mascherbauer et al. (2013) konnte gezeigt werden, dass der Tod signifikant mit dem Level an Fibrose korreliert. Ähnliche Ergebnisse lieferte die Arbeit von Krum et al. (2011). In dieser Studie wurde der Grad an Herzfibrose von HFpEF-Patienten, gemessen an der Konzentration peripherer Kollagenmarker, im univariaten Modell als ein wichtiger Einflussfaktor auf das Überleben identifiziert. Aufbauend auf einer vorausgegangenen Studie von López et al. (2013), in der der Einfluss von Osteopontin auf Fibrose und konsekutive Herzinsuffizienz exploriert wurde, analysierten Tromp et al. (2017) den Einfluss von Osteopontin auf die Progression von HFpEF. Ihnen gelang es, die Assoziation von Osteopontin - und damit Fibrose - mit dem Überleben darzustellen und damit diesen Marker für myokardiales Remodeling als Progressionsmarker für HFpEF zu etablieren. Schelbert et al. (2017) stellen ebenfalls fest, dass Fibrose mit der Progression von HFpEF assoziiert ist. Somit konnte gezeigt werden, dass Fibrose mit der Progression der Erkrankung und dem Tod bei herzinsuffizienten Patienten assoziiert ist. Da von den 47 Patienten in der vorliegenden Arbeit keine Gewebeproben zur Verfügung standen, konnten die methylierten 
Gene nicht mit der mikroskopisch ermittelten Menge an Fibrose korreliert werden. Unter Einbezug der beschriebenen Studien, wurde das Überleben stellvertretend für Fibrose als Maßstab für die Progression der Krankheit herangezogen.

\subsubsection{Univariat signifikante Assoziation von drei Genen mit dem Tod}

Vor diesem Hintergrund wurde zunächst in Kaplan-Meier-Analysen ermittelt, welche Werte univariat signifikant mit dem Überleben der Kohorte assoziiert sind. Neben den Parametern Alter, BMI, RR systolisch, Hinterwanddicke, KHK und Kreatinin-Clearance zeigten die betrachteten Gene RASAL1, ATP2A2 und B9D1 im univariaten Modell eine signifikante Assoziation zum Überleben. Als einziges der untersuchten Gene zeigte LAP keine Assoziation mit dem Tod. Dies deutet darauf hin, dass eine erhöhte Methylierung nur bei spezifischen Genen vorhanden ist. Die Tatsache, dass hier keine Korrelation gefunden wurde, unterstützt die Spezifität von RASAL1, ATP2A2 und B9D1.

In der Gesamtpopulation gilt ein hoher BMI als ein Risikofaktor für multiple Erkrankungen und konsekutiv ein erhöhtes Sterberisiko (Pischon et al. 2008). In dieser Arbeit konnte beobachtet werden, dass Patienten mit einem erhöhten BMI länger lebten als solche mit einem niedrigeren BMI. Diese kontraintuitive Erkenntnis ist kontrovers zu den beschriebenen Ergebnissen in der Gesamtpopulation. Bezüglich chronischer Herzinsuffizienz wurde dieses Adipositas-Paradoxon bereits von anderen Autoren untersucht. Häufig beschrieben ist ein U-förmiger Zusammenhang zwischen BMI und Überleben (Sharma et al. 2015; Qin et al. 2017). Speziell für Patienten mit HFpEF haben Haass et al. (2011) ebenfalls eine U-Kurve gefunden, die den Zusammenhang darstellt. Dieses Ergebnis deutet an, dass der BMI bezüglich des Überlebens von HFpEF-Patienten anderen Regeln folgt als in der Gesamtpopulation. Die Ergebnisse der vorliegenden Arbeit widersprechen diesen Erkenntnissen nicht. Eine differenziertere Betrachtung, um den Verlauf der den Zusammenhang beschreibenden Kurve zu ermitteln, war jedoch nicht Gegenstand dieser Arbeit.

Die enge Beziehung zwischen eingeschränkter Nierenfunktion und Herzinsuffizienz spielt eine wichtige Rolle bei Betrachtung der Überlebenszeit. Ohne zwischen HFrEF und HFpEF zu differenzieren, stellten McAlister et al. (2004) die Bedeutung von Niereninsuffizienz für die Progression von Herzinsuffizienz heraus und schlugen vor, dass Patienten mit Herzinsuffizienz und eingeschränkter Nierenfunktion als Hochrisikopatienten eingestuft werden sollten. Die Nierenfunktion - in dieser Arbeit durch die Kreatinin-Clearance repräsentiert - zeigte in der Kaplan-Meier-Analyse eine starke Assoziation mit dem Überleben. Dieses Ergebnis ist in der Literatur wiederzufinden. Casado et al. (2013) zeigten, 
dass eine reduzierte Nierenfunktion, in ihrer Arbeit repräsentiert durch die eGFR, bei Patienten mit HFpEF stark mit dem Tod assoziiert ist. Tampe et al. (2015) konnten im Mausmodell zeigen, dass die im Blut gemessene RASAL1-Promotormethylierung mit dem Fibrosegrad in der Niere korreliert. Eine Assoziation der RASAL1-Promotormethylierung mit Herzfibrose wurde ebenfalls beschrieben (Xu et al. 2015).

In der vorliegenden Kohorte primär herzkranker Patienten ließ sich keine signifikante Korrelation von methylierten Genen und der Nierenfunktion feststellen. Auffällig ist, dass Patienten mit hoher NT-proBNP- oder BNP-Konzentration sich nicht signifikant von jenen mit niedriger Konzentration bezüglich des Überlebens unterschieden. In früheren Arbeiten wurden NT-proBNP und BNP als maßgebende Progressionsmarker aufgeführt (Daniels und Maisel 2007; Sanders-van Wijk et al. 2015). Anand et al. (2003) betonen die Bedeutung von BNP als Marker für die Progression von chronischer Herzinsuffizienz. Van Veldhuisen et al. (2013) unterstützen in ihrer Arbeit die These, dass BNP unabhängig von der LVEF prognostische Aussagekraft für das Überleben von Patienten mit HFpEF hat. In der untersuchten Kohorte waren NT-proBNP und BNP nicht mit dem Überleben assoziiert, die Erkenntnisse der Literatur ließen sich anhand der Ergebnisse der vorliegenden Arbeit nicht nachvollziehen. Dies kann mit dem durchschnittlichen Alter der Patienten zusammenhängen. Sayama et al. (1999) stellen in ihrer Arbeit heraus, dass der prognostische Wert von BNP mit dem Alter nachlässt. Die von ihnen untersuchte Kohorte ist jedoch im Durchschnitt mit 83,4 $\pm 0,8$ Jahren fast 10 Jahre älter als die Kohorte dieser Arbeit.

In aktuellen Arbeiten wird der Unterschied in der Aussage von BNP bezüglich HFpEF und HFrEF diskutiert. Bei der Untersuchung von drei Gruppen mit verschiedenen EF (HFrEF: n=860; HFmrEF: n=318; HFpEF: n=614) konnte eine unterschiedliche Relevanz in der Aussagekraft des Progressionsmarkers BNP gezeigt werden. So verlor BNP an prognostischer Relevanz bei HFpEF gegenüber HFrEF (Hamatani et al. 2017). Dass die Relevanz von BNP und NT-proBNP nicht in dieser Arbeit reflektiert wird, kann darüber hinaus auch an der relativ kleinen Kohorte liegen. Insgesamt wird jedoch deutlich, dass die untersuchten Gene in ihrer Aussage zur Progression spezifischer als die beiden etablierten Marker sind, da sie bei kleinem $\mathrm{n}$ bereits eine signifikante Assoziation zeigen.

Auffallend ist ebenfalls, dass weder RASAL1 noch ATP2A2 mit E/e' korrelieren. Der Quotient aus Mitralfüllungs- und Mitralanulusgeschwindigkeit E/e` wird von der ESC empfohlen, um Patienten mit diastolischer Dysfunktion zu identifizieren (Ponikowski et al. 2016). Sharifov et al. (2016) untersuchen die Empfehlung der ESC anhand einer Metaanalyse und kommen zu dem Ergebnis, dass E/e‘ nicht mit der myokardialen Steifheit 
des Ventrikels in Verbindung steht. Dies deutet darauf hin, dass E/e' nicht mit Fibrose und demnach nicht mit der Progression von HFpEF assoziiert ist, sondern lediglich ein Marker für die Erfassung des Status quo der diastolischen Funktion ist. Die Tatsache, dass E/e in der Kaplan-Meier-Analyse dieser Arbeit nicht mit dem Überleben assoziiert ist, stützt diese Annahme. Zhou et al. (2018) erwähnen E/e` als einen Marker, der prognostisch relevant für das Auftreten von Ereignissen bei Patienten mit arterieller Hypertonie und erhaltener LVEF ist. Sie definieren kardiales Ereignis als Herzinfarkt, neu aufgetretene Angina pectoris und Herzinsuffizienz, was die unterschiedlichen Resultate begründen könnte, da in der vorliegenden Arbeit das Überleben betrachtet wird. Wang et al. (2003) hingegen definierten den Tod als Ereignis, untersuchten jedoch 353 Patienten mit Herzerkrankungen, welche in ihrer Genese nicht genauer spezifiziert werden. Ihnen gelang es, die prognostische Bedeutung von E/e' für das Überleben der Patienten darzustellen. Die nicht genauere Spezifizierung von Herzerkrankungen macht es dennoch schwer, ihre Ergebnisse mit den Vorliegenden zu vergleichen.

\subsection{3. $R A S A L 1$ und $A T P 2 A 2$ als Progressionsmarker im multivariaten Modell}

Um Abhängigkeiten zwischen den Parametern herauszufinden, wurden in CoxRegressionen verschiedene Modelle betrachtet. Im ersten Modell wurden die univariat signifikanten Parameter ohne den Einfluss der drei untersuchten Gene RASAL1, ATP2A2 und B9D1 betrachtet. Lediglich KHK, Hinterwanddicke und BMI zeigten sich unabhängig von anderen Einflussgrößen. In diesem Modell war der Einfluss der KHK auf das Überleben am größten. Zusätzlich verlor das Alter an Signifikanz unter Hinzunahme der genannten Parameter in das Modell. Der bereits diskutierte negative Zusammenhang zwischen BMI und Überleben ist in diesem wie in den folgenden Modellen, zu finden. Rusinaru et al. (2014) haben den prognostischen Wert von KHK bei herzinsuffizienten Patienten untersucht. Genau wie in dieser Arbeit, ist KHK in ihrer Kohorte univariat mit letalem Ausgang assoziiert. Im multivariaten Modell zeigte KHK jedoch nur noch bei HFrEF, nicht jedoch bei HFpEF prognostisch signifikante Werte. Die unterschiedlichen Ergebnisse können mit der Auswahl an konfundierenden Variablen im multivariaten Modell zusammenhängen, da sich der p-Wert im Cox-Modell aus der intervariablen Abhängigkeit der betrachteten Variablen ergibt.

Unter Hinzunahme von RASAL1-Methylierung in das Modell verbesserte sich die Gesamtgüte des Modells maßgeblich. Die zuvor signifikanten Parameter KHK, BMI und Hinterwanddicke blieben signifikant. Die Hazard-Ratio für RASALl überstieg jedoch diejenige von KHK. Der Methylierungsgrad von RASAL1-Promotoren stellt somit einen 
stärkeren Prädiktor für das Überleben und die Progression der Krankheit dar. Die Bedeutung von RASAL1 als Progressionsmarker konnte bereits für die Niere etabliert werden (Tampe und Zeisberg 2014; Bechtel et al. 2010). Bezogen auf das Herz beschrieben Xu et al. (2015) einen signifikanten Zusammenhang zwischen der Hypermethylierung von RASAL1Promotoren und einem erhöhten Level an Fibrose. In ihrer Arbeit konzentrierten sich die Autoren jedoch nicht auf Patienten mit HFpEF, sondern betrachteten acht Patienten mit NYHA-Klasse IV und einer EF von $22,1 \pm 6,8 \%$. Kausal hängt die RASAL1 Hypermethylierung eng mit der Entstehung von Fibrose zusammen, wie in der Einleitung beschrieben. Darüber hinaus konnte im Tierversuch gezeigt werden, dass Herzfibrose durch eine Inhibition des Wachstumsfaktors TGF- $\beta$ unterdrückt werden kann (Kuwahara et al. 2002). TGF- $\beta$ ist eng mit dem RASAL1-Signalweg verknüpft (Xu et al. 2016), weshalb hierdurch erneut der Zusammenhang zwischen Fibrose, RASAL1-Methylierung und konsekutiv Mortalität deutlich wird. Die bisher unveröffentlichten Ergebnisse aus früheren Arbeiten der Gruppe unterstützen die Bedeutung der Promotormethylierung von RASAL1 als Biomarker für die Progression von HFpEF. Die Ergebnisse dieser Arbeit weisen darauf hin, dass die im Blut gemessene Promotormethylierung von RASAL1 Aussagekraft für die Sterblichkeit der Patienten mit HFpEF besitzt.

Ein statistisch noch signifikanteres Modell wurde durch Austausch von RASALI durch ATP2A2 erreicht. Dieselben Parameter wie zuvor diskutiert zeigten in diesem Modell Unabhängigkeit und Relevanz als Prognoseparameter. Jedoch überstieg die Hazard-Ratio von ATP2A2 deutlich die der anderen Parameter. Auf Grundlage dieses Modells stellt ATP2A2 einen Marker für die Progression von HFpEF dar. Obwohl über die Bedeutung von $A T P 2 A 2$ als Progressionsmarker für HFpEF in der Literatur insgesamt wenig zu finden ist, weisen Teile der Ergebnisse dieser Arbeit Parallelen zu Arbeiten anderer Autoren auf. Wie erwähnt, konnte im murinen Modell gezeigt werden, dass Atp2a2-Promotormethylierung zu einer geringeren Serca2a-Expression führen kann (Kao et al. 2010).

In weiteren Mausstudien konnten Hinweise darauf geliefert werden, dass epigenetische Veränderungen von Atp2a2-Promotoren zur Progression von Herzinsuffizienz beitragen (Angrisano et al. 2014). In humanen Kardiomyozyten ist zu diesem Sachverhalt bisher wenig bekannt, jedoch weisen Ergebnisse unveröffentlichter Vorarbeiten auf einen Zusammenhang zwischen der Progression von HFpEF und aberranter ATP2A2-Methylierung hin. In anderen Studien wird die Bedeutung der Isoformen von SERCA diskutiert. In der Literatur gibt es Hinweise für eine verminderte Expression von SERCA2a bei Herzinsuffizienz (Hasenfuß et al. 1994), während in einer unveröffentlichten Arbeit der Arbeitsgruppe SERCA2b reduziert 
gefunden wurden. In dieser Arbeit wird nicht zwischen den Isoformen unterschieden, da lediglich das Gen betrachtet wird.

Im Gegensatz dazu konnte die in der univariaten Betrachtung beobachtete Assoziation von B9D1 und dem Überleben im multivariaten Modell nicht verifiziert werden. Nicht nur B9D1, sondern alle weiteren Parameter bis auf BMI verloren in dieser Konstellation von Confoundern ihren Einfluss auf die Überlebenszeit. Wie bereits in Abschnitt 1.5 erwähnt, ist über die Bedeutung von B9D1 im Herzen wenig bekannt. In der Arbeit von Meder et al. (2017) wurde B9D1 als das Gen identifiziert, das von 59 Untersuchten das am stärksten aberrant methylierte ist. Hierbei wurden Proben von Patienten mit dilatativer Kardiomyopathie (DCM), einer mit Fibrose assoziierten Erkrankung, untersucht. Aus diesem Grund wurde B9D1 in diese Arbeit einbezogen, um den Einfluss dieses Gens auf die Progression der Krankheit zu untersuchen. Es ist zu erwähnen, dass die Methylierung von B9D1 bei DCM-Patienten in der Arbeit von Meder mit einer gesunden Kohorte verglichen wurde. Insgesamt fand man bei DCM-Patienten eine geringere Methylierung (Hypomethylierung) als bei der gesunden Kohorte. Bei Betrachtung der Streuung fällt jedoch auf, dass in der DCM-Kohorte einige Patienten hypermethyliertes B9D1 aufweisen.

Wird in unserer Kohorte die Verteilung der Methylierung betrachtet, findet sich ebenfalls eine Normalverteilung mit hypermethylierten Genen. Im Gegensatz zu Meder wurde in der vorliegenden Arbeit der Zusammenhang der Methylierung mit dem Überleben untersucht und nicht mit einer gesunden Kohorte verglichen. Darüber hinaus wird in der Literatur beschrieben, dass ein Defekt oder Mangel von B9D1 mit kongenitalen Herzfehlern assoziiert ist (Dowdle et al. 2011). Dies impliziert, dass die Expression von B9D1, die bei Hypomethylierung gewährleistet ist, protektiven Charakter haben könnte. Dieser Zusammenhang unterstützt die in dieser Arbeit gezeigten Ergebnisse der univariaten Analyse, dass eine hohe B9D1-Methylierung mit konsekutiver niedriger B9D1-Expression mit ungünstigem Verlauf assoziiert ist. Der Verlust der Aussagekraft auf die Progression im multivariaten Modell ist mit dem heutigen Kenntnisstand über B9D1 schwer zu interpretieren. Es ist zu wenig über das Gen bekannt, als dass über die Abhängigkeiten von anderen Confoundern sinnvoll diskutiert werden könnte.

Konkurrieren alle drei Gene um den Einfluss auf das Überleben, verlieren B9D1 und RASAL1 gegenüber ATP2A2 deutlich an Bedeutung. Die zuvor diskutierten Parameter KHK, Hinterwanddicke und BMI behalten ihr Gewicht. An dieser Stelle muss auf die Limitationen im statistischen Cox-Modell eingegangen werden. Es sollte beachtet werden, dass die 
Ergebnisse nur im jeweiligen Modell interpretiert werden dürfen. Wenn die Confounder geändert werden, ändert sich der Einfluss der hier betrachteten Gene. Zusätzlich wird die Anzahl der zulässigen Confounder diskutiert, die abhängig von der Anzahl der Events in der Kohorte sind. Bei Erhöhung der Anzahl der Confounder, erhöht sich auch der Fehler des Modells, wodurch die Aussagen vorsichtiger abgeleitet werden müssen.

Von den untersuchten Genen zeigten drei in der univariaten Betrachtung eine signifikante Korrelation mit dem Überleben in der vorliegenden Kohorte. In der multivariaten Untersuchung konnte gezeigt werden, dass die Methylierung von B9Dl abhängig von anderen Parametern ist und die Vorhersagekraft dieses Markers im multivariaten Modell keinen Bestand hat. Im Gegensatz dazu verloren RASAL1 und ATP2A2 in der multivariaten Analyse nicht an Aussagekraft. Als unabhängige Parameter mit statistisch signifikantem Einfluss auf das Überleben eignen sie sich für die betrachtete Kohorte als Biomarker für die Progression von HFpEF. Bei Betrachtung aller drei Gene im Modell zeigte sich ATP2A2 als einziger unabhängig von anderen Größen. Die Überlegenheit von ATP2A2 gegenüber RASAL1 sollte vor dem Hintergrund des statistischen Fehlers in diesem Modell in weiteren Studien untersucht werden. Insgesamt weisen die Gene RASAL1 und ATP2A2 eine deutliche Überlegenheit als Marker für die Progression von HFpEF gegenüber etablierten Markern und anderen Patientencharakteristika auf.

\subsection{Klinische Implikationen}

\subsubsection{Therapie der Herzinsuffizienz}

Nach aktuellen Leitlinien liegt das Therapieziel bei Patienten mit HFrEF darin, Hospitalisierung zu reduzieren, die Sterblichkeit $\mathrm{zu}$ senken und die Lebensqualität zu verbessern. Hierfür gibt es eine Vielzahl von etablierten Therapiemöglichkeiten (Nanayakkara et al. 2018). Die Behandlung erfolgt gemäß der Einteilung der New York Heart Association. Lebensverlängernde Medikamente sind Angiontensin-convertingenzyme-Hemmer (ACE-Inhibitor), Mineralkortikoid-Rezeptorantagonisten (MRA), Angiotensin-Rezeptor/Neprilysin-Hemmer (ARNI) und Beta-Blocker. Die kardiale Resynchronisationstherapie (CRT) kann die Mortalität reduzieren, wohingegen implantierte Kardioverter/Defibrillatoren (ICD) die Gesamtmortalität nicht senken (European Society of Cardiology 2016). Dem gegenüber zu stellen ist die bisher wenig aussichtsreiche Therapie der HFpEF. Es ist keine Behandlung bekannt, die die Morbidität und Mortalität senkt. In der I-PRESERVE-Studie konnte nachgewiesen werden, dass Irbesartan keine lebensverlängernde Wirkung hat (Massie et al. 2008). Analog wurde in der CHARM-Studie 
gezeigt, dass Candesartan die Mortalität nicht senken kann (Yusuf et al. 2003) und in der TOPCAT-Studie, dass Spironolacton keinen Einfluss auf die Mortalität von HFpEFPatienten hat (Pitt et al. 2014). Der aktuelle Stand der Therapie sieht daher lediglich eine Symptomkontrolle als Therapieziel vor. Es gibt Hinweise darauf, dass Diuretika die Stauungszeichen verbessern und die systolische Hypertonie therapiert werden sollte (European Society of Cardiology 2016). In der Patientengruppe der HFpEF gibt es Patienten, die häufiger als ihre Vergleichsgruppe stationär aufgenommen werden und eine höhere Mortalität verzeichnen. Diese Risikopatienten können ein Ziel für neue Therapien darstellen (Carson et al. 2015).

\subsubsection{Neue Therapiemöglichkeiten durch Verständnis der Epigenetik}

Das Verständnis epigenetischer Zusammenhänge bei der Entstehung von HFpEF ermöglicht die Etablierung neuer Therapieansätze. Hydralazin wurde 1952 als blutdrucksenkendes Medikament vorgestellt (Wilkinson et al. 1952). Heute wird es nicht als Mittel der Wahl bei Bluthochdruck eingesetzt, findet aber aufgrund geringer Nebenwirkungen als vasodilatierendes Mittel gegen Bluthochdruck weiterhin in der Schwangerschaft Anwendung (James et al. 2014; Amaral et al. 2017). Einer der Mechanismen von Hydralazin beruht auf der demethylierenden Eigenschaft (Tampe et al. 2015). Hydralazin modifiziert die methylierten Cytosin-Reste durch Induktion der Ten-eleven translocation (TET)Enzyme. TET3 oxidiert 5-Methylcytosin (5mC) zu 5-Hydroxymethylcytosin (5hmC) und 5Carboxylcytosin $(5 \mathrm{caC})$, was dazu führt, dass die aberrant methylierten Cytosin-Reste durch unmethyliertes Cytosin ersetzt werden können (Tampe und Zeisberg 2018). Diese Form von aktiver DNA-Demethylierung ist für die Niere beschrieben worden und es konnte bereits gezeigt werden, dass Hydralazin in geringer Dosierung zu einer Demethylierung von RASAL1 mit konsekutiver erhöhter RASAL1-Expression führen kann (Tampe et al. 2017). Daher wird Hydralazin in der Forschung für die Therapie der chronischen Herzinsuffizienz vorgeschlagen (Zeisberg und Zeisberg 2016).

\subsubsection{Volkswirtschaftliche Relevanz}

Eine frühzeitige Identifizierung von Risikopatienten bietet die Chance rechtzeitig eine suffiziente Therapie zu beginnen. Hospitalisierung und vorzeitiger Tod könnten hinausgezögert werden, wovon nicht nur der Patient, sondern auch die Volkswirtschaft profitiert. Cook et al. (2014) haben in ihrer Arbeit 197 Länder einbezogen, um herauszufinden, wie hoch die jährlich durch dieses Krankheitsbild verursachten Kosten für die Gesellschaft sind. Für das Jahr 2012 haben sie Kosten in Höhe von 108 Milliarden Euro 
berechnet. Darin enthalten sind die direkten Kosten für das Gesundheitssystem, wie Krankenhauskosten und Medikamente, sowie indirekte Kosten durch nicht bezahlte Behandlungskosten oder frühe Sterblichkeit und dadurch verlorengegangene Arbeitskraft. Durch die demographische Entwicklung der Gesellschaft erwarten die Autoren eine Zunahme dieser Kosten. Hollingworth et al. (2016) haben die Kosten in den letzten fünf Lebensjahren von herzinsuffizienten Patienten untersucht. Sie haben herausgefunden, dass die Kosten zum Ende des Lebens dieser Patienten steigen und 90\% der Kosten durch stationäre Krankenhausaufenthalte entstehen. Hierdurch wird die volkswirtschaftliche Belastung deutlich und verstärkt die Notwendigkeit von frühzeitiger Diagnostik und neuen Therapieansätzen bei Patienten mit HFpEF.

Zusammengefasst verdeutlichen die vorliegenden Ergebnisse die Bedeutung weiterer Forschung auf diesem Gebiet und bieten Grundlage für aufbauende Studien und Diskussionen. 


\section{Zusammenfassung}

Im Gegensatz zum in der Regel stabilen Krankheitsverlauf von Patienten mit HFpEF zeigen vereinzelte Patienten eine rasche Progression der Erkrankung und damit assoziiert eine erhöhte kardiovaskuläre Mortalität. Um diese Risikopatienten identifizieren zu können, war die Etablierung von Biomarkern für die klinische Progression von HFpEF Gegenstand dieser Arbeit. Zirkulierende DNA-Fragmente der Gene RASAL1, ATP2A2 und B9D1 wurden auf ihre Aussagekraft bezüglich des Überlebens von Patienten analysiert. Hierbei wurden aberrant methylierte Promotorabschnitte quantifiziert. Der Vergleich mit 20 weiteren Patientenparametern diente zur Überprüfung der Überlegenheit der untersuchten Gene als Biomarker.

Aus der Pathophysiologie des Krankheitsbildes konnte abgeleitet werden, dass der Fibrosegrad im Herzen zur Progression der Krankheit beiträgt. Durch einen Mangel an Herzgewebebiopsien wurde in der vorliegenden Arbeit die Zeit bis zum Todeseintritt als stellvertretender Marker für die Progression der Krankheit bzw. Fibrose herangezogen.

Zur Bestimmung des Methylierungsgrads der Promotoren wurden die epigenetisch veränderten Abschnitte der aus Vollblut isolierten DNA im Rahmen einer MeDIP mit Hilfe von Antikörpern fixiert und in einer rtPCR der Anteil methylierter Promotoren ermittelt. Die 47 Proben wurden umfassend statistisch analysiert. Für alle drei Gene RASAL1, ATP2A2 und B9D1 konnte ein signifikanter Unterschied im Überleben ober- und unterhalb des Mediansplits festgestellt werden. Der Zusammenhang der aberranten Methylierung mit dem Überleben zeigte sich erneut in der Korrelationsanalyse, da dort für alle Gene eine signifikante Korrelation mit dem Überleben zu beobachten war. Darüber hinaus ließ sich aus den Ergebnissen der Korrelationsanalyse ableiten, dass die Gene unterschiedliche Aspekte der Krankheit messen. Während RASAL1 nur mit dem Todeseintritt korreliert und damit für einen Fibrosemarker stehen könnte, korrelieren ATP2A2 und B9D1 mit weiteren der 20 Patientenparameter. Um die von den Genen gemessenen Aspekte eindeutig identifizieren zu können, muss der Beitrag der beiden Gene zur Fibrogenese des Herzens zukünftig genauer verstanden werden.

In der Kaplan-Meier-Analyse wurden die Patientenvariablen ermittelt, die sich ober- und unterhalb eines in der ROC-Analyse gefundenen Schwellenwertes bezüglich des Patientenüberlebens signifikant unterschieden. An dieser Stelle zeigten die drei Gene RASAL1, ATP2A2 und B9D1 eine bessere Assoziation mit dem Überleben als bereits etablierte Marker wie BNP und NT-proBNP. Das Kontrollgen LAP zeigte keine Signifikanz. Unter Hinzunahme des Parameters Geschlecht, wurden die im univariaten Modell 
signifikanten Variablen im multivariaten Modell auf Abhängigkeiten getestet, sodass die Parameter Alter, BMI, Krea-Clearance, Hinterwanddicke, KHK und systolischer Blutdruck in verschiedenen Modellen mit den drei signifikanten Genen analysiert wurden. Lediglich B9D1 verlor hier an Einfluss, die anderen beiden Gene zeigten sich in verschiedenen Modellen als unabhängige Prognosemarker für das Überleben. Im letzten Modell wurden alle drei Gene RASAL1, ATP2A2 und B9D1 analysiert, es erwies sich nur ATP2A2 als unabhängig und statistisch signifikant. Dieser Einfluss sollte jedoch durch den statistischen Fehler des Modells, der mit der Anzahl der analysierten Parameter ansteigt, vorsichtig interpretiert werden.

Insgesamt werden in dieser Arbeit drei mit dem Überleben von HFpEF-Patienten assoziierte Gene analysiert und deren Qualifikation als Biomarker für die klinische Progression von HFpEF herausgestellt. Zusätzlich konnte in dieser Kohorte deren Überlegenheit als Progressionsmarker über bisher etablierte Marker gezeigt werden. 


\section{Literaturverzeichnis}

Abouzied MM, Eltahir HM, Fawzy MA, Abdel-Hamid NM, Gerges AS, El-Ibiari HM, Nazmy MH (2015): Estimation of leucine aminopeptidase and 5-nucleotidase increases alpha-fetoprotein Sensitivity in Human Hepatocellular Carcinoma Cases. Asian Pac J Cancer Prev 16, 959-963

Allen M, Chu S, Brill S, Stotler C, Buckler A (1998): Restricted tissue expression pattern of a novel human rasGAP-related gene and its murine ortholog. Gene $\underline{218}, 17-25$

Amaral LM, Wallace K, Owens M, LaMarca B (2017): Pathophysiology and current clinical management of preeclampsia. Curr Hypertens Rep $\underline{19}, 61$

Anand IS, Fischer L, Chiang Y-T, Latini R, Masson S, Maggioni A, Glazer R, Tognoni G, Cohn J (2003): Changes in brain natriuretic peptide and norepinephrine over time and mortality and morbidity in the valsartan heart failure trial (Val-HeFT). Circulation $\underline{107}$, $1278-1283$

Angrisano T, Schiattarella GG, Keller S, Pironti G, Florio E, Magliulo F, Bottino R, Pero R, Lembo F, Avvedimento EV et al. (2014): Epigenetic switch at atp2a2 and myh7 gene promoters in pressure overload-induced heart failure. PLoS ONE $\underline{9}$, e106024

Annes JP, Munger JS, Rifkin DB (2003): Making sense of latent TGF-beta activation. J Cell Sci $\underline{116}, 217-224$

Bechtel W, McGoohan S, Zeisberg EM, Müller GA, Kalbacher H, Salant DJ, Müller CA, Kalluri R, Zeisberg M (2010): Methylation determines fibroblast activation and fibrogenesis in the kidney. Nat Med $\underline{16}, 544-550$

Bers DM, Bassani JWM, Bassani RA (1996): Na-Ca Exchange and Ca fluxes during contraction and relaxation in mammalian ventricular muscle. Ann NY Acad Sci $\underline{779}$, $430-442$

Bird A (2002): DNA methylation patterns and epigenetic memory. Genes Dev. 16, 6-21

Bird AP, Wolffe AP (1999): Methylation-induced repression — belts, braces, and chromatin. Cell 99, 451-454

Braunwald E (2015): The war against heart failure: the Lancet lecture. Lancet $\underline{385}$, 812-824 
Carlson KJ, Lee DC-S, Goroll AH, Leahy M, Johnson RA (1985): An analysis of physicians' reasons for prescribing long-term digitalis therapy in outpatients. J Chron Dis $\underline{38}, 733$ 739

Carson PE, Anad IS, Win S, Rector T, Haass M, Lopez-Sendon J, Miller A, Teerlink JR, White M, McKelvie RS et al. (2015): The hospitalization burden and posthospitalization mortality risk in heart failure with preserved ejection fraction: results from the I-PRESERVE trial (Irbesartan in heart failure and preserved ejection fraction). J Am Coll Cardiol $\underline{3}, 429-441$

Casado J, Montero M, Formiga F, Carrera M, Urrutia A, Arevalo JC, Perez-Calvo JI (2013): Clinical characteristics and prognostic influence of renal dysfunction in heart failure patients with preserved ejection fraction. Eur J Intern Med 24, 677-683

Chapman D, Weber KT, Eghbali M (1990): Regulation of fibrillar collagen types I III and basement membrane type IV and collagen gene expression in pressure overloaded rat myocardium. Circ Res $\underline{67}, 787-794$

Cheng W, Li B, Kajstura J, Li P, Wolin MS, Sonnenblick EH, Hintze TH, Olivetti G, Anversa P (1995): Stretch-induced programmed myocyte cell death. J Clin Invest $\underline{96}$, $2247-2259$

Cleutjens J, Kandala J, Guarda E, Guntaka R, Weber KT (1995): Regulation of collagen degradation in the rat myocardium after infarction. J Mol Cell Cardiol 27, 1281-1292

Cook C, Cole G, Asaria P, Jabbour R, Francis DP (2014): The annual global economic burden of heart failure. Int J Cardiol 171, 368-376

Daniels LB, Maisel AS (2007): Natriuretic peptides. J Am Coll Cardiol 50, 2357-2368

Desmouliere A, Geinoz A, Gabbiani F, Gabbiani G (1993): Transforming growth factor-beta 1 induces alpha-smooth muscle actin expression in granulation tissue myofibroblasts and in quiescent and growing cultured fibroblasts. J Cell Biol 122, 103-111

Dobaczewski M, Chen W, Frangogiannis NG (2011): Transforming growth factor (TGF)- $\beta$ signaling in cardiac remodeling. J Mol Cell Cardiol 51, 600-606

Dowdle WE, Robinson JF, Kneist A, Sirerol-Piquer MS, Frints SGM, Corbit KC, Zaghloul NA, Zaghloul NA, van Lijnschoten G, Mulders L et al. (2011): Disruption of a ciliary B9 protein complex causes Meckel syndrome. Am J Hum Genet $\underline{89}$, 94-110 
Dunlay SM, Roger VL, Redfield MM (2017): Epidemiology of heart failure with preserved ejection fraction. Nature Reviews Cardiology

Eriksson H, Caidahl K, Larsson B, Ohlson L-O, Welin L, Wilhelmsen L, Svärdsudd K (1987): Cardiac and pulmonary causes of dyspnoe - validation of a scoring test for clinical-epidemiological use: The study of men born in 1913. Eur Heart J $\underline{8}, 1007-1014$

European Society of Cardiology (2016): Pocket-Leitlinie: Herzinsuffizienz. Version 2016, 2. Auflage; ESC 2016

Feng XH, Derynck R (2005): Specificity and versatility in TGF-beta signaling through Smads. Annu Rev Cell Dev Biol 21, 659-693

Frangogiannis NG (2012): Regulation of the inflammatory response in cardiac repair. Circ Res $\underline{110}, 159-173$

Frank KF, Bölck B, Brixius K, Kranias E, Schwinger RHG (2002): Modulation of SERCA: implications for the failing human heart. Basic Res Cardiol 97, 72-78

Garcia-Gonzalo FR, Corbit KC, Sirerol-Piquer MS, Ramaswami G, Otto EA, Noriega TR, Seol AD, Robinson JF, Bennett CL, Josifova DJ et al. (2011): A transition zone complex regulates mammalian ciliogenesis and ciliary membrane composition. Nat Genet $\underline{43}$, $776-784$

Goumans M-J, Valdimarsdottir G, Itoh S, Rosendahl A, Sideras P, Dijke P ten (2002): Balancing the activation state of the endothelium via two distinct TGF-beta type I receptors. EMBO J 21, 1743-1753

Grimaldi V, Pascale MR de, Zullo A, Soricelli A, Infante T, Mancini FP, Napoli C (2017): Evidence of epigenetic tags in cardiac fibrosis. J Cardiol $\underline{69}, 401-408$

Grossman W, Jones D, McLaurin LP (1975): Wall stress and patterns of hypertrophy in the human left ventricle. J Clin Invest $\underline{56}, 56-64$

Gurtner GC, Werner S, Barrandon Y, Longaker MT (2008): Wound repair and regeneration. Nature $\underline{453}, 314-321$

Haass M, Kitzman DW, Anand IS, Miller A, Zile MR, Massie BM, Carson PE (2011): Body mass index and adverse cardiovascular outcomes in heart failure patients with preserved ejection fraction: Results from the Irbesartan in heart failure with preserved ejection fraction (I-PRESERVE) trial. Circ Heart Fail 4, 324-331 
Hamatani Y, Nagai T, Shiraishi Y, Kohsaka S, Nakai M, Nishimura K, Kohno T, Nagatomo Y, Asaumi Y, Goda A et al. (2017): Long-term prognostic significance of plasma Btype natriuretic peptide level in patients with acute heart failure with reduced, midrange, and preserved ejection fractions. Am J Cardiol 121, 731-738

Hasenfuß G, Reinecke H, Studer R, Meyer M, Peske B, Holtz J, Holubarsch C, Posival H, Hanjörn J, Drexler H (1994): Relation between myocardial function and expression of sarcoplasmic reticulum $\mathrm{Ca}^{2+}$-ATPase in failing and nonfailing human myocardium. Circ Res $\underline{75}, 434-442$

Higuchi R, Dollinger G, Walsh PS, Griffith R (1992): Simultaneous amplification and detection of specific DNA sequences. Biotechnology 10, 413-417

Ho JE, Gona P, Pencina MJ, Tu JV, Austin PC, Vasan RS, Kannel WB, D'Agostino RB, Lee DS, Levy D (2012): Discriminating clinical features of heart failure with preserved vs. reduced ejection fraction in the community. Eur Heart J $\underline{33}$, 1734-1741

Ho KKL, Pinsky JL, Kannel WB, Levy D (1993): The epidemiology of heart failure: The Framingham Study. J Am Coll Cardiol 22, A6-A13

Hollingworth W, Biswas M, Maishman RL, Dayer MJ, McDonagh T, Purdy S, Reeves BC, Rogers CA, Williams R, Pufulete M (2016): The healthcare costs of heart failure during the last five years of life: A retrospective cohort study. Int J Cardiol 224, 132-138

Jalil JE, Doering CW, Janicki JS, Pick R, Shroff SG, Weber KT (1989): Fibrillar collagen and myocardial stiffness in the intact hypertrophied rat left ventricle. Circ Res $\underline{64}, 1041-$ 1050

James PA, Oparil S, Carter BL, Cushman WC, Dennison-Himmelfarb C, Handler J, Lackland DT, LeFevre ML, MacKenzie TD, Ogedegbe O et al. (2014): 2014 Evidencebased guideline for the management of high blood pressure in adults: Report from the panel members appointed to the Eighth Joint National Committee (JNC 8). JAMA $\underline{311}$, $507-520$

Janicki JS, Brower GL (2002): The role of myocardial fibrillar collagen in ventricular remodeling and function. J Card Fail $\underline{8}$, S319-25

Jones PA, Laird PW (1999): Cancer epigenetics comes of age. Nat Genet 21, 163-167 
Kao YH, Chen YC, Cheng CC, Lee TI, Chen YJ, Chen SA (2010): Tumor necrosis factoralpha decreases sarcoplasmic reticulum $\mathrm{Ca}^{2+}$-ATPase expressions via the promoter methylation in cardiomyocytes. Crit Care Med $\underline{38}, 217-222$

Kimura T, Nakamori M, Lueck JD, Pouliquin P, Aoike F, Fujimura H, Dirksen RT, Takahashi MP, Dulhunty AF, Sakoda S (2005): Altered mRNA splicing of the skeletal muscle ryanodine receptor and sarcoplasmic/endoplasmic reticulum $\mathrm{Ca}^{2+}$-ATPase in myotonic dystrophy type 1 . Hum Mol Genet $\underline{14}$, 2189-2200

Krum H, Elsik M, Schneider HG, Ptaszynska A, Black M, Carson PE, Komajda M, Massie BM, McKelvie RS, McMurray JJ et al. (2011): Relation of peripheral collagen markers to death and hospitalization in patients with heart failure and preserved ejection fraction: Results of the I-PRESERVE collagen substudy. Circ Heart Fail $\underline{4}, 561-568$

Kuwahara F, Kai H, Tokuda K, Kai M, Takeshita A, Egashira K, Imaizumi T (2002): Transforming growth factor-beta function blocking prevents myocardial fibrosis and diastolic dysfunction in pressure-overloaded rats. Circulation $\underline{106}, 130-135$

Lam CSP, Donal E, Kraigher-Krainer E, Vasan RS (2011a): Epidemiology and clinical course of heart failure with preserved ejection fraction. Eur J Heart Fail $\underline{13}$, 18-28

Lam CSP, Lyass A, Kraigher-Krainer E, Massaro JM, Lee DS, Ho JE, Levy D, Redfield MM, Pieske BM, Benjamin EJ et al. (2011b): Cardiac dysfunction and noncardiac dysfunction as precursors of heart failure with reduced and preserved ejection fraction in the community. Circulation $\underline{124}, 24-30$

Linzbach AJ (1960): Heart failure from the point of view of quantitative anatomy. Am J Cardiol $\underline{5}, 370-382$

Lipskaia L, Chemaly ER, Hadri L, Lompre A-M, Hajjar RJ (2010): Sarcoplasmic reticulum $\mathrm{Ca}^{2+}$ ATPase as a therapeutic target for heart failure. Expert Opin Biol Ther 10, 29-41

Lompré A-M, Hajjar RJ, Harding SE, Kranias EG, Lohse MJ, Marks AR (2010): Ca ${ }^{2+}$ cycling and new therapeutic approaches for heart failure. Circulation $\underline{121}, 822-830$

López B, González A, Lindner D, Westermann D, Ravassa S, Beaumont J, Gallego I, Zudaire A, Brugnolaro C, Querejeta R et al. (2013): Osteopontin-mediated myocardial fibrosis in heart failure: A role for lysyl oxidase? Cardiovasc Res $\underline{99}, 111-120$

Mascherbauer J, Marzluf BA, Tufaro C, Pfaffenberger S, Graf A, Wexberg P, Panzenböck A, Jakowitsch J, Bangert C, Laimer D et al. (2013): Cardiac magnetic resonance 
postcontrast $\mathrm{T} 1$ time is associated with outcome in patients with heart failure and preserved ejection fraction. Circ Cardiovasc Imaging $\underline{6}, 1056-1065$

Massagué J (2000): How Cells Read TGF-beta Signals. Nat Rev Mol Cell Biol 1, 169-178

Massie BM, Carson PE, McMurray JJ, Komajda M, McKelvie R, Zile MR, Anderson S, Donovan M, Iverson E, Staiger C et al. (2008): Irbesartan in patients with heart failure and preserved ejection fraction. N Engl J Med 359, 2456-2467

Mauviel A (2005): Transforming growth factor-beta: a key mediator of fibrosis. Methods Mol Med 117, 69-80

McAlister FA, Ezekowitz J, Tonelli M, Armstrong PW (2004): Renal insufficiency and heart failure: Prognostic and therapeutic implications from a prospective cohort study. Circulation $\underline{109}, 1004-1009$

Meder B, Haas J, Sedaghat-Hamedani F, Kayvanpour E, Frese K, Lai A, Nietsch R, Scheiner C, Mester S, Martins Bordalo D et al. (2017): Epigenome-wide association study identifies cardiac gene patterning and a novel class of biomarkers for heart failure. Circulation 136, $1528-1544$

Mizutani S, Shibata K, Kikkawa F, Hattori A, Tsujimoto M, Ishii M, Kobayashi H (2007): Essential role of placental leucine aminopeptidase in gynecologic malignancy. Expert Opin Ther Targets $\underline{11}, 453-461$

Mullis KB, Faloona FA (1987): Specific synthesis of DNA in vitro via a polymerasecatalyzed chain reaction. Methods Enzymol 155, 335-350

Nanayakkara S, Patel HC, Kaye DM (2018): Hospitalisation in patients with heart failure with preserved ejection fraction. Clin Med Insights Cardiol 12, 1179546817751609

Nicoletti A, Heudes D, Hinglais N, Appay M-D, Philippe M, Sassay-Prigent C, Bariety J, Michel J-B (1995): Left ventricular fibrosis in renovascular hypertensive rats effect of Losartan and Spironolactone. Hypertension 26, 101-111

Pagani ED, Alousi AA, Grant AM, Older TM, Dziuban SW, Allen PD (1988): Changes in myofibrillar content and Mg-ATPase activity in ventricular tissues from patients with heart failure caused by coronary artery disease, cardiomyopathy, or mitral valve insufficiency. Circ Res $\underline{63}$, 380-385 
Pischon T, Boeing H, Hoffmann K, Bergmann M, Schulze MB, Overvad K, van der Schouw YT, Spencer E, Moons KGM, Tjønneland A et al. (2008): General and abdominal adiposity and risk of death in europe. N Engl J Med 359, 2105-2120

Pitt B, Pfeffer MA, Assmann SF, Boineau R, Anand IS, Claggett B, Clausell N, Desai AS, Diaz R, Fleg JL et al. (2014): Spironolactone for heart failure with preserved ejection fraction. N Engl J Med 370, 1383-1392

Pollman MJ, Yamada T, Horiuchi M, Gibbons GH (1996): Vasoactive substances regulate vascular smooth muscle cell apoptosis: Countervailing influences of Nitric Oxide and Angiotensin II. Circ Res $\underline{79}$, 748-756

Ponikowski P, Voors AA, Anker SD, Bueno H, Cleland JGF, Coats AJS, Falk V, GonzálezJuanatey JR, Harjola VP, Jankowska EA et al. (2016): 2016 ESC guidelines for the diagnosis and treatment of acute and chronic heart failure: The task force for the diagnosis and treatment of acute and chronic heart failure of the European Society of Cardiology (ESC) developed with the special contribution of the heart failure Association (HFA) of the ESC. Eur Heart J 37, 2129-2200

Qin W, Liu F, Wan C (2017): A U-shaped association of body mass index and all-cause mortality in heart failure patients: A dose-response meta-analysis of prospective cohort studies. Cardiovasc Ther $\underline{35, \text { e } 12232}$

Rifkin DB, Mazzieri R, Munger JS, Noguera I, Sung J (1999): Proteolytic control of growth factor availability. APMIS $\underline{107}, 80-85$

Rusinaru D, Houpe D, Szymanski C, Lévy F, Maréchaux S, Tribouilloy C (2014): Coronary artery disease and 10-year outcome after hospital admission for heart failure with preserved and with reduced ejection fraction. Eur J Heart Fail 16, 967-976

Sanders-van Wijk S, van Empel V, Davarzani N, Maeder MT, Handschin R, Pfisterer ME, Brunner-La Rocca HP (2015): Circulating biomarkers of distinct pathophysiological pathways in heart failure with preserved vs. reduced left ventricular ejection fraction. Eur J Heart Fail 17, 1006-1014

Sayama H, Nakamura Y, Saito N, Kinoshita M (1999): Why is the concentration of plasma brain natriuretic peptide in elderly inpatients greater than normal? Coron Artery Dis $\underline{10}$, 537-540 
Schelbert EB, Fonarow GC, Bonow RO, Butler J, Gheorghiade M (2014): Therapeutic targets in heart failure: Refocusing on the myocardial interstitium. J Am Coll Cardiol $\underline{63}, 2188-2198$

Schelbert EB, Fridman Y, Wong TC. et al. (2017): Temporal relation between myocardial fibrosis and heart failure with preserved ejection fraction: Association with baseline disease severity and subsequent outcome. JAMA Cardiol 2, 995-1006

Schwarzenbach H, Hoon DSB, Pantel K (2011): Cell-free nucleic acids as biomarkers in cancer patients. Nat Rev Cancer 11, 426-437

Sedej S, Schmidt A, Denegri M, Walther S, Matovina M, Arnstein G, Gutschi E-M, Windhager I, Ljubojević S, Negri S et al. (2014): Subclinical abnormalities in sarcoplasmic reticulum $\mathrm{Ca}(2+)$ release promote eccentric myocardial remodeling and pump failure death in response to pressure overload. J Am Coll Cardiol $\underline{63}, 1569-1579$

Shah SJ (2010): Evolving approaches to the management of heart failure with preserved ejection fraction in patients with coronary artery disease. Curr Treat Options Cardiovasc Med $12,58-75$

Sharifov OF, Schiros CG, Aban I, Denney TS, Gupta H (2016): Diagnostic accuracy of tissue doppler index E/e' for evaluating left ventricular filling pressure and diastolic dysfunction/heart failure with preserved ejection fraction: A systematic review and meta-analysis. J Am Heart Assoc $\underline{5}, 1-19$

Sharma A, Lavie CJ, Borer JS, Vallakati A, Goel S, Lopez-Jimenez F, Arbab-Zadeh A, Mukherjee D, Lazar JM (2015): Meta-analysis of the relation of body mass index to allcause and cardiovascular mortality and hospitalization in patients with chronic heart failure. Am J Cardiol 115, 1428-1434

Shi Y, Massagué J (2003): Mechanisms of TGF- $\beta$ signaling from cell membrane to the nucleus. Cell $\underline{113}, 685-700$

Steinberg BA, Zhao X, Heidenreich PA, Peterson ED, Bhatt DL, Cannon CP, Hernandez AF, Fonarow GC (2012): Trends in patients hospitalized with heart failure and preserved left ventricular ejection fraction: Prevalence, therapies, and outcomes. Circulation $\underline{126}, 65-75$

Su MYM, Lin LY, Tseng YHE, Chang CC, Wu CK, Lin JL, Tseng WYI (2014): CMRverified diffuse myocardial fibrosis is associated with diastolic dysfunction in HFpEF. JACC Cardiovasc Imaging $\underline{7}, 991-997$ 
Swynghedauw B (1999): Molecular mechanisms of myocardial remodeling. Physiol Rev $\underline{79}$, $215-262$

Tampe B, Zeisberg M (2014): Evidence for the involvement of epigenetics in the progression of renal fibrogenesis. Nephrol Dial Transplant 29 Suppl 1, i1-i8

Tampe B, Zeisberg M (2018): Chromatin dynamics at the core of kidney fibrosis. Matrix Biol $\underline{68-69}, 194-229$

Tampe B, Tampe D, Zeisberg EM, Müller GA, Bechtel-Walz W, Koziolek M, Kalluri R, Zeisberg M (2015): Induction of Tet3-dependent epigenetic remodeling by low-dose hydralazine attenuates progression of chronic kidney disease. EBioMedicine 2, $19-36$

Tampe B, Steinle U, Tampe D, Carstens JL, Korsten P, Zeisberg EM, Müller GA, Kalluri R, Zeisberg M (2017): Low-dose hydralazine prevents fibrosis in a murine model of acute kidney injury-to-chronic kidney disease progression. Kidney Int 91, 157-176

Tromp J, Khan MAF, Klip IT, Meyer S, de Boer RA, Jaarsma T, Hillege H, van Veldhuisen DJ, van der Meer P, Voors AA (2017): Biomarker profiles in heart failure patients with preserved and reduced ejection fraction. J Am Heart Assoc $\underline{6}, 1-11$

Upadhya B, Pisani B, Kitzman DW (2017): Evolution of a geriatric syndrome: Pathophysiology and treatment of heart failure with preserved ejection fraction. J Am Geriatr Soc $\underline{65}, 2431-2440$

van Heerebeek L, Borbély A, Niessen HWM, Bronzwaer JGF, van der Velden J, Stienen GJM, Linke WA, Laarman GJ, Paulus WJ (2006): Myocardial structure and function differ in systolic and diastolic heart failure. Circulation 113, 1966-1973

van Veldhuisen DJ, Linssen GCM, Jaarsma T, van Gilst WH, Hoes AW, Tijssen JGP, Paulus WJ, Voors AA, Hillege HL (2013): B-type natriuretic peptide and prognosis in heart failure patients with preserved and reduced ejection fraction. J Am Coll Cardiol $\underline{61}$, $1498-1506$

Walker SA, Kupzig S, Bouyoucef D, Davies LC, Tsuboi T, Bivona TG, Cozier GE, Lockyer PJ, Buckler A, Rutter GA et al. (2004): Identification of a Ras GTPase-activating protein regulated by receptor-mediated $\mathrm{Ca}^{2+}$ oscillations. EMBO J $\underline{23}, 1749-1760$

Wang M, Yip GWK, Wang AYM, Zhang Y, Ho PY, Tse MK, Lam PKW, Sanderson JE (2003): Peak early diastolic mitral annulus velocity by tissue Doppler imaging adds independent and incremental prognostic value. J Am Coll Cardiol 41, 820-826 
Watson CJ, Collier P, Tea I, Neary R, Watson JA, Robinson C, Phelan D, Ledwidge MT, McDonald KM, McCann A et al. (2014): Hypoxia-induced epigenetic modifications are associated with cardiac tissue fibrosis and the development of a myofibroblast-like phenotype. Hum Mol Genet 23, 2176-2188

Weber KT, Brilla CG, Janicki JS (1993): Myocardial fibrosis: functional significance and regulatory factors. Cardiovasc Res $\underline{27}, 341-348$

Weber KT, Sun Y, Katwa LC, Cleutjens JPM (1997): Tissue repair and angiotensin II generated at sites of healing. Basic Res Cardiol 92, 75-78

Weber M, Davies JJ, Wittig D, Oakeley EJ, Haase M, Lam WL, Schübeler D (2005): Chromosome-wide and promoter-specific analyses identify sites of differential DNA methylation in normal and transformed human cells. Nat Genet $\underline{37}, 853-862$

Westermann D, Kasner M, Steendijk P, Spillmann F, Riad A, Weitmann K, Hoffmann W, Poller W, Pauschinger M, Schultheiss HP et al. (2008): Role of left ventricular stiffness in heart failure with normal ejection fraction. Circulation 117, 2051-2060

Wilkinson EL, Backman H, Hecht HH (1952): Cardiovascular and renal adjustments to a hypotensive agent. J Clin Invest $\underline{31}, 872-879$

Wittwer CT, Herrmann MG, Moss AA, Rasmussen RP (2013): Continuous fluorescence monitoring of rapid cycle DNA amplification. BioTechniques $\underline{54}, 314-320$

Wuytack F, Raeymaekers L, Missiaen L (2002): Molecular physiology of the SERCA and SPCA pumps. Cell Calcium $\underline{32}, 279-305$

Xu X, Tan X, Tampe B, Nyamsuren G, Liu X, Maier LS, Sossalla S, Kalluri R, Zeisberg M, Hasenfuß G et al. (2015): Epigenetic balance of aberrant Rasall promoter methylation and hydroxymethylation regulates cardiac fibrosis. Cardiovasc Res $\underline{105}$, 279-291

Xu X, Tan X, Hulshoff MS, Wilhelmi T, Zeisberg M, Zeisberg EM (2016): Hypoxia-induced endothelial-mesenchymal transition is associated with RASAL1 promoter hypermethylation in human coronary endothelial cells. FEBS Lett $\underline{590}, 1222-1233$

Yancy CW, Jessup M, Bozkurt B, Butler J, Casey DE, Drazner MH, Fonarow GC, Geraci SA, Horwich T, Januzzi JL et al. (2013): 2013 ACCF/AHA guideline for the management of heart failure: A report of the American College of Cardiology Foundation/American Heart Association task force on practice guidelines. Circulation $\underline{128}$, e240-327 
Yusuf S, Pfeffer MA, Swedberg K, Granger CB, Held P, McMurray JJV, Michelson EL, Olofsson B, Östergren J (2003): Effects of candesartan in patients with chronic heart failure and preserved left-ventricular ejection fraction: The CHARM-Preserved Trial. Lancet $\underline{362}, 777-781$

Zeisberg EM, Zeisberg M (2013): The role of promoter hypermethylation in fibroblast activation and fibrogenesis. J Pathol $\underline{229}, 264-273$

Zeisberg EM, Zeisberg M (2016): A rationale for epigenetic repurposing of hydralazine in chronic heart and kidney failure. J Clin Epigenet $\underline{2}, 1$

Zeisberg EM, Tarnavski O, Zeisberg M, Dorfman AL, McMullen JR, Gustafsson E, Chandraker A, Yuan X, Pu WT, Roberts AB et al. (2007): Endothelial-to-mesenchymal transition contributes to cardiac fibrosis. Nat Med $\underline{13}, 952-961$

Zhou D, Huang Y, Fu M, Cai A, Tang S, Feng Y (2018): Prognostic value of tissue Doppler E/e' ratio in hypertension patients with preserved left ventricular ejection fraction. Clin Exp Hypertens $\underline{5}, 1-6$

Zile MR, Baicu CF, Gaasch WH (2004): Diastolic heart failure-abnormalities in active relaxation and passive stiffness of the left ventricle. N Engl J Med 350, 1953-1959

Statistisches Bundesamt (2017): Todesursachen in Deutschland. http://www.gbebund.de/oowa921install/servlet/oowa/aw92/dboowasys921.xwdevkit/xwd_init?gbe.isgbetol/xs_start_ne u/\&p_aid=i\&p_aid=56773036\&nummer=516\&p_sprache=D\&p_indsp=4065\&p_aid= 57052877\#SOURCES, Statistisches Bundesamt, abgerufen am: 29.1.2018 